NUREG/CR-3443 -

PNL-4805

\title{
TRUST-II Utility Package: Partially Saturated Soil Characterization, Grid Generation, and Advective Transport Analysis
}

Prepared by T. J. McKeon, S. W. Tyler, D. W. Mayer, A. E. Reisenauer

Pacific Northwest Laboratory

Operated by

Battelle Memorial Institute

Prepared for

U.S. Nuclear Regulatory

Commission 


\section{NOTICE}

This report was prepared as an account of work sponsored by an agency of the United States Government. Neither the United States Government nor any agency thereof, or any of their employees, makes any warranty, expressed or implied, or assumes any legal liability of responsibility for any third party's use, or the results of such use, of any information, apparatus, product or process disclosed in this report, or represents that its use by such third party would not infringe privately owned rights.

\section{Availability of Reference Materiais Cited in NRC Publications}

Most documents cited in NAC publications will be available from one of the following sources:

1. The NAC Public Document Room, 1717 H Street, N.W.

Washington, DC 20555

2. The NAC/GPO Sales Program, U.S. Nuciear Regulatory Commission, Washington, DC 20555

3. The National Technical Information Service, Springfield, VA 22161

Although the listing that follows represents the majority of documents cited in NRC publications, it is not intended to be exhaustive.

Referenced documents available for inspection and copying for a fee from the NAC Public Document Room include NAC correspondence and ir.ternal NAC memoranda; NAC Office of Inspection and Enforcement bulletins, circulars, information notices, inspection and investigation notices; Licensee Event Reports; vendor reports and correspondence; Commission papers; and applicant and licensee documents and correspondence.

The following documents in the NUREG series are available for purchase from the NAC/GPO Sales Program: formal NRC staff and contractor reports, NAC-sponsored conference proceedings, and NAC booklets and brochures. Also available are Regulatory Guides, NAC regulations in the Code of Federal Regulations, and Nuclear Regulatory Commission /ssuances.

Documents available from the National Technical Information Service include NUREG series reports and technical reports prepared by other federal agencies and reports prepared by the Atomic Energy Commission, forerunner agency to the Nuclear Regulatory Commission.

Documents available from public and special technical libraries include all open literature items, such as books, journal and periodical articles, and transactions. Federal Register notices, federai and state legisiation, and congressional reports can usually be obtained from these libraries.

Documents such as theses, dissertations, foreign reports and translations, and non-NAC confarence proceedings are available for purchase from the organization sponsoring the publication cited.

Single copies of NAC draft reports are available free upon written request to the Division of Technical Information and Document Control, U.S. Nuclear Regulatory Commission, Washington, DC 20555.

Copies of industry codes and standards used in a substantive manner in the NAC regulatory process are maintained at the NRC Library, 7920 Norfolk Avenue, Bethesda, Maryland, and are available there for reference use by the public. Codes and standards are usually copyrighted and may be purchased from the originating organization or, if they are American National Standards, from the American National Standards institute, 1420 Broadway, New York, NY 10018. 
NUREG/CR-3443

PNL-4805

RU

\section{TRUST-II Utility Package: Partially Saturated Soil Characterization, Grid Generation, and Advective Transport Analysis}

Manuscript Completed: August 1983

Date Published: September 1983

Prepared by

T. J. Mckeon, S. W. Tyler, D. W. Mayer, A. E. Reisenauer

Pacific Northwest Laboratory

Richland, WA 99352

Prepared for

Division of Health, Siting and Waste Manegement

Office of Nuclear Regulatory Research

U. S. Nuclear Regulatory Commission

Washington, D.C. 20555

NRC FIN B2370 



\section{ABSTRACT}

This report describes the TRUST-II utility package developed at Pacific Nortnwest Laboratory. The TRUST-II utility package is used in conjunction with the TRUST-II computer model to simulate multi-dimensional, variably saturated fluid flow, and advective contaminant transport under steady-state or transient conditions in neterogeneous porous media. The TRUST-II utility package consists of SOILGEN, a set of codes to generate soil characteristics data; GRIDGEN, a grid-generating code; and MLTRAN, an advective contaminant transport code. This report provides the information and details that the user needs to operate the above programs and models. It also discusses test cases that verify the models, and provides example problems. 
. 
Item $\underline{\text { Page }}$

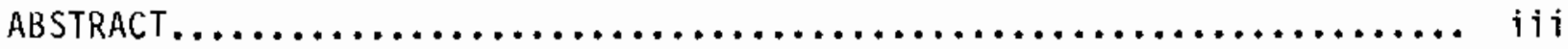

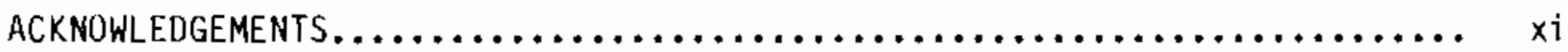

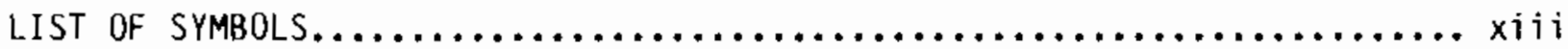

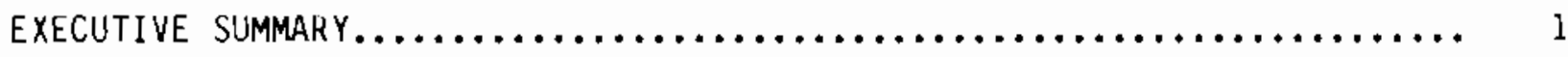

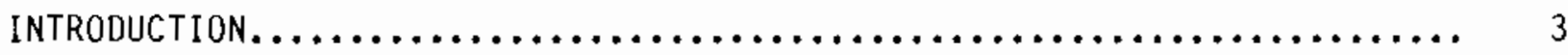

1.0 OVERVIEW OF THE TRUST-I I UTILITY PACKAGE..................... 5

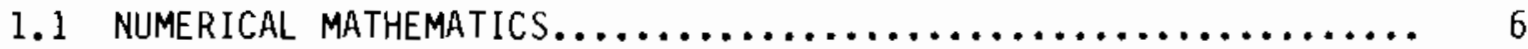

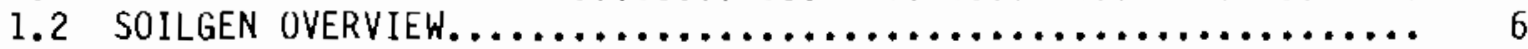

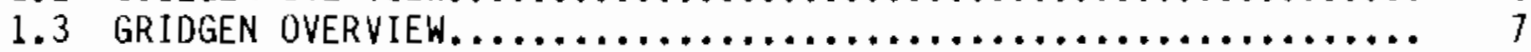

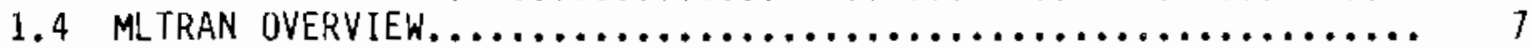

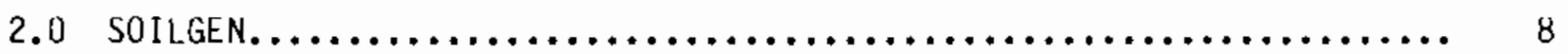

2.1 PREVIOUS WORK ON REPRESENTING SOIL CHARACTERISTIC DATA ........ 8

2.2 FUNCTIONAL RELATIONSHIPS FOR SOIL-WATER RETENTION............ 11

2.2.1 Haverkamp et al. (1977)........................ 11

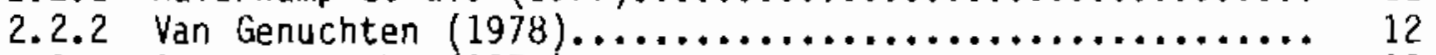

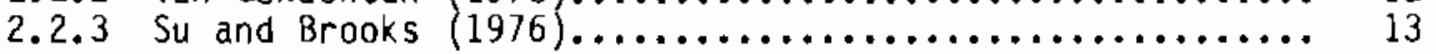

2.3 HYDRAULIC CONDUCTIVITY FUNCTIONS ....................... 15

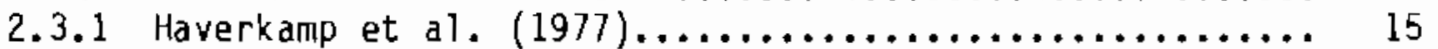

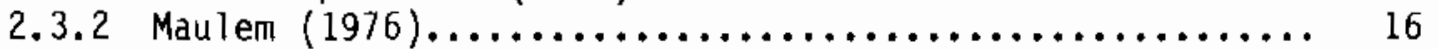

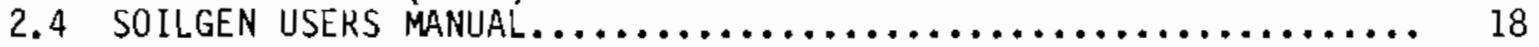

2.4 .1 HAVERFIT and VANFIT Programs..................... 20

2.4 .2 SUBROOKS Program.............................. 22

2.4 .3 HCONFIT Program.............................. 23

2.4 .4 CUNDGEN Program............................... 23

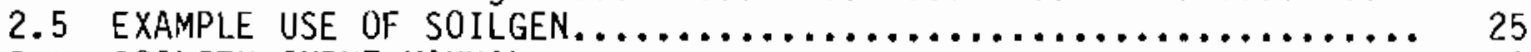

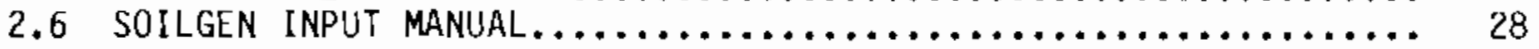

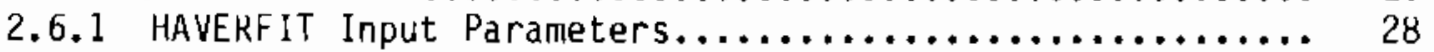

2.6 .2 VANFIT Input Parameters....................... 30

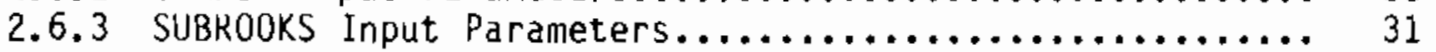

2.6 .4 HCONFIT Input Parameters........................ 32

2.6 .5 CONDGEN Input Parameters........................ 33

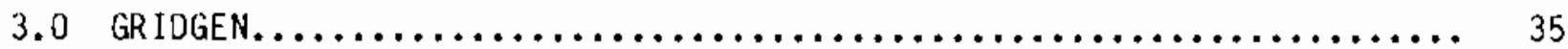

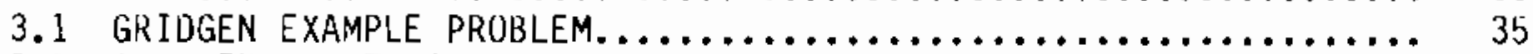

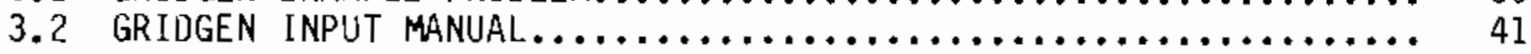

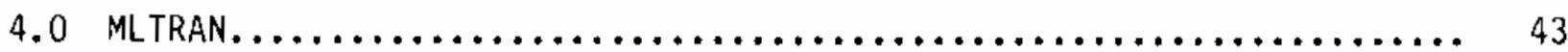

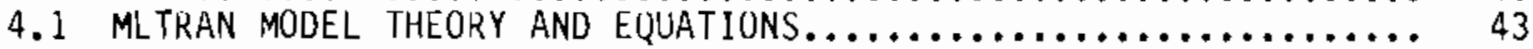

4. 2 FINITE-DIFFERENCE TO FINITE-ELEMENT GRID CONVERSION . . . . . . . . 52

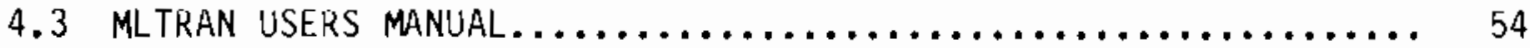




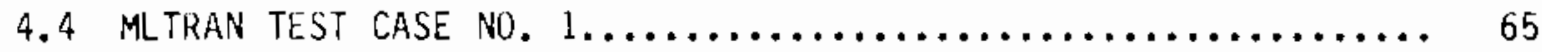

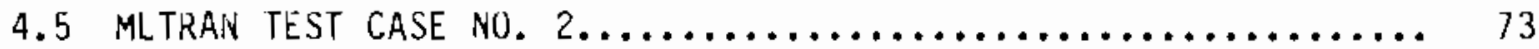

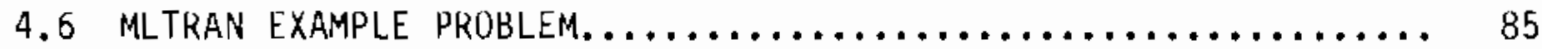

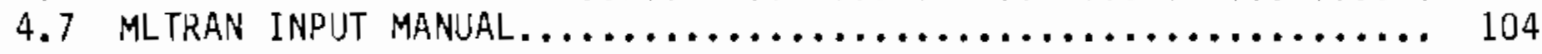

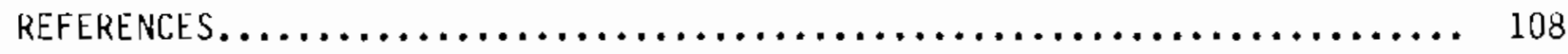

APPENIDIX A OERIVATION OF TWO-DIMENSIONAL STEADY

STATE PATHLINES............................. 110

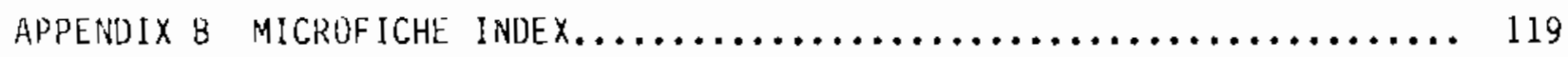

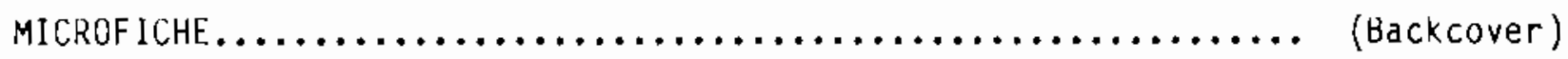




\section{FIGURES}

$\underline{\text { Item }}$

Page

2.1 Soil-Water Retention Data for Uranium Mill Tailings

Data Fit Using Haverkamp (1977) ModeT....................... 13

2.2 Soil-Water Retention Data for Uranium Mill Tailings

Data Fit Using Van Genuchten (1978) Model..................... 14

2.3 Soil-Water Retention Data for Uranium Mill Tailings

Data Fit Using Su and Brooks (1976) Model.................... 16

2.4 Curve Fit of Haverkamp et al. (1977) to Predicted Permeabilities

of Uranium Mill Tailings.............................. 17

2.5 Comparison of Analytically Generated Conductivity Data

(Van Genuchten 1978) to Data Generated by CONDGEN............... 19

2.6 Permeabilities Calculated by CONDGEN for Uranium Mill

Tailings slime..................................... 27

3.1 GRIDGEN Example Problem........................... 36

3.2 Location of $s z$ for a Typical Node......................... 37

3.3 Example of Internal Node Numbering Scheme Used by GRIDGEN........ 4U

4.1 The $i$ th Integrated Finite Difference Element with the

Central $i$ th Node Connected to the $j$ th Nodes in the

Surrounding Elements................................ 46

4.2 Schematic Diagram for Projected Flow Area Weighting of the

$u_{i j}$ and $v_{i j}$ Component Pore Velocities..................... 48

4.3 Integrated Finite-Difference Grid (left) and Finite-Element

Grid Overlaying the Finite-Difference Grid (right)............. 53

4.4 Integrated Finite-bifference Grid with Thin Nodes (left), overlaid by a Finite-Element Grid (right)................... 53

4.5 Integrated Finite-Bifference Grid with Zero-Volume Nodes

(left), Overlaid by a Finite-Element Grid (right)............. 54

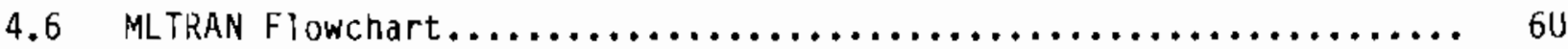

4.7 Steady-State Flow Field for Test Case No. $1 \ldots \ldots \ldots \ldots \ldots \ldots \ldots \ldots$

4.8 Discretized Flow Domain for Test Case No. $1 \ldots \ldots \ldots \ldots \ldots \ldots \ldots \ldots \ldots$. 
4.9 Test Case No. 1 -- Analytical Pathlines (solid lines) Compared with the MLTRAN Analytical Velocity Field Pathlines

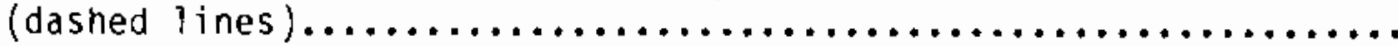

4.10 Test Case No. 1 -- Analytical Patnlines (solid lines) Compared with TRUST-1I MLTRAN Pathlines (dasned lines)................. 71

4.11 Arrival Time Versus Arrival Location on River................. 73

4.12 Test Case No. 2 Transient Flow System....................... 74

4.13 Discretized Flow Domain Test Case No. 2.................... 76

4.14 Test Case No. 2: Departure Time $=50$ Days; Pathlines from PATHS Model (solid lines); Pathlines from MLTRAN Model with Analytical Velocity Fields (dasned lines)..................... 77

4.15 Test Case No. 2: Departure Tine $=500$ Days; Patnlines from PATHS Model (solid lines); Pathlines from MLTRAN Model with Analytical Velocity Fields (dashed lines)................... 78

4.16 Analytical Potential Contours Time $=50$ Days $\ldots \ldots \ldots \ldots \ldots \ldots \ldots . . . .81$

4.17 Analytical Potential Contours Time $=500$ Days.............. 82

4.18 Test Case No. 2 Arrival Time Versus Arrival Location Curve........ 84

4.19 Partially Saturated Hydraulic Conductivity for Example Problem..................................... 88

4.20 Soil Characteristic Curve for Example Problem................. 89

4.21 Discretized Flow Domain for Example Problem................. 90

4.22 Pressure Head Contours, for Example Problem Time $=0.5$ Days; Analytical $=$ Solid Lines; TRUST-II = Dashed Lines............... 92

4.23 Pressure Head Contours, for Example Problem Time $=1.0$ Days; Analytical $=$ Solid Lines; TRUST-II = Dashed Lines.............. 92

4.24 Ml TRAN Pathlines for Example Problem....................... 93

4.25 MLTRAN Water Fronts for Example Problem.................... 95 


\section{TABLES}

$\underline{\text { Item }}$

Page

2.1 SOILGEN Programs.....................................

3.1 GRIDGEN Input Data............................... 36

3.2 GRIDGEN Output Data............................... 38

4.1 MLtRAn Submodels.................................. 55

4.2 Test Case No. 1: Steady-State Saturated Flow................ 68

4.3 Analytical Results for Test Case No. 1: Pathline Arrival Data............................................ 70

4.4 MLTRAN Results with Analytical Velocity Field for Test Case No. 1: Pathline Arrival Data......................... 70

4.5 MLTRAN Results with TRUST Velocity Field for Test Case No. 1: Pathline Arrival Data......................... 72

4.6 Test Case No. 1: Error Analysis of MLTRAN Results Compared with Analytical Results.................................. 72

4.7 Test Case No. 2: Transient Saturated Flow.................... 75

4.8 MLTRAN Results with Analytical Velocity Field Test Case No. 2: Transient Saturated Flow, Departure Time $=50$ Days............. 79

4.9 MLTRAN Results with Analytical Velocity Field Test Case No. 2: Transient Saturated Flow, Departure Time $=500$ Days............ 80

4.10 Quasi-Analytical Results from PATHS Model Test Case No. 2: Transient Saturated Flow, Departure Time $=50$ Days (Pathline Arrival Data)...............................

4.11 Quasi-Analytical Results from PATHS Model Test Case No. 2: Transient Saturated Flow, Departure Time $=500$ Days

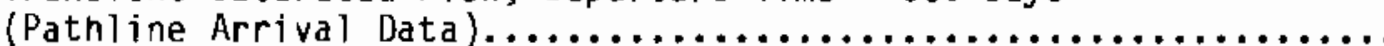

4.12 Test Case No. 2: Transient Saturated Flow, Error Analys is of MLTRAN Results Compared with PATHS Results................

4.13 Test Case No. 2: MLTRAN Resuits from Transient Saturated Flow (Patnline Arrival Data). 
4.14 Example, Partially Saturated Point Source for Example Problem...................................... 91

4.15 Results for MLTRAN Example Problem (Pathline Arrivai Data)........ 94

4.16 Data Fjles used by MLTRAN.......................... 103 


\section{ACKNOWLEDGEMENTS}

This study was sponsored and supported by the Division of Health, Siting and Waste Management, Office of Nuclear Regulatory Research of the United States Nuclear Regulatory Conmission under FIN B2370, Task 3: Tailings Dewatering Techniques. The authors express appreciation to Mr. R.W. (Bill) Nelson and Dr. Glendon W. Gee of Pacific Northwest Laboratory (PNL) for their interest and suggestions throughout this study. Special thanks are also due to Ms. Brenda $K$. Marshall, PNL technical editor, for ner invaluable help in preparing this document. 



\section{LIST OF SYMBOLS}

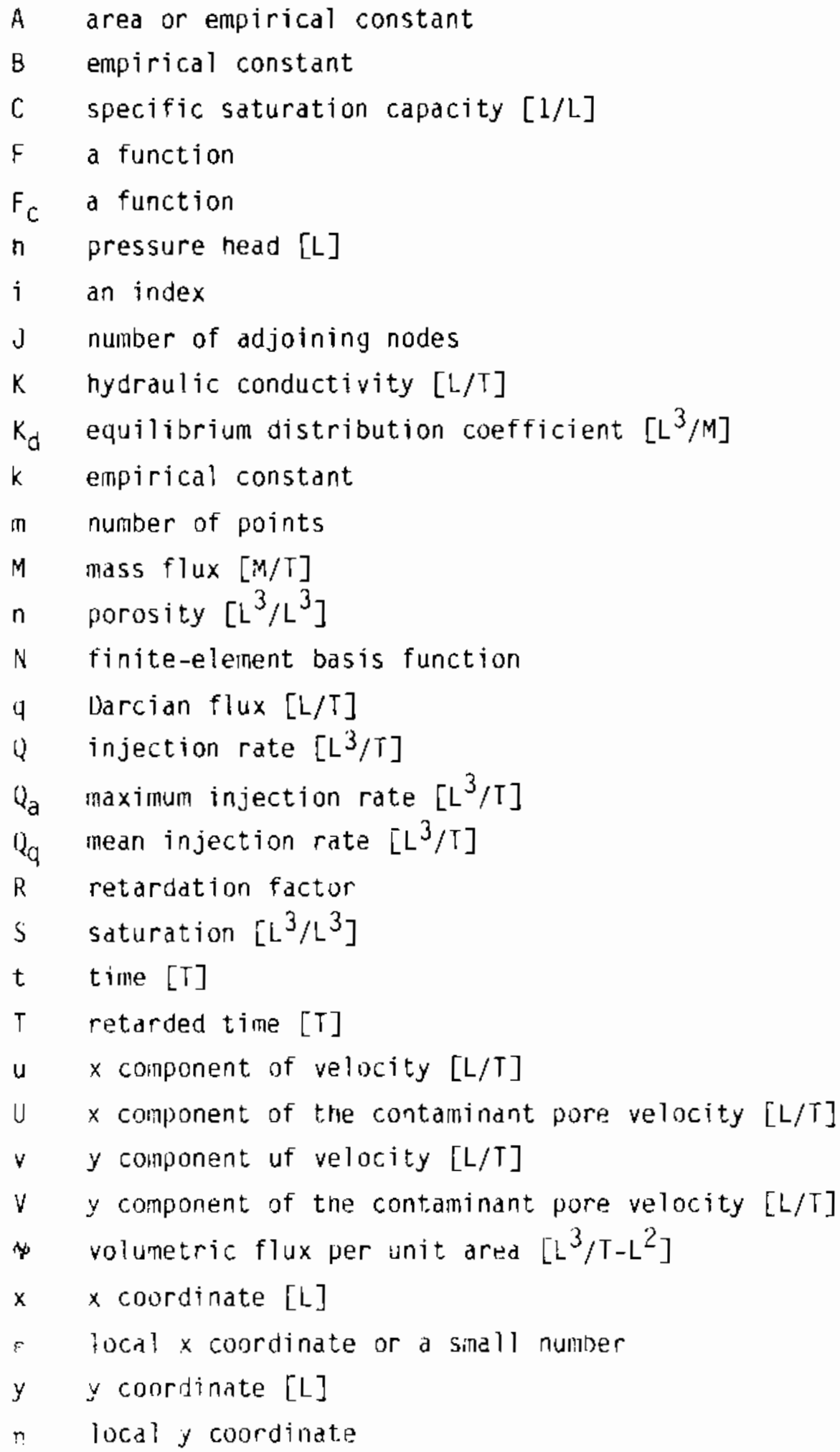


z $\quad$ c coordinate [L]

a an angle or empirical constant

A an incremental change in quantity

$\lambda$ an empirical constant

$\phi \quad$ energy potential [L]

\$ matric flux potential $\left[\mathrm{L}^{2} / \mathrm{T}\right]$

$\rho$ density $\left[M / L^{3}\right]$

$\theta$ volumetric moisture content $\left[\mathrm{L}^{3} / \mathrm{L}^{3}\right]$

$\mu \quad$ viscosity $[\mathrm{M} / \mathrm{LT}]$

$\nabla$ Del operator $[1 / L]$

subscripts

o initial

b bulk

e effective

$i$ at node $i$

$j$ at node $j$

$f$ at an inflection point

m final

$r$ residual or relative

$s$ saturated

$x \quad x$ component

$y \quad y$ component 
Important concerns during and after the disposal of uranium mill tailings include the environmental consequences associated with the flow of water and contaminants through the tailings and the surrounding media, and the release of radon gas into the atmosphere. In addition, consolidation of the mill tailings may affect the flow of water and contaminants, which might preclude the early application of radon gas suppression covers, an important environmental protection measure. Pacific Northwest Laboratory (PNL), through the support of the United States Nuclear Regulatory Commission (NRC), is developing techniques for investigating these aspects of uranium mill tailings disposal.

To perform the necessary fiow and consolidation anaiysis, a computer program that simulates multi-dimensional, variably saturated flow in a deformable porous media has been developed. This program, called TRUST-II, is a derivative of the TRUST code documented by Reisenauer et al. (1982). The purpose of our study is to document several utility programs that complement and enhance the use of the TRUST-II code.

These utility programs perform three basic functions. The first set of programs, SOILGEN, is used to analyze soil characteristics data and to generate soil characteristic curves that are compatible with TRUST-II. The next program, GRIDGEN, is used to rapidly generate nonuniform rectangular grids for TRUST-II. The final set of programs, MLTRAN, is used to analyze the output from TRUST-II (i.e., potentials and moisture content) as well as to generate the resulting pathlines of the flow of water and contaminants. Although the set of MLTRAN programs is intended to be used primarily with the TRUST-1I model, most of the programs in MLTRAN can be used with other flow models.

This package of utility programs aids the user significantly when an accurate and timely simulation of a disposal site is required. The SOILGEN group of programs allows the user to minimize the numerical problems that are often associated with the representation of the soil characteristic curves. Numerical grids that accurately represent the flow phenomena can be swiftly generated with GRIDGEN because the user can investigate the effects of varying the grid resolution easily and rapidly. The MLTRAN group of programs allows the investigator to examine the nondispersive, advective transport arising from the steady-state or transient flow field predicted by TRUST-II. In addition, this package allows nonconservative or reactive transport of contaminants to be investigated. 


\section{INTRODUCTION}

Pacific Northwest Laboratory (PNL), under contract with the Nuclear Regulatory Commission (NRC), developed a utility package used to augment the capabilities of the TRUST-II model, which simulates multi-dimensional, variably saturated flow in deformable porous media. The TRUST-II model is an enhanced version of the TRUST model (Reisenauer et al. 1982). The utility package consists of two basic parts: 1) a pair of computer programs used for processing data before the TRUST-II model is executed, and 2) a set of six computer programs, named MLTRAN, used to simulate two-dimensional, nondispersive, advective transport of dissolved conservative and nonconservative contaminants in heterogeneous, variably saturated soils. The MLTRAN model was originally developed as part of an effort to evaluate mitigative measures intended to reduce the transport of contaminants from disposal sites for uranium mill tailings.

The document provides basic inforination needed to operate the TRUST-II utility package as well as a description of the theoretical basis for the MLTRAN model. Chapter 1 provides an overview of the TRUST-II utility package and includes brief descriptions of SOILGEN, GRIDGEN, and MLTRAN. Chapter 2 describes in detail the programs for generating soil characteristics data. Chapter 3 describes the program for generating grids. Chapter 4 describes the MLTRAN submodels. The Appendices contain a derivation of the analytical pathline solution used to test the MLTRAN model and an index to the microfiche attached to the back cover. Listings of the input and output files for the example cases and listings of the codes are included on the microfiche.

Our discussion throughout this document assumes that the reader is familiar with the nomenclature and application of the TRUST-II model. The report by Reisenauer et al. (1982) provides the necessary background information. 



\subsection{OVERVIEW OF THE TRUST-II UTILITY PACKAGE}

The TRUST-II utility package consists of several interactive computer models that are divided into two basic groups: a pre-processing package with programs to generate soil characteristic curves (SOILGEN), a program to generate grids (GRIDGEN), and a postprocessing package that simulates multi-dimensional, nondispersive transport in heterogeneous, variably saturated soils (MLTRAN). The MLTRAN submodels may be executed in either batch or interactive mode. At PNL, the models are operated on a Digital Equipment Corporation VAX 11/780 computer system. Some of the important characteristics and capabilities of the TRUST-II utility package include the following:

\section{SOILGEN}

- fits functional representations to experimental saturation data

- fits a functional representation to experimental hydraulic conductivity data

n generates hydraulic conductivity data using experimental saturation data

n estimates residual volumetric water content

\section{GRIDGEN}

n creates two-dimensional, integrated finite-difference grids

- creates irregular rectangular grids

\section{MLTRAN}

allows two-dimensional sitnulations

- allows variable grid spacing

- simulates nondispersive, advective transport in variably saturated media

- simulates nonconservative or reactive transport

- simulates steady-state and/or transient conditions

- simulates heterogeneous porous media systems

n uses bilinear, quadrilateral, finite-element basis functions as interpolation functions

n performs a deterministic analysis.

To simplify the use of this document, the chapters describing the three code groups of the utiilty package are complete and designed to stand alone. Depending on the reader's needs, he or she may choose to read one or all of these chapters.

The SOILGEN and GRIDGEN programs are written in FORTRAN-77. The MLTRAN submodels are written in FLECS, a variation of FORTRAN IV (Beyer 1975). FLECS is a language extension of FORTRAN with additional control mecnanisins and is more easily read. Source codes written in FLECS are first translated by the FLECS interpreter into a FURTRAN program. The translated FORTRAN program is then compiled and execited in the same manner as any program.

The FLECS translator, which was developed at the University of Uregon, is in the public domain and freely available. The FURTRAN versions of the original FLECS programs are also available; however, they are difficult to read because of the translation. Therefore, we report the FLECS listings in this document. 
The MLTRAN model uses three file types for data storage and retrieval: formatted files, binary or unformatted files, and direct access files. Formatted files are used most often and consist of a byte code that cause the display device to print the appropriate character associated with the code. Formatted files allow the user to check for errors or anomalies in the data directly via the line printer or terminal.

Binary files consist of a inachine language representation of characters and hence cannot be examined directly. They have the advantage of already being in inachine language form and thus need not be translated from ASCII or EBCDIC code. Binary files require less storage space than equivalent formatted files and are more efficient for transferring data.

Direct access files are set up on random access disks and are designed to facilitate rapid access of data by the computer. The data are stored sequentially and each record has an address. The random access disks allow a specific address and associated record to be retrieved from storage, circumventin the reading of all of the data from the beginning of the file to the address o interest. Although direct access files nay be either formatted or unforinatted the MLTRAN model uses only unformatted direct access files. Direct access files are much faster for retrieving specific records of data from large files than binary or formatted files.

\subsection{NUMERICAL MATHEMATICS}

In this document we refer to two numerical techniques for approximating partial differential equations. The TRUST-II model uses the integrated finitedifference method to approxinate the ground-water flow equation over the discretized domain. The MLTRAN nodel uses the finite-element grid and the bilinear, quadrilateral, finite-element basis functions for interpolation within each element of the grid. The integrated finite-difference method is described by Narasiinham and Witherspoon (1976).

When the integrated finite-difference method is applied to ground-water problems, the flow domain is first divided into subdomains or cells. Nodes should be located at or near the center of mass of the cell and lines connecting adjacent nodes must be orthogonal, or nearly orthogonal, to the interface defining the boundary between cells. By using these criteria to discretize the flow domain, the gradient normal to the interface between cells may be replaced by a finite-difference approximation. A mass balance is then performed on each subdomain, resulting in a system of algebraic equations.

\subsection{SOILGEN DVERVIEW}

To model partially saturated flow in porous media, the TRUST-II code uses tabular pairs of saturation versus pressure head data and intrinsic permeability versus pressure head data. The SOILGEN programs, which characterize partially saturated materials, are designed to provide these required data. Five codes for soil data analysis form the SOILGEN group. Three of the codes fit functional relationships to experimentally determined pairs of saturation and pressure head data; one code is designed to fit a functional relationship 
to experimental pairs of hydraulic conductivity (or intrinsic permeability) and pressure head data; and one code is designed to generate pairs of hydraulic conductivity (or intrinsic permeability) and pressure head data from the saturation versus pressure head curve. Based on the type of experimental data available, the user chooses specific programs of the SOILGEN group to create the input data necessary for the TRUST-II code.

Typically, the user first activates each of the saturation versus pressure head coles HAVERFIT, VANFIT, and SUBROOKS to determine which functional form most accurately represents the measured saturation versus pressure head data. Ideally, the best-fitting function must be able to represent the experimental data while maintaining a smooth and continuous curve throughout the range of saturation. Based on the type of conductivity data available, the user next proceeds to one of two conductivity codes, HCONFIT or CONDGEN. Finally, the user merges output files from the best-fitting soil-water retention code (saturation versus pressure head data) with the proper conductivity code to form the input data on the material properties for the TRUST-II code.

\subsection{GRIDGEN OVERVIEW}

The GRIDGEN program, written in FORTRAN 77 , is an invaluable tool for addressing problems with the TRUST-II model because of the comparatively large amount of data required to define an integrated finite-difference grid. Since unsaturated flow problems are highly nonlinear, appropriate grid definition is critical and difficult to determine without several iterations. With GRIDGEN, the user may generate different grids quickly and easily to determine what grid resolution is required to accurately simulate the problem considered. The GRIDGEN program also reduces costs since it does away with the need to manually develop grids containing many nodes. GRIDGEN generates irregular rectangular grids only; the DIGRD programs (see Foote et al. 1982) can be used to modify or develop more complex grids.

\subsection{MLTRAN OVERVIEW}

The MLTRAN model consists of six staged submodels that are executed in the following order: MILGRID, MILSTRT, MILFLUX, MILPLOT, MILTVL, and MILFRNT. The submodel MILGRID displays a plot of the finite-element grid used to model the flow domain. The submodel MILSTRT generates data files used by other submodels. MILFLUX reads the TRUST-II input and output files and writes head, water content, and velocity data to a direct access file. The submodel MILPLOT displays contours of potential head, water content, and pressure head. MILTVL calculates water pathlines, travel times, and contaminant movenent. These data are displayed graphically and are written to a file used by MILFRNT. The submodel MILFRNT plots the movement of water fronts and contaminant fronts. 


\subsection{SOILGEN}

To model partially saturated flow of fluid through porous media, the TRUST-II code requires input data characterizing the hydraulic properties of the porous inedia. The TRUST-II code requires two types of hydraulic property data: the dependence of fluid saturation and the dependence of intrinsic perineability on the fluid pressure heads. The SOILGEN group of codes simplifies the generation of this data in a format that is compatible with TRUST-II. Table 2.1 lists these codes and their functions.

The fluid saturation of a porous medium is defined as the ratio of the fluid volume to the total volume of the voids and is controlled by the fluid pressure head. In this document, the porosity and saturated water content are taken to be equivalent. For this analysis, when the pressure head is positive or zero, the medium is considered to be at maximum saturation. As the pressure head becomes negative, fluid drains from pores with progressively smaller diameters. The medium is said to be "partially saturated" at negative pressure heads.

As the porous inedium becones less saturated, the hydraulic conductivity also decreases because fluid flow must now take place in smaller pores which offer greater resistance to flow. Because the intrinsic permeability is proportional to the hydraulic conductivity (the constant of proportionality depending on fluid properties alone), the perinedbility also decreases with increasingly negative pressures heads.

The saturation and permeability data constitute those properties of the media required as input to the TRUST-II code. Measurements and calculated estimates of these properties are represented in the TRUST-II code in tabular form in Block 2 of the TRUST-II input deck. Because most experimentally determined soil data sets do not contain enough data points for numerical modeling, the user rmust generate intermediate data points between those gathered through experiments. In this report, we outline several techniques for constructing the necessary input for the TRUST-II code.

\subsection{PREVIOUS WORK ON REPRESENTING SATURATION DATA}

Saturation data for numerical codes have typically been generated through one of two techniques. In the first, a linear or nonlinear interpolator is used to generate intermediate data points between the experimentally measured data points. In the second, a functional relationship between pressure head (h) and volumetric water content (9) or saturation (S) is fit to the experiinental data. Intermediate data points necessary for the computer code are determined from the functional relationship. Since the numerical flow codes have difficulty with calculations when the data on the property of materials are discontinuous or erratic, the latter technique is advantageous because functional forms can provide a smooth and continuous set of generated data points. Numerous researchers have attempted to fit various forms of the functional relationships to saturation data. For a thorough review of this subject, the reader is referred to Su and Brooks (1976). For the SOILGEN 
TABLE 2.1. SOILGEN Programs

Code Name Subroutines

HAVERFIT ZXMIN

HAVERF

VANF IT

ZXMIN

MUALEMF

SUBROOKS AUXFON

NONLIN

BACK

HCONFIT ZXMIN

HCONF

CONDGEN DCADRE
Function

Determines curve-fitting

parameters for functional

representation of soil-

water retention data of

Haverkamp (1977)

Determines curve fitting

parameters for functiona

representation of soil-

water retention data of

Van Genuchten (1978)

Determines curve fitting parameters for functional representation of soilwater retention data of

Su and Brooks (1976)

Determines curve fitting parameters for functional representation of conductivity data of Haverkamp (1977)

Generates conductivity data using the method of Mualem (1976) $\frac{\text { Input Files }}{\text { User ramed }} \frac{\text { Output Files }}{2 \text { user named }}$ input output

User named 2 user named input output

User named 2 user named input output

User named 2 user named input output

User named input

2 user named output 
group, we chose three forms of functional representations based upon the work of Haverkamp et al. (1977), Van Genuchten (1978), and Su and Brooks (1976).

We can also generate additional conductivity values from experimental data by using an interpolating scheme or a functional representation. Unlike the soil-water retention data which can be readily measured in the laboratory, the dependence of hydraulic conductivity on pressure head is more difficult to measure experimentally. To overcome this difficulty, investigators have formulated computational schemes to determine the hydraulic conductivity by using knowledge of other properties of the porous medium that are easier to measure. Such properties should represent the pore structure and pore-size distribution of the media. Because the microscopic structure of a naturally occurring porous media is too complicated to model in exact mathematical terms, we must make simplifying assumptions about the pore-size distributions and structure.

In general, two main groups of predictive models have been used in the past. The first is based on a generalization of Kozeny's (1927) approach to conductivity of partially saturated porous media. In this technique, the relative conductivity, $K_{r}$, is taken to be a power function of the effective saturation, $\mathrm{S}_{\mathrm{e}}$ :

$$
k_{r}=k / k_{s}=\left(s_{e}\right)^{\beta}
$$

where $S_{e}=\frac{{ }_{0}-\theta_{r}}{\theta_{s}-A_{r}}$

The $0, r$, and $s$ subscripts represent the actual, residual, and saturated volumetric water contents, respectively, $k_{s}$ represents the hydraulic conductivity when the medium is fully saturated, and $B$ is a curve-fitting parameter.

The second group of predictive models includes those of Burdine (1953), Childs and Collis-George (1950), and Millington and Quirk (1961). The models in this group utilize the soil-water retention curve as a measure of the poresize distribution to predict the hydraulic conductivity as a function of saturation. Mualem (1976) compared these methods using data from 45 soils and derived an alternative formulation that provides a better fit to the data. His new method, founded along the same lines as the Burdine model, yields the following equation:

$$
\frac{k\left(S_{e}\right)}{k_{s}}=\left(S_{e}\right)^{n}\left[\int_{0}^{S_{e}} \frac{d S_{e}}{d h} / \int_{0}^{1} \frac{d S_{e}}{d h}\right]^{2}
$$




\subsection{FUNCTIONAL RELATIONSHIPS FOR SOIL-WATER RETENTION}

To provide proper input data for the TRUST-II code, tabular values of saturation versus pressure head are required. We chose functional relationships to provide this data. Each relationship was chosen for its ability to adequately represent typical laboratory data and to provide acceptable input data for the TRUST-1I code. We wrote FORTRAN-77 computer codes to help the user fit these relationships to actual data. The following paragraphs briefly outline the theoretical basis and the solution techniques necessary for each of the functional relationships. A users guide to each of the codes is found in Section 2.4 and copies of the codes are on microfiche and can be found in the back of this document.

\subsubsection{Haverkamp et al. (1977)}

Based on laboratory column data of infiltration into soils, Haverkamp et al. (1977) proposed the following functional relationship between volumetric water content $(\theta)$ and pressure head, $(h)$ :

$$
\theta=\frac{\alpha\left(\rho_{s}-\cap_{r}\right)}{\alpha+|h|^{R}}+n_{r}
$$

where the subscript $s$ refers to saturation (i.e., the value of $A$ for which $h=0$ ), the subscript $r$ refers to the residual water content, and $\alpha$ and $a$ are empirically determined constants.

Equation 2.3 provides for proper behavior of the soil-water retention curve; that is, at a pressure head of zero, the predicted volumetric water content is the saturated value, and at highly negative pressures $(h \rightarrow-\infty)$ the volumetric water content approaches the residual value. Equation (2.3) also produces a sinooth and continuous curve throughout the pressure range which is essential to providing acceptable TRUST-II input data.

Equation (2.3) has two soil-dependent, empirically derived constants: a and $R$. Also included in Equation (2.3) are two experimentally derived soil properties: the saturated and residual water contents. In general, the saturated water content is an easily measured quantity often taken as the total porosity. On the other hand, the residual water content is a rather illdefined quantity, often taken to be that quantity of fluid in the medium that is immobile and is not routinely measured in the lab. Therefore, the value of the residual water content can be considered to be an empirically derived constant, leaving Equation (2.3) with three curve-fitting parameters. To obtain the three curve-fitting parameters ( $\alpha$,, , and the residual water content, $\left.{ }_{r}\right)$, we wrote a short computer code, HAVERFIT. The code minimizes the squared error between the functional relationship given by Equation (2.3) and the input experimental data. The summed squared error term is given by: 


$$
\text { summed squared error } \left.=\sum_{i=1}^{m} \text { (actual value - predicted value }\right)^{2}
$$

where $m=$ number of data points.

The code HAVERFIT uses the International Mathematics and Statistical Library (IMSL) subroutine 'ZXMIN' to obtain a minimum squared error. A users guide to the code is found in Section 2.4 in this document, a list of input variables can be found in Section 2.6, and a listing of the code can be found on microfiche in the back of this document.

Figure 2.1 snows a typical representation using the Haverkamp model. The soil data is from uranium mill tailings reported by Sherry (1982). Figure 2.1 indicates that the representation provides a good fit to the experimental data. The root mean squared error for this curve fit is $1.488 \times 10^{-3}$.

\subsubsection{Van Genuchten (1978)}

Van Genuchten (1978) presents a further development of the relationship presented by Haverkamp et al. (1977) to derive an expression for hydraulic conductivity. The resulting functional relationship of pressure nead and volumetric water content is:

$$
\theta=\left(\theta_{s}-\theta_{r}\right)\left[\frac{1}{1+|\alpha h|^{\beta}}\right]^{\lambda}+\theta_{r}
$$

where $\alpha$ and $\beta$ are taken as empirically derived constants and $\lambda=1-\frac{1}{\beta}$. As in the previous functional relationship of Haverkamp et al. (1977), the ßesidual water content is taken to be an empirically derived constant.

Equation (2.4) provides the same limits and smoothness as those found in Equation (2.3). Fits of experimental data to Equation (2.4), however, will generally yield a lower value of residual water content than will the model of Haverkamp et al. (1977). In some cases, unrealistic negative values of residual water content have been calculated using the SOILGEN code, VANFIT. Therefore, although either Equation (2.3) or (2.4) may provide adequate data matching, the user must carefully observe whether the curve exhibits realistic behavior over the entire range of water contents.

We wrote the computer code, VANFIT, to estimate the curve-fitting parameters in Equation (2.4), using experimental data as input. As in HAVERFIT, the code minimizes the squared error of the function over the experimental data. A users guide is found in Section 2.4 of this document, a list of input variables is given in Section 2.6, and a listing of the code is found on microfiche in the back of this document. 


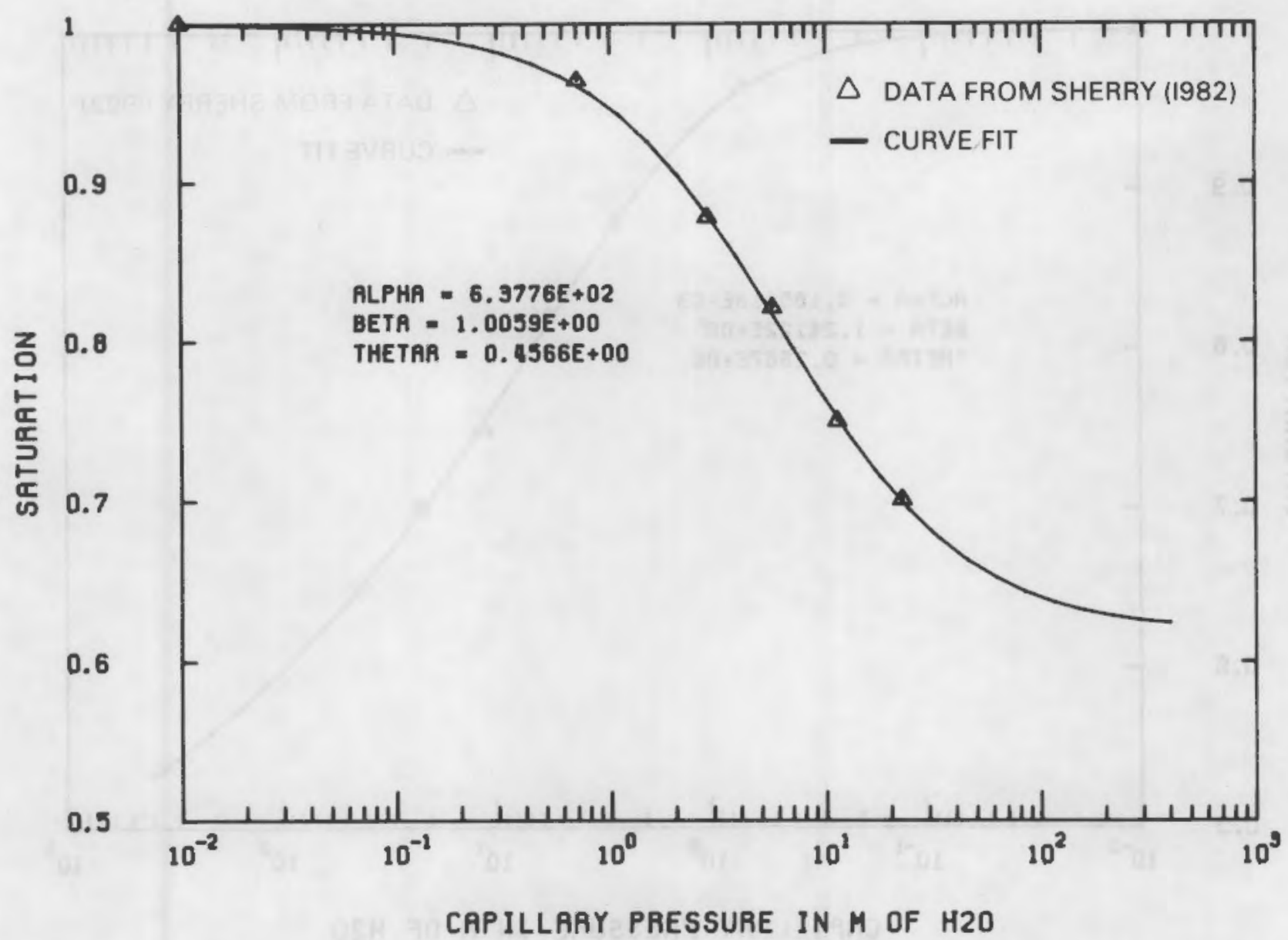

FIGURE 2.1. Soil-Water Retention Data for Uranium Mill Tailings Data Fit Using the Haverkamp (1977) Model

Figure 2.2 shows the resulting curve that is fit to the experimental data of Sherry (1982) by using Equation (2.4). The root mean squared error is $2.011 \times 10^{-3}$.

\subsubsection{Su and Brooks (1976)}

Su and Brooks (1976) approach the functional relationship problem from a different perspective by dividing the soil-water retention curve into two regions: one of upward concavity and one of downward concavity. To each region, a Pearson Type VIII distribution is fit, which is then matched at a fictitious inflection point. The resulting functional relationship for the soil-water retention curve is given by:

$$
h=h_{f}\left(\frac{s-s_{r}}{a}\right)\left(\frac{1-s}{b}\right)^{b m / a}
$$




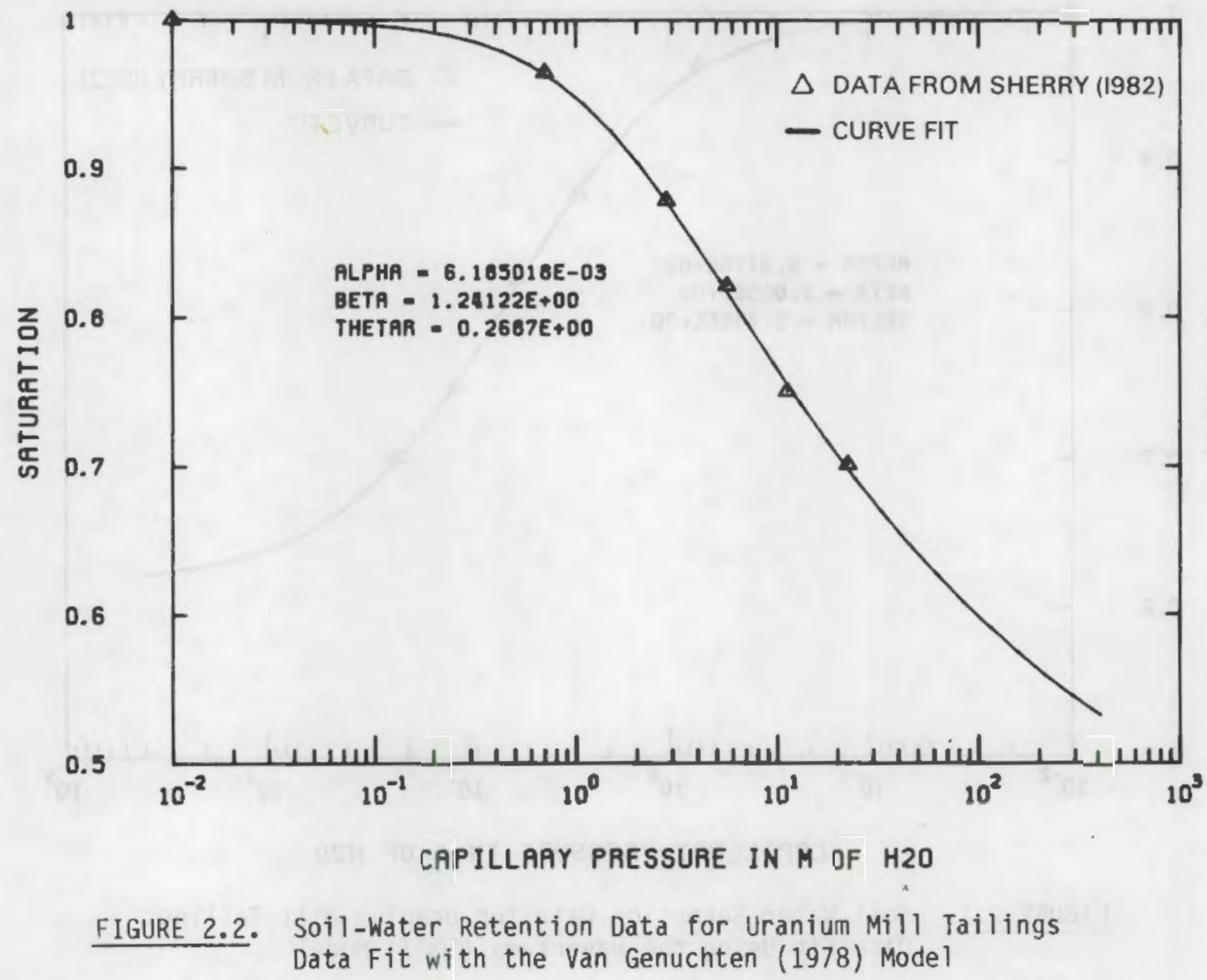

where $a, b$, and $m=$ curve fitting parameters

$h_{f}=$ pressure head at the fictitious inflection point

$S_{r}=$ residual saturation $\left(\frac{{ }}{\rho_{s}}\right)$

$S=$ saturation $\left(\frac{\Theta}{\Theta_{S}}\right)$.

Equation (2.5) yields the pressure head as a function of the saturation, as compared to the two previous relationships which use the pressure head as the independent variable.

Su and Brooks present a four-point forcing method to solve for the empirical constants $a, b, m$, and $h_{f}$. This technique forces the soil-water retention curve to pass through four input experimental data points. This solution technique provides the user with the option of choosing which data points are to be used. The FORTRAN code that Su and Brooks present to solve 
for the necessary parameters has been modified to provide TRUST-II compatible output. Figure 2.3 shows the resulting fit of Equation (2.5) to experimental data of uranium tailings from Sherry (1982). As can be seen in the figure, the functional representation passes exactly through four of the data points and also provides a good approximation of the remaining two data points. A users guide is found in Section 2.4 and a listing of the code is found on microfiche in the back of this document.

\subsection{HYDRAULIC CONDUCTIVITY FUNCTIONS}

Two methods are presented for generating hydraulic conductivity data for the TRUST-II code input. If experimental data are available, a two-parameter functional relationship presented by Haverkamp et al. (1977) is used in the code HCONFIT. If experimental data are lacking, partially saturated hydraulic conductivity may be synthesized from the soil-water retention data using the method of Mualem (1976) in the code CONDGEN. These two methods chosen for TRUST-II input are described below.

\subsubsection{Haverkamp et a1. (1977)}

Based on data from Yolo light clay and a sand, Haverkamp et al. (1977) proposed the following equation to fit experimentally derived hydraulic conductivity data:

$$
K(h)=K_{s}\left(\frac{A}{A+|h|^{B}}\right)
$$

where

$K_{s}=$ saturated hydraulic conductivity

$h=$ the fluid pressure head

$A$ and $B=$ empirically derived constants.

We wrote the computer code, HCONFIT, to perform a two-parameter, least squares fit of Equation (2.6) to experimental data. Due to the wide range of conductivity values which are commonly encountered, the curve-fitting routine log transforms Equation 2.6 to the following:

$$
\log K(h)=\log \left[K_{S}\left(\frac{A}{A+|h|^{B}}\right)\right]
$$

This transformation gives more weight to those points at pressure heads that are highly negative and provides a better curve fit to the data at these higher pressures. Figure 2.4 shows the resulting curve fit of Equation (2.7) to permeability data generated by the method of Mualem (1976). In general, the 


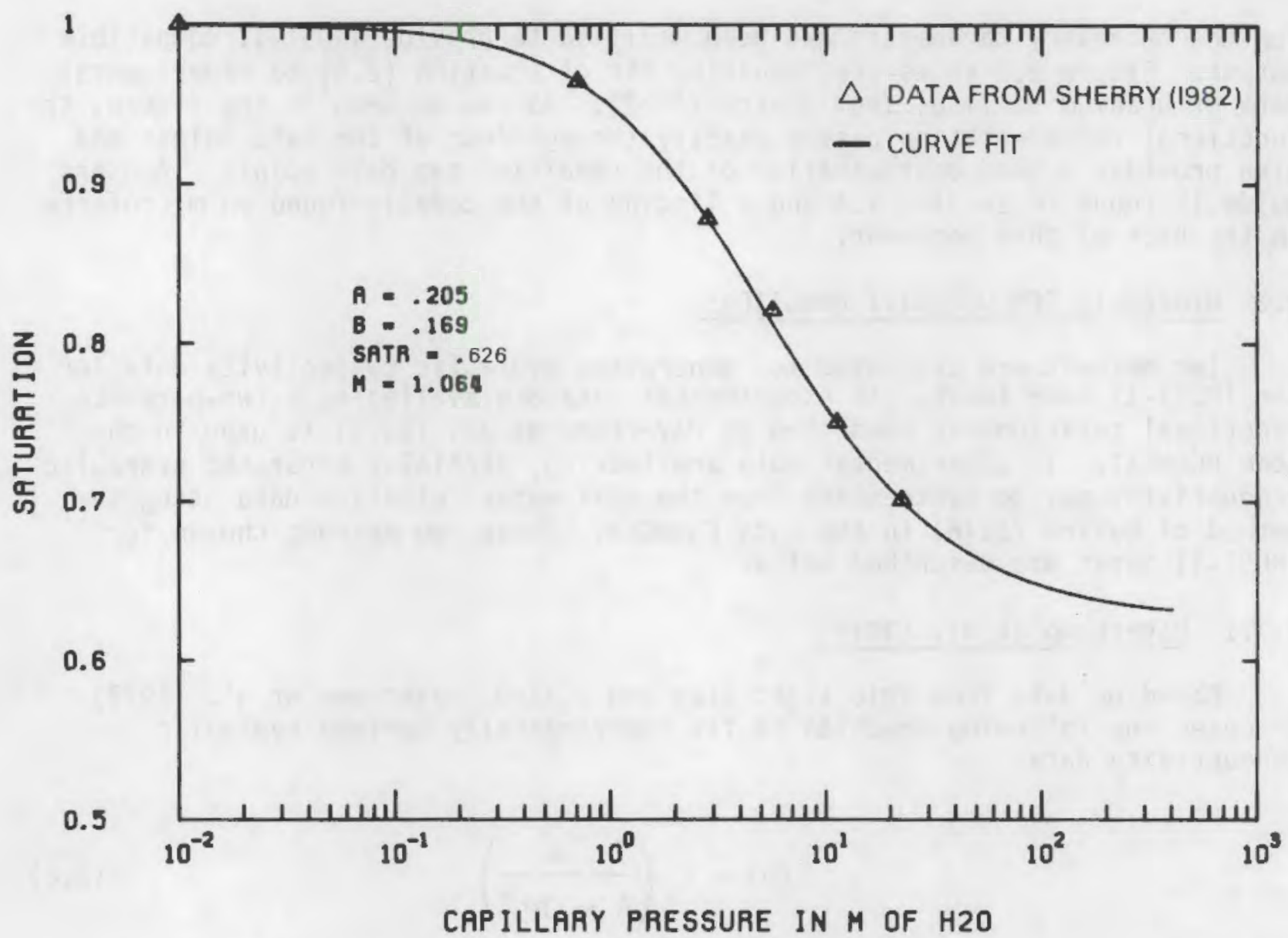

FIGURE 2.3. Soil-Water Retention Data for Uranium Mill Tailings Data Fit Using the Su and Brooks (1976) Model

fit is quite good, although some error occurs at the more saturated end of the curve. This is primarily due to the lack of input data points at these pressures and to the low statistical weighting given to these points by Equation (2.7). Because the code attempts to minimize the squared error at all the data points, those portions of the curve that have the highest density of data points will be fit the best. The code outputs pressure head and intrinsic permeability data that are compatible with TRUST-II input. A users guide is found in Section 2.4 of this document, a list of input variables is given in section 2.6, and a listing of the code is in the microfiche pocket.

\subsubsection{Mualem (1976)}

Mualem (1976) compared several models for predicting hydraulic conductivity of unsaturated soils and then presented a new model. He compared his new model to existing models and found it to yield statistically better results when fit to experimental data. Mualem's new model is based on the 


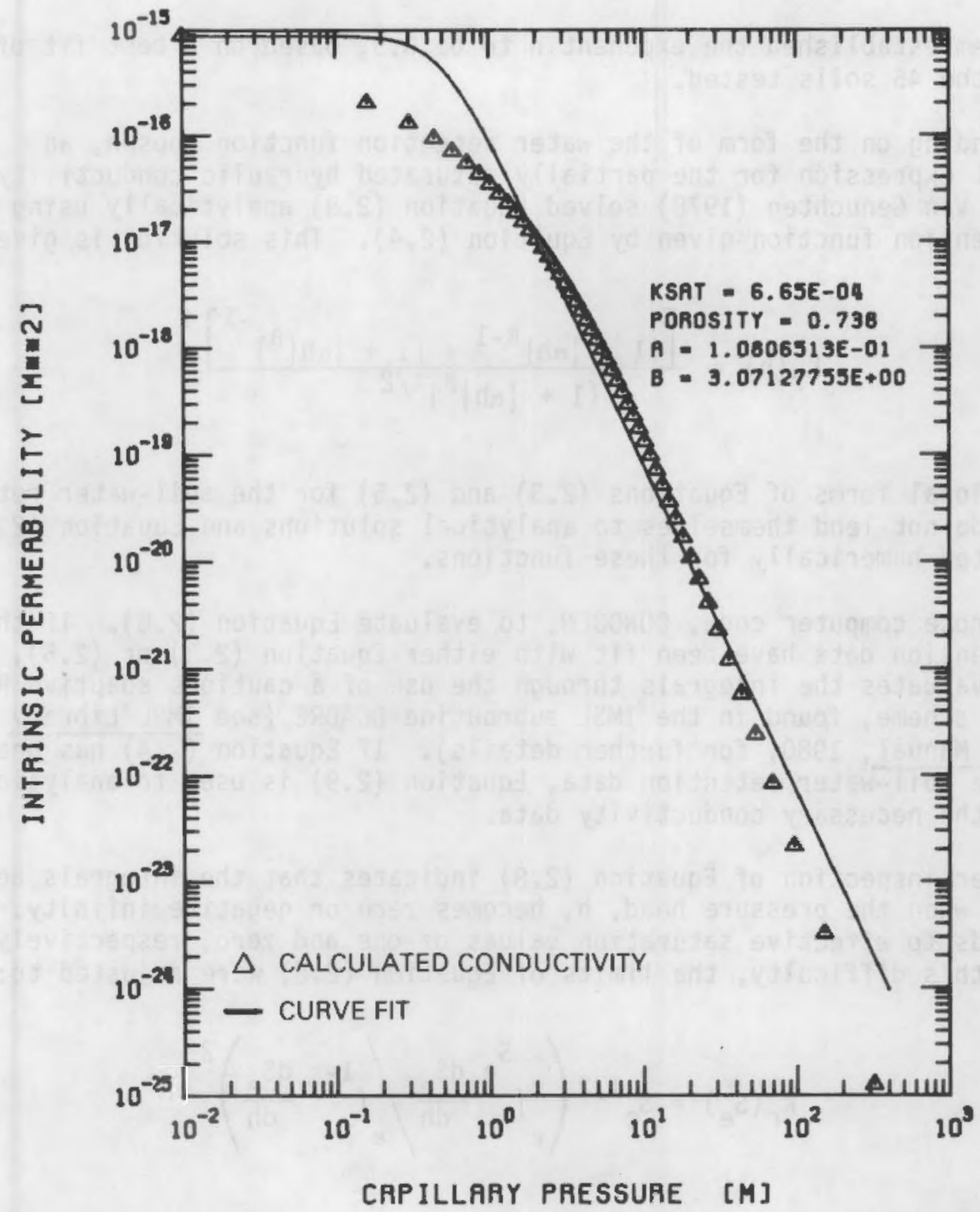

FIGURE 2.4. Curve Fit of Haverkamp et al. (1977) to Predicted Permeabilities of Uranium Mill Tailings.

relationship between the pore size distribution and the water retention characteristics. The model equation is given by:

$$
k_{r}\left(S_{e}\right)=s_{e}^{n}\left[\begin{array}{ll}
t^{e} & \frac{d S_{e}}{h} / \frac{d S_{e}}{h}
\end{array}\right]^{2}
$$


Mualem established the exponent $n$ to be 0.5 , based on a best fit of the model to the 45 soils tested.

Depending on the form of the water retention function chosen, an analytical expression for the partially saturated hydraulic conductivity may be derived. Van Genuchten (1978) solved Equation (2.8) analytically using the water retention function given by Equation (2.4). This solution is given by:

$$
K_{r}(h)=\frac{\left[\left(1-|a h|^{\beta-1} \cdot\left(1+|\alpha h|^{\beta}\right)^{-\lambda}\right]^{2}\right.}{\left(1+|\alpha h|^{\beta}\right)^{\lambda / 2}}
$$

The functional forms of Equations (2.3) and (2.5) for the soil-water retention function do not lend themselves to analytical solutions and Equation (2.8) must be evaluated numerically for these functions.

We wrote computer code, CONDGEN, to evaluate Equation (2.8). If the soilwater retention data have been fit with either Equation (2.3) or (2.5), the program evaluates the integrals through the use of a cautious adaptive Rhomberg iteration scheme, found in the IMSL subroutine DCADRE (see IMSL Library

Reference Manual, 1980, for further details). If Equation (2.4) has been used to fit the soil-water retention data, Equation (2.9) is used to analytically generate the necessary conductivity data.

Closer inspection of Equation (2.8) indicates that the integrals become undefined when the pressure head, $h$, becomes zero or negative infinity. This corresponds to effective saturation values of one and zero, respectively. To overcome this difficulty, the limits of Equation (2.8) were adjusted to:

$$
K_{r}\left(S_{e}\right)=S_{e}^{1 / 2}\left(\int_{\varepsilon}^{S^{e}} \frac{d S_{e}}{d h} / \int_{\varepsilon}^{1-\varepsilon} \frac{d S_{e}}{d h}\right)^{2}
$$

where $0.0<\varepsilon<<1.0$

To investigate the validity of adjustments made in Equation (2.10) in the code CONDGEN, we compared the analytical results obtained by using Equation (2.9) with those obtained by using the numerical integration of Equation (2.10). Figure 2.5 shows the results of one such comparison using $\varepsilon=0.0001$. Epsilon should be chosen as small as possible to produce accurate results. Too small a value of epsilon may, however, affect the accuracy of the numerical integration scheme.

\subsection{SOILGEN USERS MANUAL}

We developed five separate computer codes to help the user obtain input in the properties of materials for the TRUST-II code. The following sections 


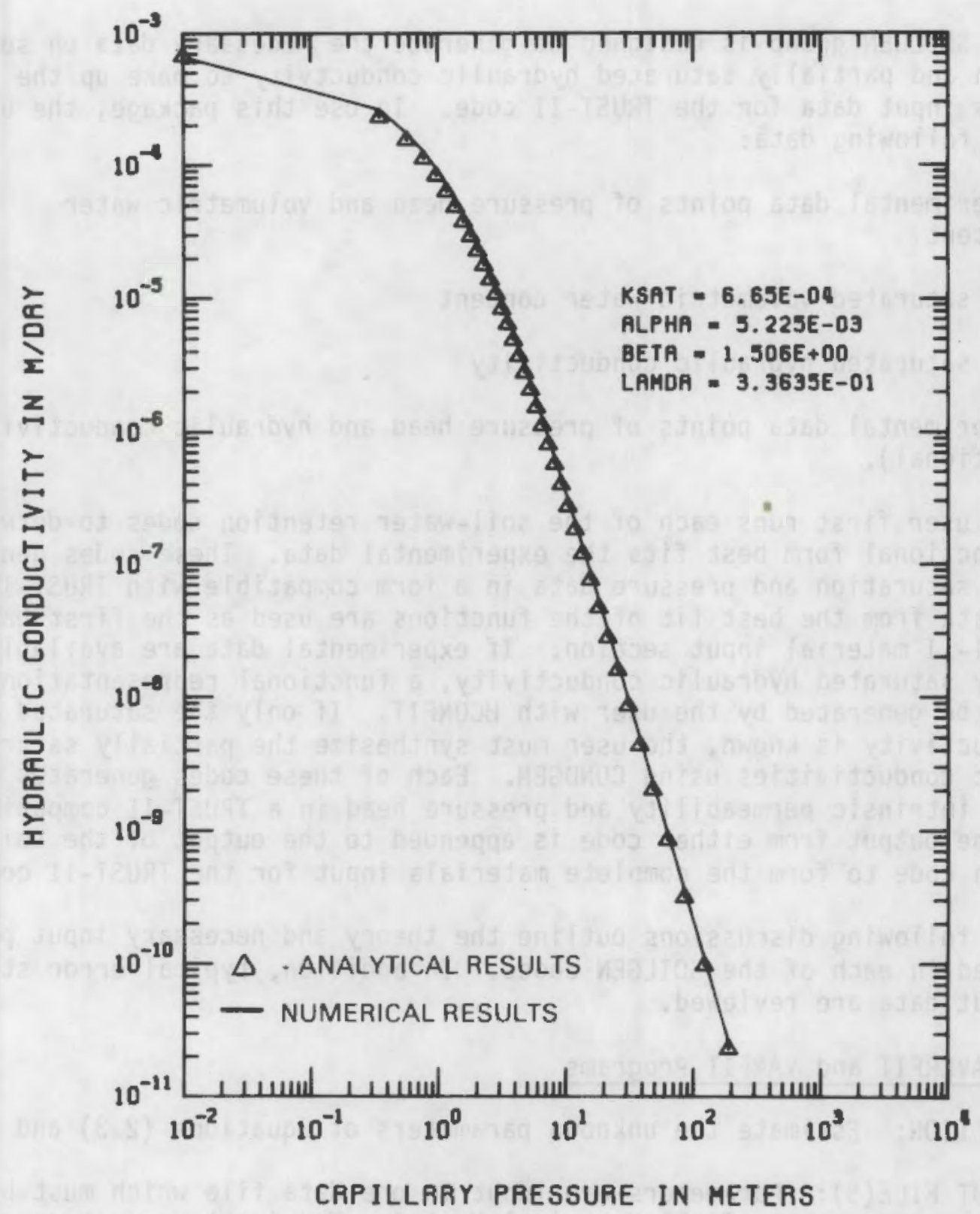

FIGURE 2.5. Comparison of Analytically Generated Conductivity Data (Van Genuchten 1978) to Data Generated by CONDGEN.

describe, in general terms, the chronological steps taken in the development of a TRUST-II input file and the working details of each of the codes necessary to generate data on the material characteristics for input to the TRUST-II code. 
The SOILGEN group is designed to generate the necessary data on soil-water retention and partially saturated hydraulic conductvity to make up the materials input data for the TRUST-II code. To use this package, the user must have the following data:

- experimental data points of pressure head and volumetric water content

- the saturated volumetric water content

- the saturated hydraulic conductivity

- experimental data points of pressure head and hydraulic conductivity (optional).

The user first runs each of the soil-water retention codes to determine which functional form best fits the experimental data. These codes generate pairs of saturation and pressure data in a form compatible with TRUST-II. The output data from the best fit of the functions are used as the first half of the TRUST-II material input section. If experimental data are available on the partially saturated hydraulic conductivity, a functional representation of this data can be generated by the user with HCONFIT. If only the saturated hydraulic conductivity is known, the user must synthesize the partially saturated hydraulic conductivities using CONDGEN. Each of these codes generates data pairs of intrinsic permeability and pressure head in a TRUST-II compatible form. The output from either code is appended to the output of the soil-water retention code to form the complete materials input for the TRUST-II code.

The following discussions outline the theory and necessary input parameters used in each of the SOILGEN codes. In addition, typical error statements and output data are reviewed.

\subsubsection{HAVERFIT and VANFIT Programs}

FUNCTION: Estimate the unknown parameters of Equations (2.3) and (2.4).

INPUT FILE(S): Parameters are input in one data file which must be assigned by the user to FORTRAN Logical Unit 3. The input parameters are listed in Section 2.6.

OUTPUT FILE(S): Curve-fitting parameters and saturation versus pressure head data pairs are output to two data files. One output data file assigned to FORTRAN Logical Unit 7 and is useful for data inspection and plotting. The output data file assigned to FORTRAN Logical Unit 8 forms the first half of the TRUST-II materials input section.

As can be seen in Equations 2.3 and 2.4, both contain three unknown curvefitting parameters: $\alpha, \beta$, and $\theta_{r}$. The codes make use of similar curve-fitting routines. Both codes use a least squared error curve-fitting analysis to estimate the unknown parameters. Initial estimates of the unknown parameters are input to the code along with the data points to be fit by the curve. Each 
code revises the parameter estimates to minimize the sum of the square of the differences between the predicted values and the experimental data points.

The revision and minimization technique used is a quasi-Newton scheme. The technique is contained in an IMSL subroutine "ZXMIN". [See IMSL Library Reference Manual 1980 for further details on the minimization technique.]

The user inputs the convergence criteria, NSIG, which determines the degree of accuracy required of the functional fit. If this convergence criterion is not met during the computation, one of the following error messages will be sent to the user:

- $\quad$ IER $=130-$ - implies that the iteration was terminated because rounding errors were becoming dominant. The parameters have not been determined to 'NSIG' digits.

- $\quad$ IER $=131$-- implies that the iteration was terminated because MAXFN, the number of iterations, was exceeded.

Upon meeting the convergence criterion set by the user, the code(s) outputs the revised curve-fitting parameters to a data file. In addition, the root mean squared error (RMS) is calculated and output. This 'goodness of fit' indicator is calculated as:

$$
R M S=\sqrt{\left.\frac{m}{j=1} \text { (actual value }- \text { predicted value }\right)^{2}}
$$

where

$m$ = number of data points.

In addition to the above-mentioned input parameters, the user enters the range of pressues and the number of data points required as input for the TRUST-II code. Each code calculates pressure and saturation data pairs using the functional representation over the range of pressures that is specified by the user. These data pairs are distributed logarithmically so that the nighest density of data points is calculated near saturation.

of particular concern to the TRUST-II user is the specific moisture capacity term, C. This term is a function of the slope of the soil-water retention curve and is a measure of the soil's ability to absorb or release water from storage as a result of saturation changes. If the porosity, $n$, is assumed to be a constant, the specific moisture capacity is given by: 


$$
C=\frac{d \theta}{d h}
$$

If this term becomes zero, the TRUST-II code will have difficulty solving the equations of partially saturated flow. However, Figures 2.1 through 2.3 indicate that the capacity term may approach zero at both ends of the curve. Since TRUST-II reads input saturation data to only five significant digits, the problem can be compounded by rounding of the tabulated saturation values which may force the capacity term to become zero.

To insure that this does not happen with the TRUST-II input data, the VANFIT and HAVERFIT codes contain a test that compares adjacent saturation values in the output data file to insure that their difference is greater than zero to five significant digits. If a zero value is found, the code sends a warning to the terminal informing the user of the pressure at which the zero value was found. In most cases, the user can eliminate this problem by adjusting the range of pressures to be calculated.

\subsubsection{SUBROOKS Program}

FUNCTION: To calculate the unknown parameters of Equation (2.5) $\left(a, b, m, h_{f}\right)$.

INPUT FILE(S): Parameters are input in one data file, which must be assigned by the user to FORTRAN Logical Unit 3. The input parameters are listed in Section 2.6.

OUTPUT FILE(S): Curve-fitting parameters and saturation versus pressure head data are output to two data files. One output data file, assigned to Unit 7, is useful for data inspection and plotting. The output data file assigned to Unit 8 forms the first half of the TRUST-II materials input section.

To obtain the parameters for the retention function developed by Su and Brooks (1976), they presented a method of forcing the function to go through four experimental data points. Theoretically, the user may find the parameters by solving a system of four simultaneous equations formed by four pairs of pressure and saturation data. The solutions of these equations depend not only on the accuracy of the experimental data, but also on the criterion established for convergence in solving the system of equations. This solution scheme is different from those previously described in that the function is forced to pass through the experimental data points. This scheme gives the user better control of the representation in critical areas; however, it may produce poorer fits at those experimental points not used in the parameter estimation. The four pairs of pressure and saturation data that are selected should cover a wide range of saturation, and unreliable data should be excluded from consideration.

Su and Brooks (1976) present a FORTRAN code to solve the system of simultaneous equations. If the input data do not allow the code to converge on a 
solution, error messages are sent to the user. The code was expanded to include a TRUST-II compatible output as well as a test routine to check the specific capacity.

The most effecient way for the user to determine the four best data points to be used in the program is to plot the data and draw a best-fit-by-eye smooth curve through the data points. Those points that fall precisely on the curve are to be used as the first choice. If the system fails to converge, one or more other data pairs are substituted for those initially chosen.

In addition to selecting four pairs of data for use in the code, the user must make an initial guess of the residual saturation. Su and Brooks (1976) report that convergence of the numerical scheme is relatively insensitive to this initial guess.

\subsubsection{HCONFIT Program}

FUNCTION: Estimate the unknown parameters A and B of Equation (2.6).

INPUT FILE(S): Parameters are input in one data file, which must be assigned by the user to FORTRAN Logical Unit 3 . The input parameters are listed in Section 2.6.

OUTPUT FILE(S): Curve-fitting parameters and pairs of saturation versus pressure head data are output to two data files. One output data file assigned to Unit 7, is useful for data inspection and plotting. The output data file assigned to Unit 8 forms the second half of the TRUST-II BLOCK 2 input.

The code HCONFIT is similar to both HAVERFIT and VANFIT. A least squared error routine is used to revise the estimates of the parameters $A$ and $B$.

\subsubsection{CONDGEN Program}

FUNCTION: Estimate the hydraulic conductivity data from soil-water retention data using the technique of Mualem (1976).

INPUT FILE(S): Parameters are input in one data file, which must be assigned by the user to Unit 3 . The input parameters are listed in Section 2.6.

OUTPUT FILE(S): Pairs of permeability versus pressure head data are output to two data files. One output data file, assigned to Unit 7 , is useful for data inspections and plotting. The output data file assigned to Unit 8 forms the second half of the TRUST-II BLOCK 2 input.

CONDGEN was written to evaluate the integrals of Equation (2.10) to determine the hydraulic conductivity as a function of volumetric water content. The user enters data concerning the functional form of the soil-water retention curve and the saturated hydraulic conductivity. The code either analytically solves Equation (2.9) using the solution of Van Genuchten (1978), or numerically integrates Equation (2.10). The numerical integration is carried out in 
an IMSL subroutine using, DCADRE, a cautious, adaptive Rhomberg extrapolation scheme. [See the IMSL Library Reference Manual (1980) for further details on this subroutine.]

The following information concerning the DCADRE subroutine may be helpful to the user:

- DCAORE can, in many cases, handle jump discontinuities.

- The relative error parameter may be specified to $X$ number of digits; inclusively. For example, RERR $=0.1$ indicates that the estimate of the integral is to be correct to one digit, whereas RERR $=0.0001$ calls for four digit of accuracy. If DCADRE determines that the relative accuracy requirements cannot be satisfied, IER is set to 133.

- The absolute error parameter, AERR, should be non-negative. To give a reasonable value of AERR, the user must know the approximate magnitude of the integral that is being computed. In many cases $A E R R=0.0$ may be used. In this case, only the relative error requirement is satisfied in the computation.

The following are typical DCADRE error messages:

- $\quad I E R=65$-- implies that one or more singularities were successfully handled.

n $\quad$ IER = 66 -- implies that, in some subinterval(s), the estimate of the integral was accepted merely because the estimated error was small, even though no regular behavior was recognized.

n $\quad$ IER = 131 -- indicates failure due to insufficient internal working storage.

- IER = 132 -- indicates failure due to too much noise in the function (relative to the given error requirements) or due to an $\mathbf{1 l l \text { -behaved }}$ integrand.

- IER $=133$-- indicates that RERR is greater than 1.0, or AERR is less than 0.0 , or RERR is too small for the precision of the machine.

Even when IER is not equal to 0.0 , the IMSL subroutine DCADRE returns the best estimate of the integral that has been computed. According to the IMSL Library Reference Manual (1980): "a very cautious person would accept DCADRE results only if IER is 0 or 65 . The merely reasonable person would keep the faith even if IER $=66$. The adventurous person is quite often right in accepting DCAORE results even if IER is 131 or 132."

The remainder of the code calculates the pressures at those volumetric water contents where the hydraulic conductivity was calculated, and converts the conductivities calculated to intrinsic permeability. 
Output data is sent to two data files similar to the outputs of each of the codes mentioned in previous sections. Additional data are presented on the validity and/or errors encountered by the numerical integration technique.

\subsection{EXAMPLE USE OF SOILGEN}

This example illustrates the application of the SOILGEN group to experimental saturation data to produce a TRUST-II input data set. The experimental saturation versus pressure head data were taken from Sherry (1982), and represent the characteristics of uranium mill tailings slimes. The initial saturated volumetric water content was taken to be 0.738 .

The saturation data were fit using the SOILGEN code SUBROOKS. The important input parameters used in the code are given below:

- Estimate of residual saturation $=0.600$

- Maximum saturation $=1.000$

- Saturation data pairs $(P 1(a), S 1)=(-0.7038,0.964)$

$$
\begin{aligned}
& (P 2, S 2)=(-2.8151,0.878) \\
& (P 3, \text { S3 })=(-11,2605,0.750) \\
& (P 4, S 4)=(-22.5211,0.701)
\end{aligned}
$$

The output parameters from SUBR00KS for the functional representation are given below:

$$
\begin{array}{rlrl} 
& A & =0.205 \\
\hat{B} & B & =0.169 \\
\hat{n} & M & =1.064 \\
\hat{n} & h_{f} & =-4.681 \\
n & S R & =0.626
\end{array}
$$

The resulting functional form of Equation (2.5) is given by:

$$
h=-4.681\left(\frac{S-0.626}{0.205}\right)^{-1.064} \cdot\left(\frac{1-S}{0.169}\right)^{0.877}
$$

Figure 2.3 shows the resulting curve fit and the experimental data points.

To complete the input data section for the TRUST-II code, data must be input on the permeability versus pressure head relationship. Because these data were not experimentally available, we used the results obtained by the saturation versus pressure head relationship to generate permeability versus pressure nead data using the code CONDGEN. The important input parameters used in this portion of the example are given below:

(a) Pressure heads are in meters of water. 
- $K_{S}=6.65 \cdot 10^{-4} \mathrm{~m} /$ day

- $\varepsilon=0.001$

- Saturated Porosity $=0.738$

- RERR $=0.0001$

- AERR $=0.001$

- $\mathrm{G}=7.3157 \cdot 1 \mathrm{~g}^{10 \mathrm{~m} / \mathrm{day}^{2}}$

- $\rho=1.000 \cdot 10^{3} \mathrm{~kg} / \mathrm{m}^{3}$

- $\mu=9.71136 \cdot 10^{1} \mathrm{~kg} / \mathrm{m}-\mathrm{day}$

The resulting calculated permeabilities are shown in Figure 2.6.

The user is directed to the microfiche (in the back of this document) for listings of the input and output files used in this example. 


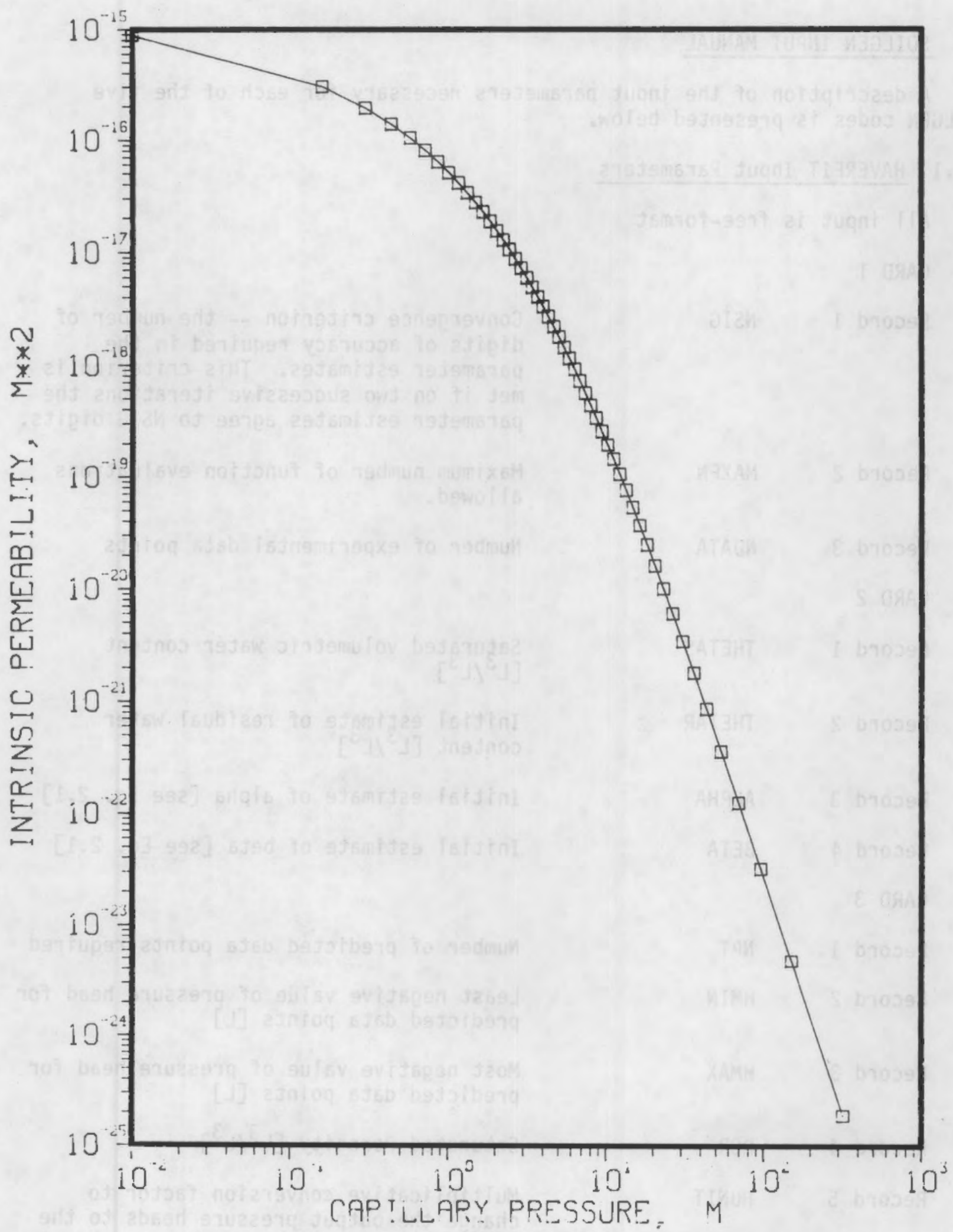

FIGURE 2.6. Permeabilities Calculated by CONDGEN for Uranium Mill Tailings Slime 


\subsection{SOILGEN INPUT MANUAL}

A description of the input parameters necessary for each of the five SOILGEN codes is presented below.

\subsubsection{HAVERFIT Input Parameters}

All input is free-format

- cARD 1

Record 1 NSIG

Convergence criterion -- the number of digits of accuracy required in the parameter estimates. This criterion is met if on two successive iterations the parameter estimates agree to NSIG digits.

Record 2 MAXFN

Record 3 NDATA

Maximum number of function evaluations allowed.

Number of experimental data points

- CARD 2

Record 1 THETAS

Saţurąted volumetric water content $\left[L^{3} / L^{3}\right]$

Record 2 THETAR

Initial estrimate of residual water content $\left[L^{3} / L^{3}\right]$

Record 3 ALPHA

Initial estimate of alpha [see Eq. 2.1]

Record 4 BETA

Initial estimate of beta [see Eq. 2.1]

- cARD 3

Record 1 NPT

Number of predicted data points required

Record 2 HMIN

Least negative value of pressure head for predicted data points [L]

Record 3 HMAX

Most negative value of pressure head for predicted data points [L]

Record $4 \quad$ POR

Saturated Porosity $\left[L^{3} / L^{3}\right]$

Record 5 HUNIT

Multiplicative conversion factor to change the output pressure heads to the appropriate units. 
- CARD 4 - (4+NDATA)

Record 1,2 THETA, HD

Experimental volumetric watęr çontent and pressure head data pairs $\left[\mathrm{L}^{3} / \mathrm{L}^{3}, \mathrm{~L}\right]$ 


\subsubsection{VANFIT Input Parameters}

All input is free-format

- CARD 1

Record $1 \quad$ NSIG

Convergence criterion -- the number of digits of accuracy required in the parameter estimates. This criterion is met if on two successive iterations the parameter estimates agree to NSIG digits.

Record 2 MAXFN

Maximum number of function evaluations

Record $3 \quad$ NDATA

Number of experimental data points

- cARD 2

Record 1 THETAS

Saţurąted volumetric water content $\left[L^{3} / L^{3}\right]$

Record 2 THETAR

Initial estimagte of residual water content $\left[\mathrm{L}^{3} / \mathrm{L}^{3}\right]$

Record 3 ALPHA

Initial estimate of alpha [see Eq. 2.2]

Record $4 \quad$ BETA

Initial estimate of beta [see Eq. 2.2]

- caRd 3

Record $1 \quad$ NPT

Record 2 HMIN

Record 3 HMAX

Record $4 \quad$ POR

Record 5 HUNIT

Number of predicted data points required

Least negative value of pressure head for . predicted data points [L]

Most negative value of pressure head for predicted data points [L]

Saturated Porosity $\left[L^{3} / L^{3}\right]$

Multiplicative conversion factor to convert output pressure heads to the appropriate units

- CARD 4 - (4+NDATA)

Record 1,2 THETA, HD

Experimental volumetric watęr çontent and pressure head data pairs $\left[L^{3} / L^{3}, L\right]$ 


\subsubsection{SUBROOKS Input Parameters}

All input is free-format

- CARD 1

Record $1 \quad \times(1)$

Record 2

- CARD 2

Record 1-4 P1,P2,P3,P4

Record 5-8 S1, S2, S3, S4

- CARD 3

Record 1 NPT

Record 2 HMIN

Record 3 HMAX

Record $4 \quad P O R$

Record 5 HUNIT
Initial estimate of residual saturation $\left[\mathrm{L}^{3} / \mathrm{L}^{3}\right]$

Maximum saturation value $\left[\mathrm{L}^{3} / \mathrm{L}^{3}\right]$

Input pressure head data points [L]

Ingut corresponding saturation values $\left[L^{3} / L^{3}\right]$

Number of predicted data points required Least negative value of pressure head for predicted data points [L]

Most negative value of pressure head for predicted data points [L]

Saturated Porosity $\left[L^{3} / L^{3}\right]$

Multiplicative conversion factor to change the output pressure heads to the appropriate units 


\subsubsection{HCONFIT Input Parameters}

All input is free-format

- caRd 1

Record 1 NSIG

Record 2 MAXFN

Record 3 NDATA

- CARD 2

Record 1 KSAT

Record 2 A

Record 3 B

n CARD 3

Record 1 NPT

Record 2 HMIN

Record 3 HMAX

Record $4 \quad$ POR

Record 5 HUNIT
Convergence criterion -- the number of digits of accuracy required in the parameter estimates. This criterion is met if on two successive iterations the parameter estimates agree to NSIG digits.

Maximum number of function evaluations

Number of experimental data points
Saturated hydraulic conductivity $[\mathrm{L} / \mathrm{T}]$

Initial estimate ' $A$ ' in Eq. (2.7)

Initial estimate ' $B$ ' in Eq. (2.7)

Number of predicted data points required

Least negative value of pressure head for predicted data points [L]

Most negative value of pressure head for predicted data points [L]

Saturated Porosity $\left[\mathrm{L}^{3} / \mathrm{L}^{3}\right]$

Multiplicative conversion factor to change the output pressure neads to the appropriate units

- CARD 4

Record 1 RHO

Density of fluid $\left[M / L^{3}\right]$

Record 2 GR

Acceleration due to gravity $\left[\mathrm{L} / \mathrm{T}^{2}\right]$

Record $3 \quad$ VISC

Viscosity of fluid [MT/L]

- CARD 5 - (5+NDATA)

Record 1,2 HD, HCON

Experimental pressure head and

conductivity data pairs $[\mathrm{L}, \mathrm{L} / \mathrm{T}]$ 


\subsubsection{CONDGEN Input Parameters}

All input is free format

- CARD 1

Record 1 FIT

Control variable for type of curve fit used for the soil water retention data 1 = Havercamp (1977)

2 = Van Genuchten (1978)

$3=$ Su and Brooks (1976)

- caRd 2

Record 1 A

Lower limit of integration of demoninator integral $(\varepsilon)$

Record 2

Upper limit of integration of demoninator integral (1-E)

Record 3 RERR Desired relative error parameter

Record 4 AERR Desired absolute error parameter

- cARD 3

Record 1 KSAT

Saturated hydraulic conductivity [L/T]

Record 2 HUNIT

Multiplicative conversion of pressure head data to appropriate units

Record 3 NPT

Number of data points to be predicted for TRUST-II input

ค CARD 4

Record 1 ALPHA

Record 2 BETA

Record 3 THETAS

Record 4 THETAR
Calculated value of alpha from HAVERFIT

Calculated value of beta from HAVERFIT

Saturated volumetric water content $\left[\mathrm{L}^{3} / \mathrm{L}^{3}\right]$

Calculated value of residual water content from HAVERFIT $\left[\mathrm{L}^{3} / \mathrm{L}^{3}\right]$ 


\begin{tabular}{|c|c|c|c|}
\hline ค & CARD 4 & & 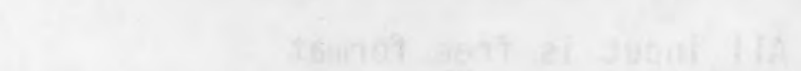 \\
\hline & Record 1 & ALPHA & Calculated value of alpha from VANFIT \\
\hline & Record 2 & BETA & Calculated value of beta from VANFIT \\
\hline & Record 3 & THETAS & $\begin{array}{l}\text { Saţura̧ted volumetric water content } \\
{\left[\mathrm{L}^{3} / \mathrm{L}^{3}\right]}\end{array}$ \\
\hline & Record 4 & THETAR & $\begin{array}{l}\text { Calculated value of reşidyal water } \\
\text { content from VANFIT }\left[\mathrm{L}^{3} / \mathrm{L}^{3}\right]\end{array}$ \\
\hline
\end{tabular}

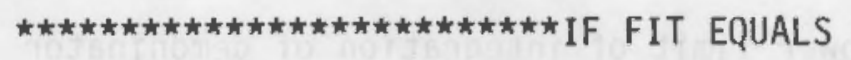

n CARD 4

$\begin{array}{lll}\text { Record } 1 & \text { A } & \text { 'A' parameter from SUBROOKS } \\ \text { Record } 2 & \text { B } & \text { 'B' parameter from SUBROOKS } \\ \text { Record } 3 & \text { XM } & \text { 'M' parameter from SUBROOKS } \\ \text { Record } 4 & \text { PF } & \text { 'HF' parameter from SUBR00KS }\end{array}$

- CARD 5

Record 1 VISC

Viscosity of fluid [MT/L]

Record 2 RHO

Density of fluid $\left[M / L^{3}\right]$

Record 3

G

Acceleration due to gravity $\left[L / T^{2}\right]$ 


\subsection{GRIDGEN}

The grid generation program, GRIDGEN, was developed to facilitate quick and easy generation of grids for use with the TRUST-II code. This is required because initial estimates of an appropriate grid size are frequently wrong and often the only way to find an appropriate size is to compare results that are obtained using various grid sizes. The program GRIDGEN can generate nonuniform rectangular grids. After the user determines the appropriate grid size, the rectangular grid can be modified in areas defining different material zones, sources, sinks, and varying boundaries.

Another program developed at PNL, DIGRID (Foote et al. 1982), can be used to interactively develop grids or to refine existing grids. Generally, the user should determine the necessary grid resolution through several applications of GRIDGEN or by comparing model results with a known solution. If an irregular, nonrectangular grid is required, DIGRID can then be used to generate the necessary grid. The mesh resolution requirements found with the aid of GRIDGEN, however, should be adhered to.

The data file created by GRIDGEN includes Blocks 4 and 5 of the TRUST-II input deck (Reisenauer et al. 1982). Block 4 describes the integrated finitedifference nodes and cells. Data written to the Block 4 section consists of: the node number, the material zone number of the node, the node type indicator (explicit or implicit), the length, width, and depth of the cell, and the elevation of the node. Block 5 describes the internal fluid flow connections. Data written to the Block 5 section consists of: the node numbers of connected nodes (node pairs); the distance from each of the node pairs to the connected interface; and the length and depth of the connected interface between each of the node pairs; the distance from each of the node pairs to the connected interface; and the length and depth of the connected interface between each of the node pairs. The regular rectangular cells along boundaries may have two or three internal connections and the rest of the rectangular cells will have four internal connections.

\subsection{GRIDGEN EXAMPLE PROBLEM}

The problem illustrated in Figure 3.1 demonstrates some of the feature of the GRIDGEN program. The configuration consists of 8 nodes and 8 internal connections. Four of the nodes are zero volume nodes (Nodes $1,2,7,8$ ). Nodes $3,4,5$, and 6 are 1.0 unit by 1.0 unit in size. All of the nodes are 1.0 unit thick.

The input data for this grid generation problem are listed in Table 3.1 . Card one selects the output logical unit numbers for writing the BLOCK 4 and 5 data that will be used as input to TRUST-II. (Note that these files must be saved by the user through job control cards.) Card two gives the input values for the $x, y$, and $z$ coordinates for node 1. The next four cards (including the 


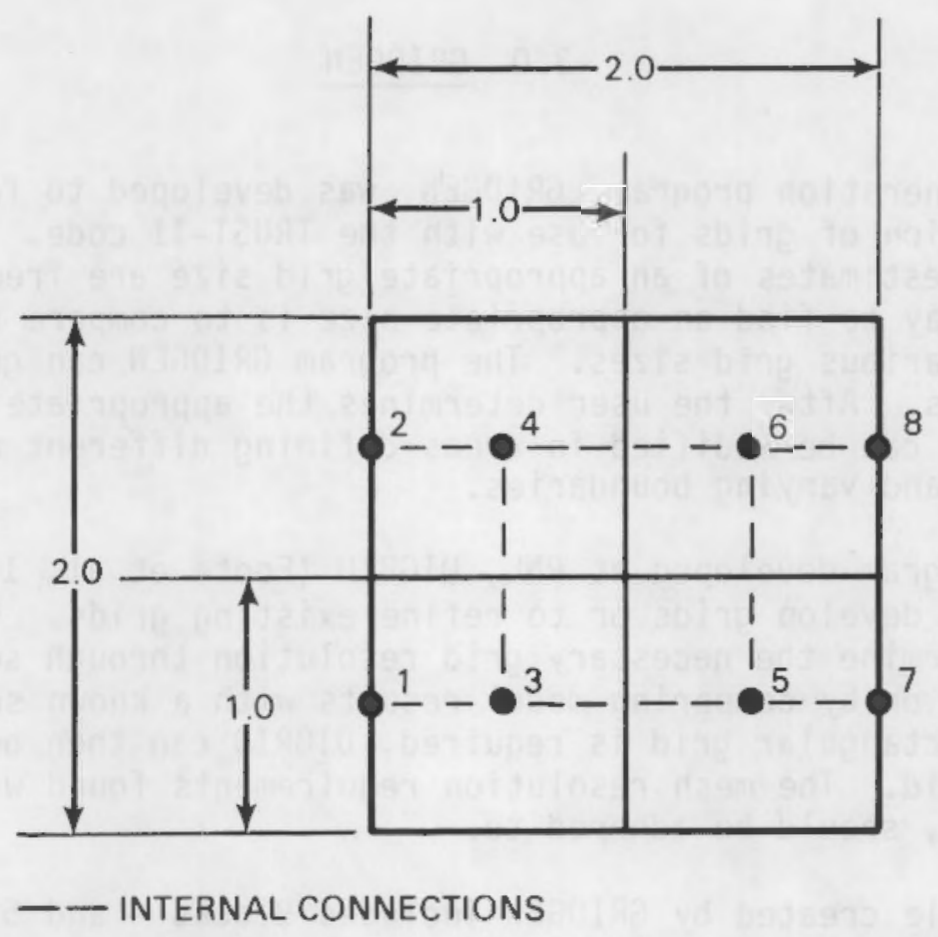

FIGURE 3.1. GRIDGEN Example Problem

TABLE 3.1. GRIDGEN Input Data

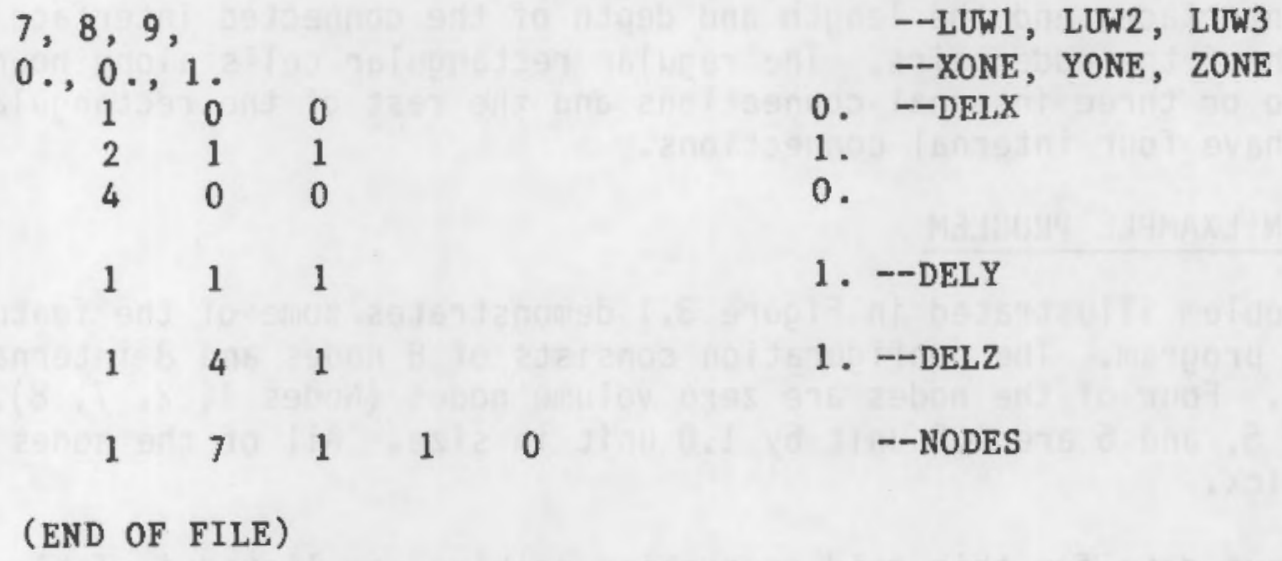


blank card) specify the values for $\Lambda x$. The next two cards specify the values for $\Delta y$, and the next two cards give the value for $\Delta z$, which is constant for this problem. The last two cards assign node numbers to each of the nodes and specifies the material numbers and node types that will be used by TRUST-II for each of the nodes.

The program can account for variations in material thickness in the $x$ direction. This requires the input of $N X+1 \Delta Z$ values where $N X$ is the number of nodes in the $x$ direction. The additional $\Delta z$ value is required because a thickness for a node must be specified at both the left and right edge of the node in the $x$ direction. (This holds true for zero thickness nodes as well.) Refer to Figure 3.2 for an illustration of where the $\cdot z$ values apply.

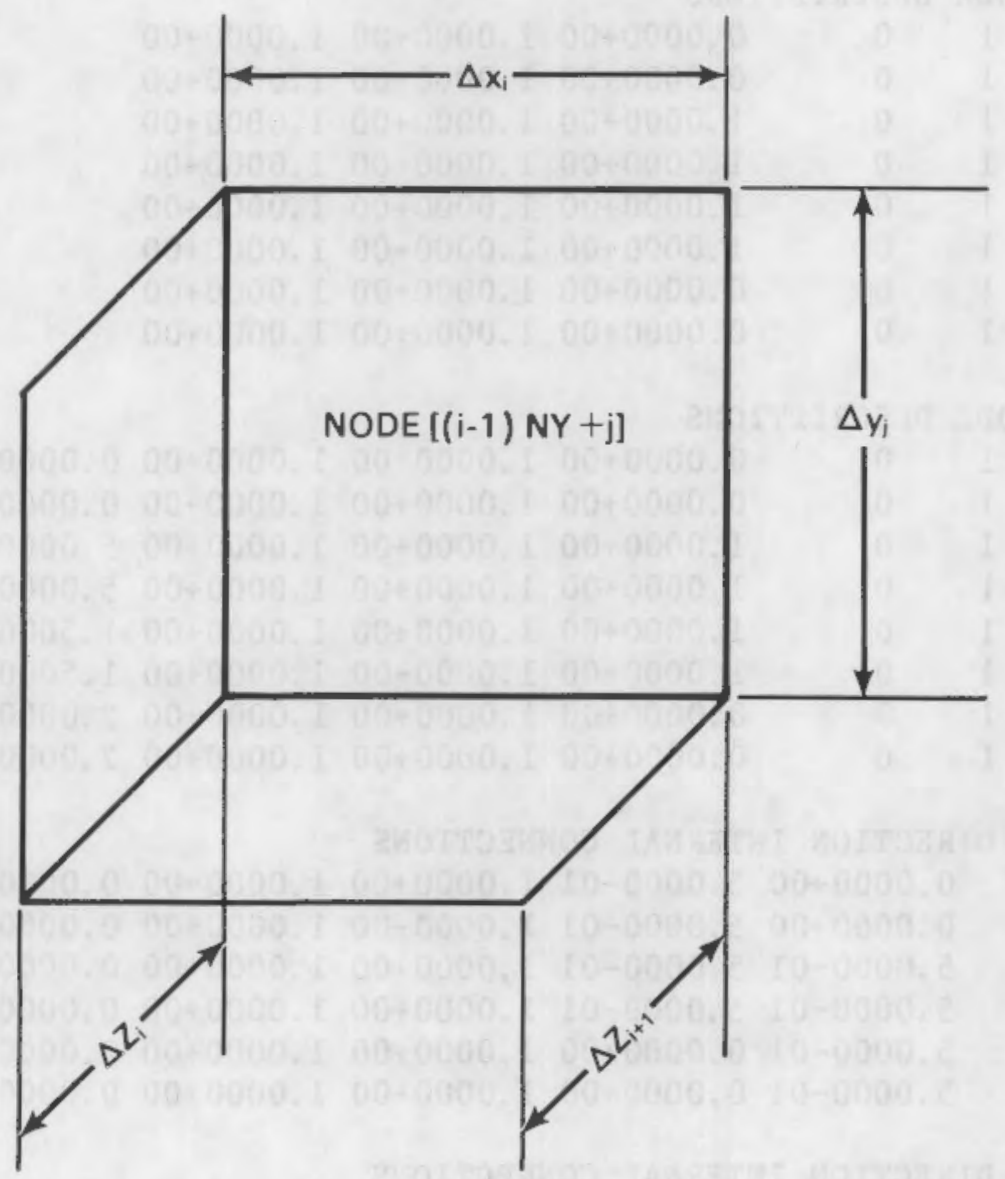

$$
\begin{aligned}
& \text { NY }=\text { \# NODES IN y DIRECTION } \\
& N X=\# \text { NODES IN } \times \text { DIRECTION }
\end{aligned}
$$

FIGURE 3.2 Location of $A z$ for a Typical Node 
The output files generated by GRIDGEN for this problem are listed in Table 3.2. The first listing of BLOCK 4 data was generated on logical unit 7 and consists of the node descriptions that would be used if the problem were a horizontally oriented problem. The elevation of each node is constant with $z$ fixed at 1.0 unit. The second listing of BLOCK 4 data was generated on logical unit 9 and consists of the node descriptions that would be used if the problem were a vertically oriented problem. The elevations of nodes $1,3,5$, and 7 are set to 0.0 units and the elevations of nodes $2,4,6$, and 8 are set to 1.0 unit.

TABLE 3.2. GRIDGEN Output Data

BLOCK 4

1

2

3

4

5

6

7

8

BLOCK 4

1

2

3

4

5

6

7

8

BLOCK 5

$\begin{array}{ll}1 & 3 \\ 2 & 4 \\ 3 & 5 \\ 4 & 6 \\ 5 & 7 \\ 6 & 8\end{array}$

BLOCK 5A

34

NODE DESCRIPTIONS

$\begin{array}{llllll}1 & 0 & 0.0000+00 & 1.0000+00 & 1.0000+00 & 1.0000+00 \\ 1 & 0 & 0.0000+00 & 1.0000+00 & 1.0000+00 & 1.0000+00 \\ 1 & 0 & 1.0000+00 & 1.0000+00 & 1.0000+00 & 1.0000+00 \\ 1 & 0 & 1.0000+00 & 1.0000+00 & 1.0000+00 & 1.0000+00 \\ 1 & 0 & 1.0000+00 & 1.0000+00 & 1.0000+00 & 1.0000+00 \\ 1 & C & 1.0000+00 & 1.0000+00 & 1.0000+00 & 1.0000+00 \\ 1 & 0 & 0.0000+00 & 1.0000+00 & 1.0000+00 & 1.0000+00 \\ 1 & 0 & 0.0000+00 & 1.0000+00 & 1.0000+00 & 1.0000+00\end{array}$

NODE DESCRIPTIONS

$\begin{array}{llllllll}1 & 0 & 0.0000+00 & 1.0000+00 & 1.0000+00 & 0.0000+00 & 0.0000+00 \\ 1 & 0 & 0.0000+00 & 1.0000+00 & 1.0000+00 & 0.0000+00 & 1.0000+00 \\ 1 & 0 & 1.0000+00 & 1.0000+00 & 1.0000+00 & 5.0000-01 & 0.0000+00 \\ 1 & 0 & 1.0000+00 & 1.0000+00 & 1.0000+00 & 5.0000-01 & 1.0000+00 \\ 1 & 0 & 1.0000+00 & 1.0000+00 & 1.0000+00 & 1.5000+00 & 0.0000+00 \\ 1 & 0 & 1.0000+00 & 1.0000+00 & 1.0000+00 & 1.5000+00 & 1.0000+00 \\ 1 & 0 & 0.0000+00 & 1.0000+00 & 1.0000+00 & 2.0000+00 & 0.0000+00 \\ 1 & 0 & 0.0000+00 & 1.0000+00 & 1.0000+00 & 2.0000+00 & 1.0000+00\end{array}$

$X$ DIRECTION INTERNAL CONNECTIONS

$$
\begin{array}{lllll}
0.0000+00 & 5.0000-01 & 1.0000+00 & 1.0000+00 & 0.0000+00 \\
0.0000+00 & 5.0000-01 & 1.0000+00 & 1.0000+00 & 0.0000+00 \\
5.0000-01 & 5.0000-01 & 1.0000+00 & 1.0000+00 & 0.0000+00 \\
5.0000-01 & 5.0000-01 & 1.0000+00 & 1.0000+00 & 0.0000+00 \\
5.0000-01 & 0.0000+00 & 1.0000+00 & 1.0000+00 & 0.0000+00 \\
5.0000-01 & 0.0000+00 & 1.0000+00 & 1.0000+00 & 0.0000+00
\end{array}
$$

$Y$ DIRECTION INTERNAL CONNECTIONS

$\begin{array}{lllll}5.0000-01 & 5.0000-01 & 1.0000+00 & 1.0000+00 & 0.0000+00\end{array}$

$\begin{array}{llllll}5.0000-01 & 5.0000-01 & 1.0000+00 & 1.0000+00 & 0.0000+00\end{array}$

(END OF FILE) 
The listing of BLOCK 5 data was generated on logical unit 8 . Note that the BLOCK 5 data has been broken into two parts: the first part gives the information necessary for forming the internal connections for the $x$ direction, and the second part uses the TRUST-II type A input option to add additional connections (in this case, the internal connection data for the $y$ direction).

The user must be careful when specifying the node numbers because the nodes are numbered sequentially according to an internal numbering scheme. The scheme essentially numbers the nodes by columns (from bottom to top) and from left to right. Figure 3.3 illustrates the scheme used by GRIDGEN for a 15-node grid. Through judicious use of the NSEQ and NADD feature, the user can renumber the nodes in any pattern that is desired. Of course, each node can be numbered individually by letting NSEQ be zero and including a card for each of the nodes.

The output generated by GRIDGEN is directly compatible with the TRUST-II input requirements. The advantage of using GRIDGEN is the rapid generation of reliable grids, which allows the user of TRUST-II to readily test the effects of a finer or coarser mesh on the accuracy of a simulation, and thereby select a grid that is just fine enough to get sufficiently accurate results without using an excessive amount of computer processing time. 


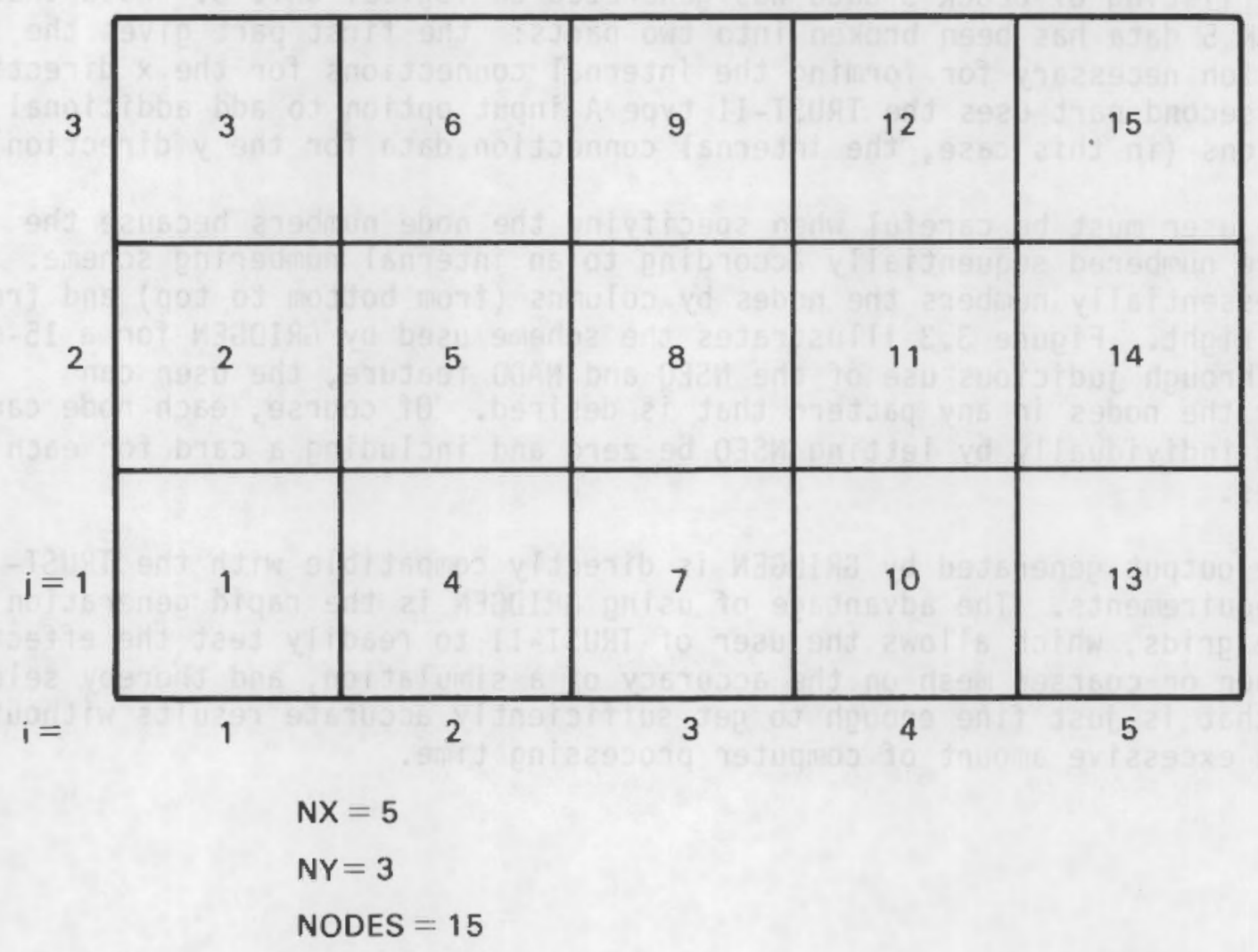

FIGURE 3.3. Example of the Internal Node Numbering Scheme Used by GRIDGEN 
3.2 GRIDGEN INPUT MANUAL

- CARD 1. Format (8I10)
$1-10$
LUW1
Logical unit number to which BLOCK 4 data will be written ( $Y$ coordinates used for elevation of node)
11-20 LUW2
Logical unit number to which BLOCK 5 data
will be written
$21-30$
LUW3
Logical unit number to which BLOCK 4 data will be written (ZONE used for elevation of node); set to zero if not desired
Note: LUW1, LUW2, and LUW3 should not be set to 5 or 6 .
- CARD 2. Format (8E10.3)

$\begin{array}{lll}1-10 & \text { XONE } & X \text { coordinate of NODEI } \\ 11-20 & \text { YONE } & Y \text { coordinate of NODE1 } \\ 20-30 & \text { ZONE } & \text { Z Coordinate of all nodes; only used if } \\ & & \text { LUW3 is greater than zero }\end{array}$

a CARD 3. Format $(3 I 5,15 X, E 10.3)$

$1-5 \quad 1$
$6-10 \quad$ NSEQ
I index value
Number of additional identical DELX
values
$11-15$
NADD
Increment between succesive values of I when using NSEQ
$16-30$
Leave blank
$31-40$
DELX
Width of cell in the $x$ direction [L]
Note: Input is terminated with a blank card.

- CARO 4. Format (3I5, 15X, E10.3)
1-5
了
$J$ index value
$6-10$
NSEQ
Number of additional identical DELY values 
11-15 NADD

Increment between sucessive values of $\mathrm{J}$ when using NSEQ

$16-30$

Leave blank

$31-40$

DELY

Width of cell in the $y$ direction [L]

Note: Input is terminated with a blank card.

- card 5.

Format $(315,15 x, E 10.3)$

$1-5$

$6-10$

$11-15$

$16-30$

$31-40$

- CARD 6. $1-5$

$6-10$

11-15

$16-20$

$21-25$

\section{I}

NSEQ

NADD

DELZX
I index value

Number of additional identical DELZX values

Increment between succesive values of I when using NSEQ

Leave blank

Thickness of cell; values correspond to the cell thicknesses at each edge (only variations in the $x$ direction can be accounted for) [L]

Note: Input is terminated with a blank card.

Format $(515,5 X, 3 E 10.3)$

NODE

Node identification number. The node identification numbers must be assigned in the sequence that GRIDGEN uses internally. It is not necessary to use the same numbers, however.

Number of additional identical nodes

Increment between successive values of NODE when using NSEQ.

NODMAT

Identification number of the material of which the node is a part.

KS

Node type indicator. Node will be a special node if KS is nonzero. Only used when KSPEC in BLOCK 1 is negative. Not needed for zero-volume and surface nodes.

Note: Input is terminated with a blank card. 


\subsection{MLTRAN}

The MLTRAN model consists of six staged submodels that are executed in the following order: MILGRID, MILSTRT, MILFLUX, MILPLOT, MILTVL, and MILFRNT. The submodel MILGRIO generates a plot of the finite-element grid used to model the flow domain. The submodel MILSTRT generates data files used by the other submodels. MILFLUX reads the TRUST-II input and output files and writes head, water content, and velocity data to a direct access file. The submodel MILPLOT displays contours of potential head, water content, and pressure nead. MILTVL calculates water pathlines, travel times, and contaminant movement. These data are displayed graphically and are written to a file used by submodel MILFRNT, which plots the movement of water fronts and contaminant fronts.

All of the MLTRAN submodels prompt the user for a name associated with the problem under consideration (i.e., CASE1). The data files used by the various submodels are identified by this name, followed by a three-character extension, (i.e., CASE1.FEE). Throughout this document, our description of data files uses the symbol <> to signify a user-supplied problem name.

This chapter describes the equations and approximations used to calculate the advective contaminant transport. We also include three simple examples of the transformation from an integrated finite-difference grid to a finiteelement grid, a user's manual, two test cases, and one example.

\subsection{MLTRAN MODEL THEORY ANO EQUATIONS}

The following is a description of the MLTRAN model theory and equations. We begin by considering a fluid particle at a given time $t_{0}$, at location $x_{0}, y_{0}$ in a pore velocity field $u$ and $v$ interior to a porous flow system. Let a function $F(x, y, t)$ travel with or follow the particular fluid particle. The convective derivative of $F$ must be zero or vanish along the path traveled by the fluid particle, i.e.:

$$
\frac{D F}{D t}=\frac{\partial F}{\partial t}+u \frac{\partial F}{\partial x}+v \frac{\partial F}{\partial y}=0
$$

where, using Darcy's Law and the volumetric moisture content, $\theta$, for partially saturated soil, the pore velocity components are given by

$$
\begin{aligned}
& u=-\frac{K}{\theta} \frac{\partial \phi}{\partial x} \\
& v=-\frac{K}{\Theta} \frac{\partial \phi}{\partial y}
\end{aligned}
$$

where $k$ is the partially saturated hydraulic conductivity, and $\phi$ is the energy potential. Substituting (4.2) and (4.3) into (4.1) produces a first-order 
partial differential equation in $F$, which is solved by the method of characteristics. The characteristic equations are

$$
\begin{aligned}
& \frac{d x}{d t}=-\frac{K}{\theta} \frac{\partial \phi}{\partial x} \\
& \frac{d y}{d t}=-\frac{K}{\theta} \frac{\partial \phi}{\partial y}
\end{aligned}
$$

which are the velocity components, expressed as differential displacements along the pathline differential equations that pass through the starting point $x_{0}, y_{0}$ at $t_{0}$.

Now consider an approximate description for a contaminant tracer particle that interacts with the porous matrix by assuming that the interaction can be described by an equilibrium distribution coefficient, $K_{d}$, to describe the retardation. The above derivation can be carried out using the retarded time, $T$, rather than water travel time $(t)$. That is, in (4.2) and (4.3), let

$$
u=\left(1+\frac{\rho_{b} K_{d}}{\theta}\right) U=-\frac{K}{\theta} \frac{\partial \phi}{\partial x}
$$

and

$$
v=\left(1+\frac{\rho_{b} K_{d}}{\theta}\right) v=-\frac{K}{\theta} \frac{\partial \phi}{\partial y}
$$

where:

$$
\begin{aligned}
& \rho_{b}=\text { the bulk density of the porous material } \\
& K_{d}=\text { the equilibrium distribution coefficient } \\
& \theta=\text { the volumetric moisture content }
\end{aligned}
$$

$U$ and $V=$ the $x$ and $y$ components of the contaminant pore velocity, respectively.

Equations (4.6) and (4.7) can be solved for the contaminant particle velocities, $U$ and $V$. The path followed by the contaminant particle yields:

$$
\frac{{ }^{D F}}{D T}=\frac{\partial F_{C}}{\partial t}+U \frac{\partial F_{C}}{\partial x}+V \frac{\partial F_{C}}{\partial y}=0
$$

where $F_{C}$ is a function following the contaminant particle. Substituting (4.6) and $(4.7)$ into $(4.8)$ yields a first-order partial differential equation, which is solved by the method of characteristics. The characteristics equations are 


$$
\begin{aligned}
& \frac{d x}{d T}=\frac{1}{R} \frac{q_{x}}{\theta} \\
& \frac{d y}{d T}=\frac{1}{R} \frac{q_{y}}{\theta}
\end{aligned}
$$

where

$$
\begin{aligned}
& q_{x}=-k \frac{\partial \phi}{\partial x} \\
& q_{y}=-k \frac{\partial \phi}{\partial y}
\end{aligned}
$$

which are the Darcian flux components; also

$$
R=1+B K_{d}
$$

where $R$ is the retardation factor; and

$$
B=\frac{P_{b}}{A} \text {. }
$$

The MLTRAN code solves the pair of ordinary differential equation, (4.9) and (4.10), numerically starting from the initial point $x_{0}, y_{0}$ at $t_{0}$ to yield pathlines. By considering several pathlines and the advance of contaminants along these pathlines, the contamination fronts are constructed.

To obtain the pathlines the pore velocity field is required throughout the flow system. The pore velocity, which is both spatially and time dependent, is calculated from the output of the TRUST-II code or another flow code. Specifically the increment of mass, $\Delta \mathrm{m}$, flowing between any two nodes during the time steps, $\Delta t$, is stored on a file for use in MLTRAN. These stored results, along with flow element dimensions and model configuration, are used to calculate the spatial and temporal pore velocity fields.

We begin by considering $i \frac{t h}{t h}$ typical integrated finite-difference grid element ABCDE containing the ith node is illustrated in Figure 4.1. The ith node in the figure is surrounded by $J=5$ adjoining elements: for example, $j_{n}=1$, $2,3,4$ and 5 . The mass flux, $\Delta m / \Delta t$, flowing into the $i$ th element from $j t h$ surrounding node is denoted by a position value of $M_{i} j_{\text {. }}$. In Figure 4.1 the area through which the mass flux $M_{i, j}$ flows is $A_{i j}$. For example, the area when $A_{j, j=1}$ is the length Co times the unit thickness out of the page. The volumetric flux per unit area denoted by $v_{i j}$ is tnen: 


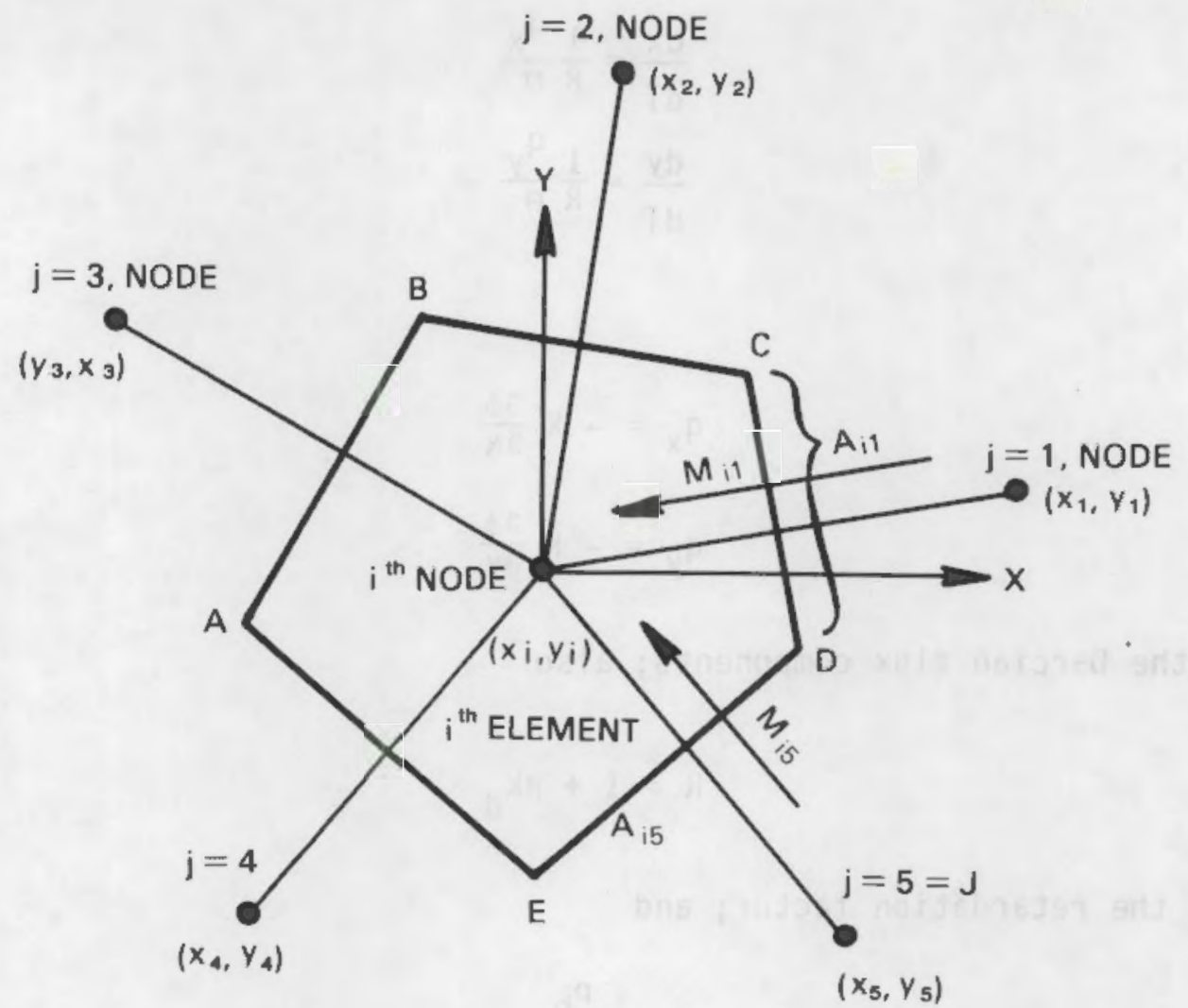

FIGURE 4.1. The ith Integrated Finite-Difference Element with the Central ith Node Connected to the jth Nodes in the Surrounding Elements

$$
\psi_{i j}=\frac{M_{i j}}{\rho A_{i j}}
$$

where $\psi_{i j}=$ the volumetric flux per unit area between nodes $i$ and $j$ $M_{j j}=$ the mass flux between nodes $i$ and $j$

$A_{i j}=$ the area of flow between $i$ th and $j^{t h}$ elements

$\rho=$ the fluid mass density.

Using the volumetric moisture content $\theta$, and denoting pore velocity in the $x$-coordinate direction as $u_{i j}$ and the $y$ direction as $v_{i j}$, then the $x$ and $y$ pore velocity components are:

$$
u_{i j}=-\frac{v_{i j}\left(x_{j}-x_{j}\right)}{\theta_{i} \sqrt{\left(x_{j}-x_{i}\right)^{2}+\left(y_{j}-y_{i}\right)^{2}}}
$$


and

$$
v_{i j}=-\frac{\psi_{i j}\left(y_{j}-y_{i}\right)}{\theta_{i} \sqrt{\left(x_{j}-x_{i}\right)^{2}+\left(y_{j}-y_{i}\right)^{2}}}
$$

where

$$
\begin{aligned}
& u_{i j}=\begin{array}{l}
\text { the component of pore velocity in the } x \text {-coordinate direction } \\
\text { associated with the flow between nodes } i \text { and } j
\end{array} \\
& v_{i j}=\text { the component of pore velocity in the } y \text {-coordinate direction } \\
& \text { associated with the flow between nodes } i \text { and } j
\end{aligned}
$$

We next combine the several velocity vector components from the total number of $\mathrm{J}$ connections to the $i$ th node. This is accomplisned by weignting the individual components by the projected flow areas normal to each velocity components, as illustrated in Figure 4.2 to give:

$$
u_{i}=\frac{\sum_{j=1}^{J} u_{i j} A_{i j} \cos \alpha_{i j}}{\sum_{j=1}^{J} A_{i j} \cos \alpha_{i j}}
$$

and

$$
v_{i}=\frac{\sum_{j=1}^{J} v_{i j} A_{i j} \sin \alpha_{i j}}{\sum_{j=1}^{J} A_{i j} \sin \alpha_{i j}}
$$




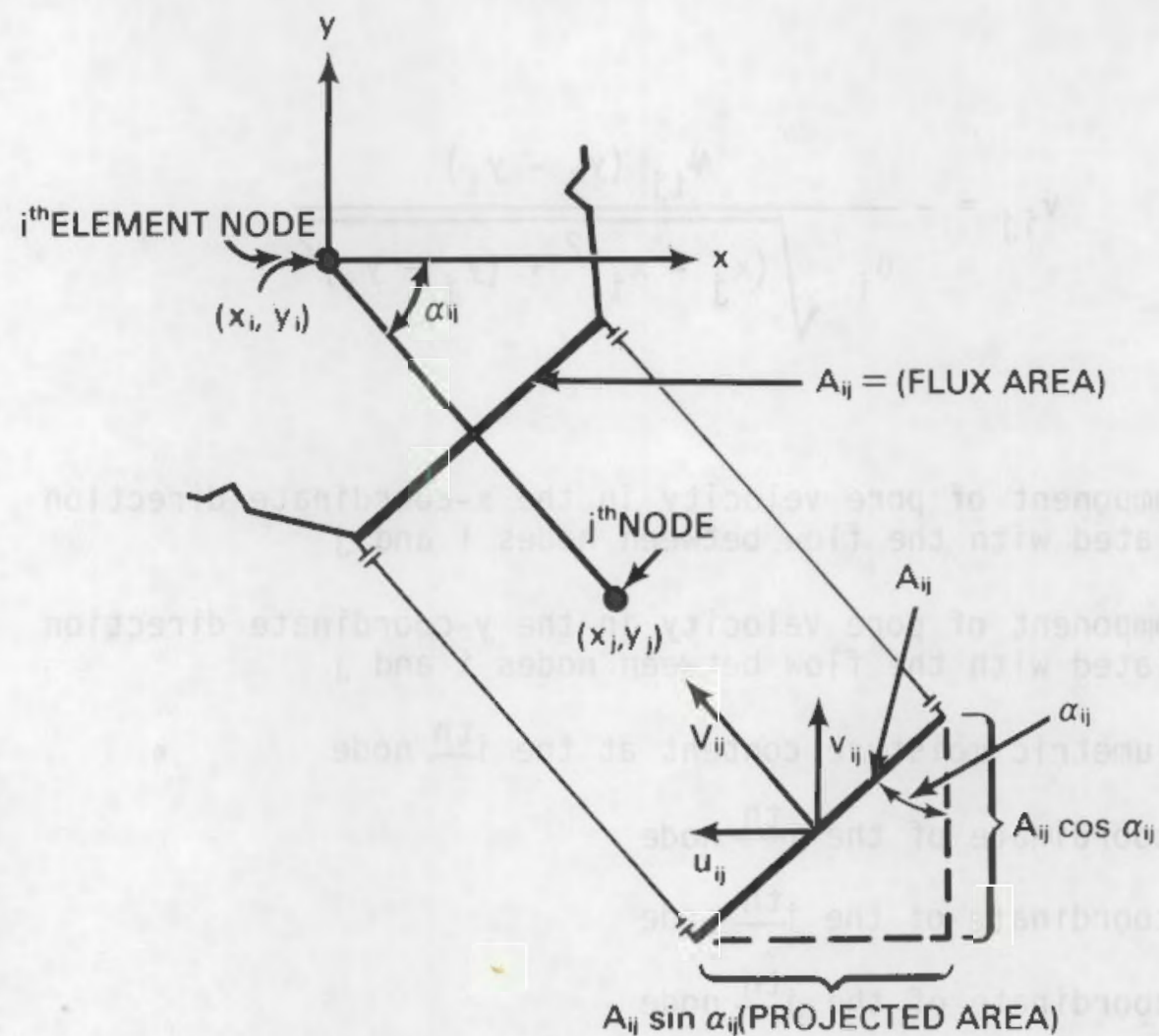

FIGURE 4.2. Schematic Diagram for Projected Flow Area Weighting of the $u_{i j}$ and $v_{i j}$ Component Pore Velocities

where

$$
\alpha_{i j}=\arctan \left(\frac{\left|y_{j}-y_{i}\right|}{\left|x_{j}-x_{i}\right|}\right)
$$

with the principle value selected such that

$$
0 \leq a_{i j}<\frac{\pi}{2}
$$

and if $y_{j}-y_{i}>0$ and $x_{j}-x_{i}=0$ then

$$
\alpha_{i j}=\frac{\pi}{2}
$$


where

$u_{i}=$ the pore velocity component in the $x$-coordinate direction at the $i$ th

$v_{i}=$ the pore velocity component in the $y$-coordinate direction at the $i$ th node.

The pore velocity components $u_{j}$ and $v_{i}$ are calculated for all of the $i t n$ integrated finite-difference elements in the flow system using Equations 4.15 through 4.22. The input from TRUST-II or another flow code of $M_{j j}$ and the element and node geometry provides the input for the above equation sequence.

With the pore velocity components calculated at the node points, the next step is to provide an effective and realistic interpolation scheme for the velocity components at any point between the nodes.

The velocity components at the discrete, integrated, finite-difference nodal points over the flow system are calculated using Equations 4.18 and 4.19. Our purpose here is to use these nodal velocities to calculate the velocity at any desired point needed when solving the pathline equations (i.e., Equations 4.4 and 4.5 or 4.9 and 4.10 ). This is accomplished by linking four nodes that were originally located in the elements of the integrated finitedifference formulation to form a single quadrilateral finite element. The locations of the ith node points are maintained and a new notation is provided that describes the linking in the finite-element quadrature notation (i.e., four nodal points are linked in the traditional counter-clockwise convention of the finite-element method).

Using the velocity vectors defined at the element corners, the bilinear, quadrilateral, finite-element basis functions are used to interpolate the velocity of points within the element. The $x, y$ global coordinates are first transformed to local coordinates where $\varepsilon$ and $n$ range from -1 to 1 .

The transformation from global to local coordinates is performed in the following manner:

$$
\begin{aligned}
& x=\frac{1}{4}\left\lceil(1-\varepsilon)(1-n) x_{1}+(1+\varepsilon)(1-\eta) x_{2}+(1+\varepsilon)(1+n) x_{3}+(1-\varepsilon)(1+n) x_{4}\right\rceil \\
& y=\frac{1}{4}\left\lceil(1-\varepsilon)(1-n) y_{1}+(1+\varepsilon)(1-n) y_{2}+(1+\varepsilon)(1+n) y_{3}+(1-\varepsilon)(1+n) y_{4}\right\rceil
\end{aligned}
$$

where $\left(x_{j}, y_{j}\right)$ are the global coordinates of the 4 nodes, $(\varepsilon, n)$ are the local coordinates and $(x, y)$ are the global coordinates of the point in question. 
These two equations and two unknowns, $\varepsilon$ and $\eta$, can be combined to result in a quadratic equation. Performing the multiplication

$$
\begin{aligned}
x= & 0.25\left(x_{1}-\varepsilon x_{1}-n x_{1}+n \varepsilon x_{1}+x_{2}+\varepsilon x_{2}-n x_{2}-\varepsilon n x_{2}\right. \\
& \left.+x_{3}+\varepsilon x_{3}+n x_{3}+\varepsilon n x_{3}+x_{4}-\varepsilon x_{4}+n x_{4}-\varepsilon n x_{4}\right)
\end{aligned}
$$

or

$$
\begin{gathered}
\varepsilon\left(x_{1}-x_{2}-x_{3}+x_{4}\right)+\varepsilon n\left(-x_{1}+x_{2}-x_{3}+x_{4}\right)+n\left(x_{1}+x_{2}-x_{3}-x_{4}\right) \\
-\left(x_{1}+x_{2}+x_{3}+x_{4}-4 x\right)=0
\end{gathered}
$$

which can be reduced to the form

$$
\varepsilon A_{1}+\varepsilon n A_{2}+n A_{3}-A_{4}=0
$$

where $A_{1}$. $A_{4}$ are equivalent to the expressions in parenthesis in Equation (4.26). Similarly,

$$
\begin{gathered}
\varepsilon\left(y_{1}-y_{2}-y_{3}+y_{4}\right)+\varepsilon n\left(-y_{1}+y_{2}-y_{3}+y_{4}\right)+n\left(y_{1}+y_{2}-y_{3}-y_{4}\right) \\
-\left(y_{1}+y_{2}+y_{3}+y_{4}-4 y\right)=0
\end{gathered}
$$

This can be reduced to the form

$$
\varepsilon B_{1}+\varepsilon n B_{2}+n B_{3}-B_{4}=0
$$

or

$$
n=\left(-\varepsilon B_{1}+B_{4}\right) /\left(\varepsilon B_{2}+B_{3}\right)
$$

where $B_{1} \ldots B_{4}$ are equivalent to the expressions in parentheses in Equation (4.28). Substituting $n$ in Equation (4.27), we have 


$$
\varepsilon A_{1}+\varepsilon A_{2}\left(-\varepsilon B_{1}+B_{4}\right) /\left(\varepsilon B_{2}+B_{3}\right)+A_{3}\left(-\varepsilon B_{1}+B_{4}\right) /\left(\varepsilon B_{2}+B_{3}\right)+A_{4}=0
$$

or

$$
\varepsilon^{2}\left(A_{1} B_{2}-A_{2} B_{1}\right)+\varepsilon\left(A_{1} B_{3}+A_{2} B_{4}-A_{3} B_{1}+A_{4} B_{2}\right)+\left(A_{4} B_{3}+A_{3} B_{4}\right)=0
$$

which can be reduced to the form

$$
a \varepsilon^{2}+b \varepsilon+c=0
$$

where $a, b, c$, are the parenthetical expressions in Equation (4.32). The roots of Equation 4.33 are:

$$
\varepsilon=\frac{-b \pm \sqrt{b^{2}-4 a c}}{2 a}
$$

The sign ( + or - ) used in Equation 4.34 is chosen such that the value of $\varepsilon$ is between the limits of -1 and 1. Substituting $\varepsilon$ into Equation (4.30) gives the value of $n$.

The bilinear, quadrilateral, finite-element basis functions for local coordinates $(\varepsilon, n)$ are:

$$
\begin{aligned}
& N_{1}=1 / 4[(1-\varepsilon)+(1-\eta)] \\
& N_{2}=1 / 4[(1-\varepsilon)+(1-\eta)] \\
& N_{3}=1 / 4[(1-\varepsilon)+(1-\eta)] \\
& N_{4}=1 / 4[(1-\varepsilon)+(1-\eta)]
\end{aligned}
$$

The velocity vector at the point of interest interior to the element is estimated using: 


$$
\begin{aligned}
& u=\sum_{k=1}^{4} N_{k} u_{k} \\
& v=\sum_{k=1}^{4} N_{k} v_{k}
\end{aligned}
$$

where $u_{k}$ and $v_{k}$ are the $x$ and $y$ velocity components at node $k$ from Equations 4.18 and 4.19 .

TRUST-II does not require the nodal coordinates. The code primarily needs the node pairs, distance between the node pairs, and the orthogonal distance, representing the intercepted distance of the flow between the given pairs of nodes. For discretization of a given problem, the user normally locates the nodes and constructs the integrated finite-difference element.

MLTRAN uses linear quadrilateral elements of four nodes, whereas the integrated finite-difference grid may nave elements formed with more than four sides. In some cases the element might be a triangle. If the integrated finite-difference element is not quadrilateral, the user will be required to redefine the grid using four-sided finite elements.

Additional nodes may be required to define quadrilateral elements. These additional nodes are placed very close to a node defined in the integrated finite-difference grid (but not at exactly the same position). The water content, potential, and velocity data are set by the MLTRAN submodel MILFLUX to that of the nearby integrated finite-difference node. In the rest of this document and in the various submodels these node pairs are referred to as additional node pairs.

\subsection{FINITE-DIFFERENCE TO FINITE-ELEMENT GRID CONVERSION}

Because the TRUST-II model uses an integrated finite-difference grid, and the MLTRAN model uses a finite-element grid, the grid originally defined in the TRUST-II input must be transformed before the user can execute the MLTRAN model. In this transformation, nodes defined in the integrated finitedifference cells become node corners of the finite-elements for MLTKAN. A simple example is illustrated in Figure 4.3 .

Figure 4.3 illustrates an important problem that will occur unless the TRUST-II grid is defined with the finite-element transformation in mind. If the cells of the integrated finite-difference grid are along a boundary, the boundary defined by the finite-element grid will be at a different location: at the integrated finite-difference node points, rather than at the edge of the 

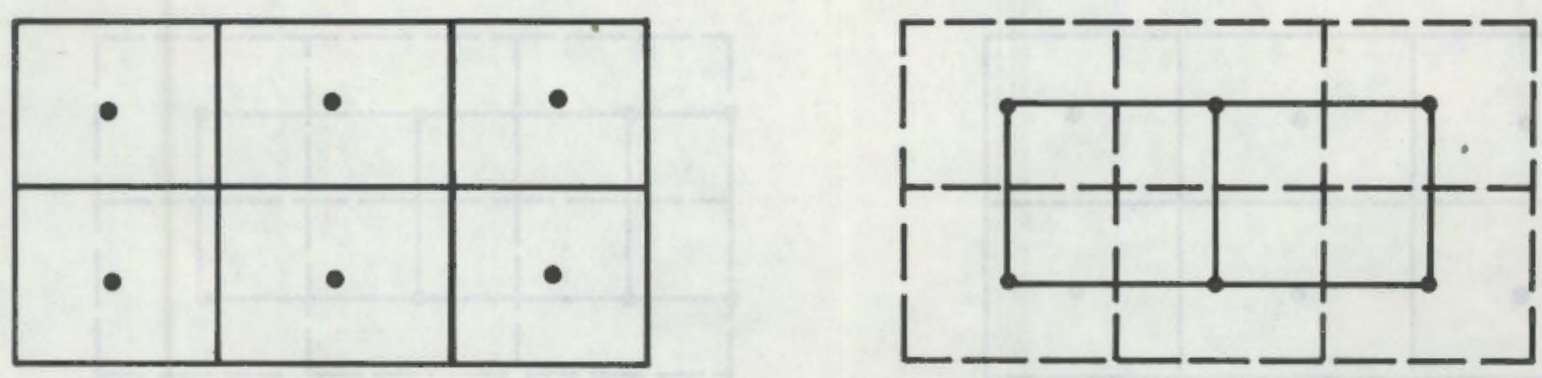

FIGURE 4.3. Integrated Finite-Difference Grid (left) and Finite-Element Grid Overlaying the FiniteDifference Grid (right)

cell. If pathlines, contours, or fronts must be examined near the boundary of the flow domain, a different TRUST-II grid must then be defined. One option is to define the integrated finite-difference grid with a row of very thin cells along boundaries, as in Figure 4.4 .

Another option is to use zero volume cells along boundaries, as shown in Figure 4.5. When zero-volume cells are placed along a boundary, they are only connected to the interior node. In other words, a series of zero-volume cells along a boundary are not connected in the integrated finite-difference grid; hence, the flux between them is defined to be zero. With a zero flux between nodes, the MLTRAN submodels define a zero-velocity vector between these nodes. This causes errors when the patnlines enter the elements along boundaries because two of the nodes defining the element have a zero-velocity vector in the direction between the boundary nodes. The potential, water content, and pore pressure contours are not affected. It is generally better (for the MLTRAN simulation) to use a row of very tnin cells rather than zero-volume cells along a boundary.
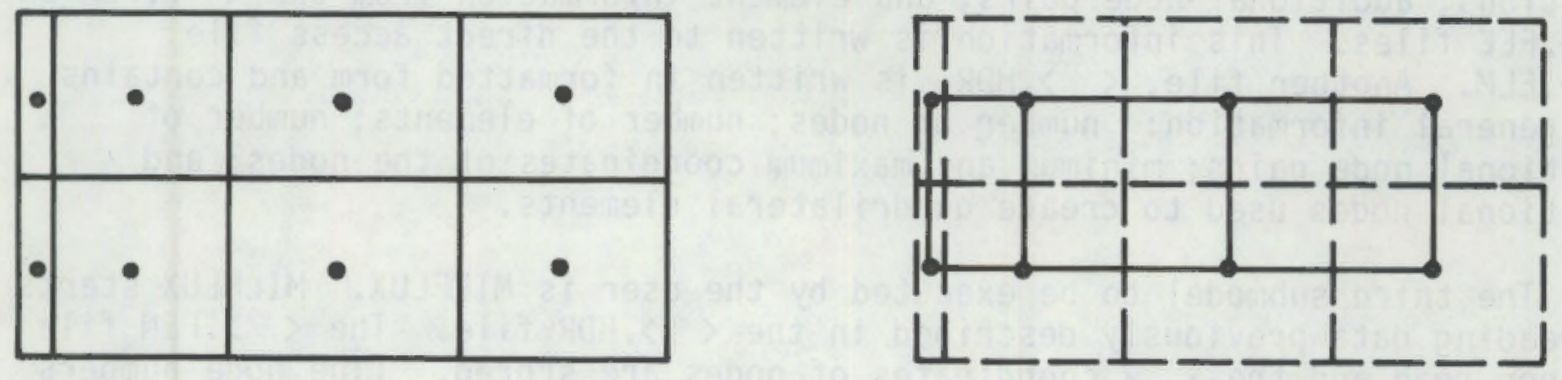

FIGURE 4.4. Integrated Finite-Difference Grid with Thin Nodes (left), overlaid by a Finite-Element Grid (right) 

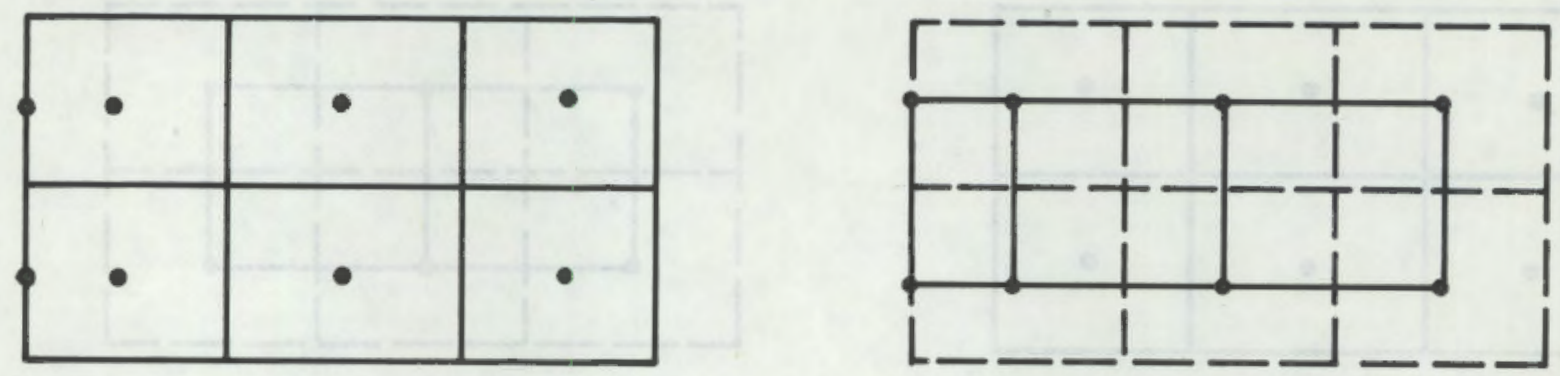

FIGURE 4.5. Integrated Finite-Difference Grid with Zero-Volume Nodes (left), Overlaid by a Finite-Element Grid (right)

\subsection{MLTRAN USERS MANUAL}

MLTRAN is executed sequentially; the user executes each subprogram and checks the results before proceeding to the next subprogram. The submodels are executed in the following order: MILGRID, MILSTRT, MILFLUX, MILPLOT, MILTVL, and MILFRNT (see Table 4.1). A flowchart depicting the execution of ML.TRAN is shown in Figure 4.6 and detailed input instructions are covered in Sec-

tion 4.7. A review of Table 4.16, located in Section 4.7, is advised to assist the reader in understanding this users manual.

The first submodel to be executed by the user is MILGRID. MILGRID reads the quadrilateral finite-element description from the $<>$.FEE file. The node locations and any additional node pairs are read from the <>.FEN file. This node and element information is used to generate plots of the discretized flow domain and material zones. The program prompts the user for the name of the plotfile. These plots are useful for examining grid definition and for locating any errors in the labeling of elements, nodes, and material zones.

The next submodel executed by the user is MILSTRT. MILSTRT reads the node locations, additional node pairs, and element information from the 〈 >.FEN and $<>$.FEE files. This information is written to the direct access file $<>$.ELM. Another file, < >.HOR, is written in formatted form and contains the general information: number of nodes; number of elements; number of additional node pairs; minimum and maximum coordinates of the nodes; and additional nodes used to create quadrilateral elements.

The tnird submodel to be executed by the user is MILFLUX. MILFLUX starts by reading data previously described in the <>.HDR file. The <>.FEN file is then read and the $x, y$ coordinates of nodes are stored. (The node numbers are relabeled in sequential order.) The next function of the MILFLUX submodel is to read the <>.TRS file. MILFLUX first reads the density of water, then the material number and elevation associated with each node. The last data read from the $<>$.TRS file are the node pairs and orthogonal distance between pairs.

MILFLUX then reads the names of the TRUST-II output files from the $<>$.FLS file. The user is prompted to input (via terminal or batch command 


\section{TABLE 4.1. MLTRAN Submodels}

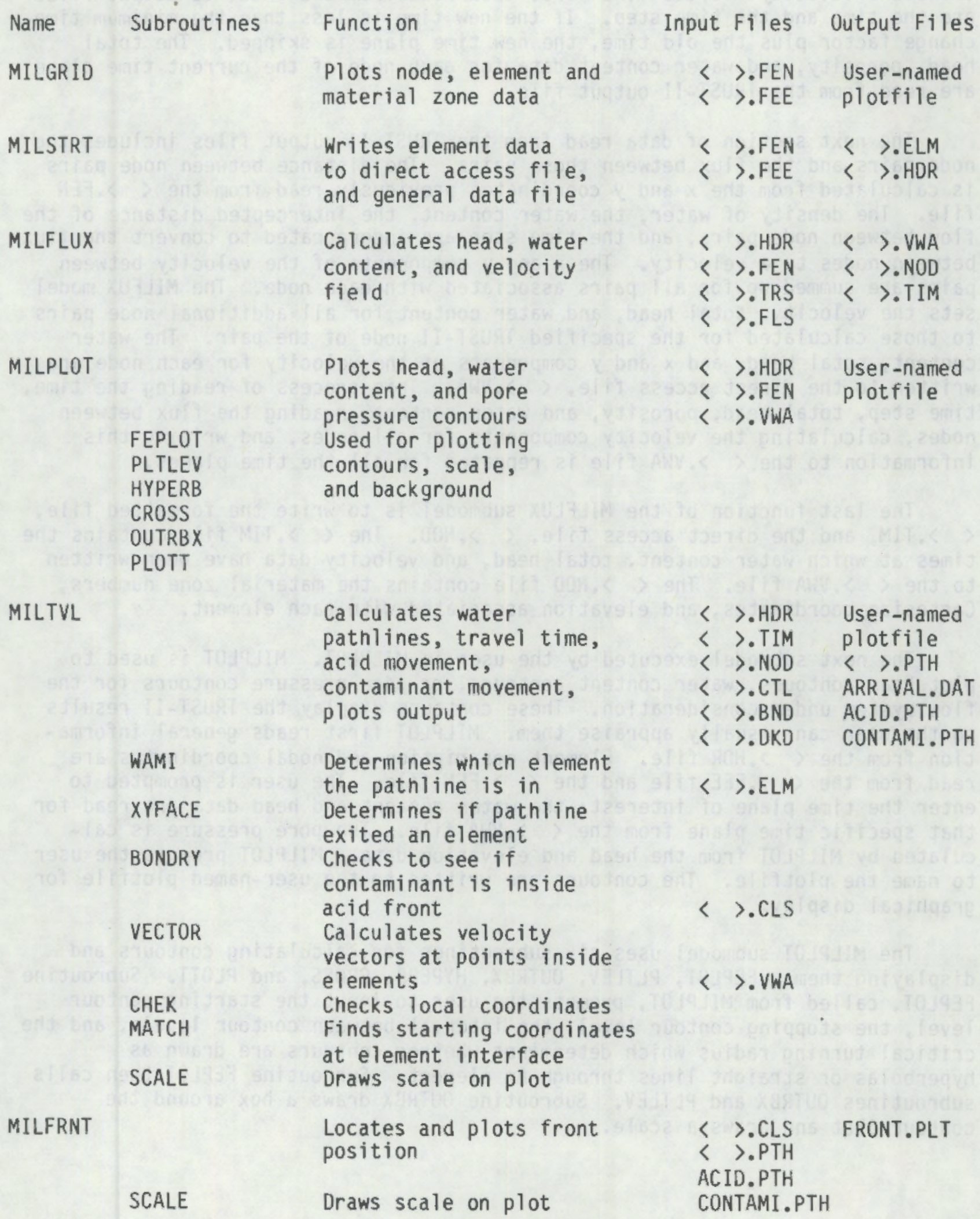


stream) a minimum time-change factor that controls the time step between the transient velocity fields. The first data read from the TRUST-II output files are the time and the time step. If the new time is less than the minimum timechange factor plus the old time, the new time plane is skipped. The total nead, porosity, and water content data for each node of the current time plane are read from the TRUST-II output file.

The next section of data read from the TRUST-II output files includes the node pairs and the flux between those pairs. The distance between node pairs is calculated from the $x$ and $y$ coordinates previously read from the $\langle>$.FEN file. The density of water, the water content, the intercepted distance of the flow between node pairs, and the time step are incorporated to convert the flux between nodes to a velocity. The $x$ and $y$ components of the velocity between pairs are summed up for all pairs associated with each node. The MILFUX model sets the velocity, total head, and water content for all additional node pairs to those calculated for the specified TRUST-II node of the pair. The water content, total head, and $x$ and $y$ components of the velocity for each node are written to the direct access file, <>.VWA. This process of reading the time, time step, total head, porosity, and water content, reading the flux between nodes, calculating the velocity components for all nodes, and writing this information to the $<>$.VWA file is repeated for all the time planes.

The last function of the MILFLUX submodel is to write the formatted file, $<>$.TIM, and the direct access file, <>.NOD. The < >.TIM file contains the times at which water content, total head, and velocity data have been written to the <>.VWA file. The <>.NOD file contains the material zone numbers, Cartesian coordinates, and elevation associated with each element.

The next submodel executed by the user is MILPLOT. MILPLOT is used to plot head contours, water content contours, or pore pressure contours for the flow system under consideration. These contours display the TRUST-II results so the user can visually appraise them. MILPLOT first reads general information from the $<>$.HDR file. Element description and nodal coordinates are read from the <>.FEE file and the <>.FEN file. The user is prompted to enter the time plane of interest; the water content and head data are read for that specific time plane from the $<>$. WWA file. The pore pressure is calculated by MILPLOT from the head and elevation data. MILPLOT prompts the user to name the plotfile. The contours are written to the user-named plotfile for grapnical display.

The MILPLOT submodel uses six subroutines for calculating contours and displaying them: FEPLOT, PLTLEV, OUTRBX, HYPERB, CROSS, and PLOTT. Subroutine FEPLOT, called from MILPLOT, prompts the user to input the starting contour level, the stopping contour level, the interval between contour levels, and the critical turning radius which determines whether contours are drawn as hyperbolas or straight lines through an element. Subroutine FEPLOT then calls subroutines OUTRBX and PLTLEV. Subroutine OUTRBX draws a box around the contour plot and draws a scale. 
Subroutine PLTLEV, called from FEPLOT, calls subroutine CROSS for each of the four faces defining an element to locate points where contour levels intersect the faces. Subroutines HYPERB and/or PLOTT are called to draw contours between the points.

Subroutine CROSS, called from PLTLEV, is used to check a given face of an element to determine if a contour level passes through any point on it. If a contour level passes through the face the point of intersection is calculated.

Subroutine HYPERB, called from PLTLEV, calculates points along a hyperbola between two points on a given contour level. Subroutine PLOTT is then called to draw a straight line between the calculated points.

The submodel MILTVL is first used to calculate pathlines of water particles, as well as travel times. The user can then execute MILTVL a second time to calculate the movement of dissolved nonconservative contaminants, such as sulfate, along the water pathlines. The neutralization of the acid front by the soil system is simulated by using distribution coefficients. After estimating the movement of the acid, the user may execute MILTVL a third time to estimate the transport of radionuclides in relation to the position of the acid front. Laboratory-measured retardation coefficients of the contaminants for the various soil types are included by the user in the model input to estimate the position and travel times of the acid and radionuclides.

MILTVL starts by reading the general information from the previously described < >.HDR file. Material numbers associated with each node are read from the < >.NOD file; time plane data are read from the < >.TIM file; and control parameters are read from the user-named control file. Tne control parameters are: length of the pathline plot, $z$ exaggeration factor, output file name, title for the arrival data output, and a flag used to initiate plotting of the boundary. The boundary coordinates to be plotted are read from the <>.BND file. The next file read is the <>.DKD file, which contains the bulk density of the soil, the retardation coefficients for the acid, and radionuclides for each material zone. The $<>$.CLS file is then read to define the boundary of the flow domain.

MILTVL then starts the travel-time calculation loop for each pathline by reading the $x$ and $y$ starting coordinates, starting time, and maximum travel time from the user-named control file. The element associated with the starting coordinates is located using the subroutines WAMI and XYFACE, along with element information read from the < >.ELM file. Subroutine CHEK is called to check if the local coordinates calculated by WAMI are within the element. Subroutine VECTOR is called to calculate the velocity components at the starting location, and subroutine DELT is called to determine the time step to be used. The starting location is updated by:

$$
\Delta x=u \Delta t
$$


This stepping process continues until the patnline exits the current element and the subroutines WAMI, XYFACE, and CHEK are called to determine which element the pathline has entered. When a pathline has entered a new element, the location where the pathline crossed the element face is calculated and is used as the starting location in the new element. This procedure continues until the pathline reaches a boundary. The travel time calculation loop is then restarted with new $x$ and $y$ starting coordinates. The $x$ and $y$ coordinates and travel time for each step of each pathline are written to the formatted file, <>.PTH.

The subroutine WAMI, called by the MILTVL submodel, first calls subroutine XYFACE to determine if the point in question is within an element bounded by coordinates $X Q(i), Y Q(i)--[i=1,4]$. If XYFACE determines that the point is in the current element, subroutine WAMI transforms the global coordinates of the point to local or elemental coordinates.

Subroutine XYFACE is used to determine if a pathline has crossed a boundary of the current element. XYFACE first calculates the normal vectors from the center of the unit square (local coordinates of the element) to the sides of the element. The vectors from the point in question to the sides of the element are then calculated and the vector dot product formed with the normal vectors. If the dot product is positive, the point is inside the face of the element; if the dot product is negative, the point in question is outside the face. This check is performed for each of the four faces of the element.

Subroutine VECTOR is called by the MILTVL submodel. VECTOR uses the finite-element basis functions to bilinearly interpolate velocities within an element. VECTOR calls subroutine BONDRY to determine if the point is inside or outside the acid front. This step is performed only if MILTVL is being used to calculate radionuclide movement. VECTOR reads the water content, head, and velocity data for the four nodes of an element from the < >.VWA file. If MILTVL is being used to calculate water pathlines, the velocity within the element is bilinearly interpolated through the nodal velocity values. If MILTVL is being used to calculate acid movement, the nodal velocity values are divided by an acid retardation coefficient (greater than one) and the velocity within the element is interpolated.

If MILTVL is being used to calculate radionuclide movement, two possible cases are examined. If the point is behind the acid front, the nodal velocities are divided by two retardation coefficients, one for the acid in water and another for the radionuclides in acid. If the point is ahead of the acid front, the nodal velocities are divided by a retardation coefficient for the radionuclide in water. The $x$ and $y$ velocity components are interpolated using Equations (4.39) and (4.40). Subroutine VECTOR compares the current time with the midpoint between time planes. If the current time exceeds this midpoint, the velocity vectors are updated to the next time plane. 
Subroutine BONDRY is called by the subroutine VECTOR from MILTVL. BONDRY checks the number of times the boundary defining the acid front crosses the line $y=y_{0}$ when $x$ is greater than or equal to $x_{0}$. If the number of crossings is even, the point is outside the boundary. The points defining the acid front are read from the ACID.PTH file in subroutine VECTOR.

Subroutine DELT is called by the MILTVL submodel. DELT determines the time step used to update the pathline coordinates. The criteria used to determine the time step consist of: the maximum $x$ and $y$ distances across an element, the number of moves per element (set to 25), and the velocity at the point of interest. DELT divides the maximum $x$ and $y$ distances by the number of moves and multiplies these quantities by the $x$ and $y$ velocity components. The minimum time step, $x$ or $y$, is returned to the MILTVL submodel.

Subroutine CHEK is called by MILTVL and is used to check if the local coordinates calculated by WAMI are between -1 and 1 . Subroutine MATCH is called by MILTVL and is used to find the starting local coordinates in an adjoining element when a pathline has crossed the interface between elements.

The last submodel in MLTRAN, MILFRNT, is used to plot the front movement of water, acid, and radionuclides. MILFRNT first reads the boundary data from the <>.CLS file. MILFRNT then locates the $x$ and $y$ coordinates of each pathline for a user-specified time in the $<>$.PTH file. MILFRNT prompts the user to decide if pathlines snould be plotted along with the fronts. The $x, y$ coordinates are interpolated between time steps. When the user wants to plot acid fronts, MILFRNT reads from the ACID.PTH file rather than the <>.PTH file. The output of the MILFRNT model is written to a plotfile named FRONT.PLT.

Figure 4.6 is a flowchart depicting the execution sequence for the MLTRAN submodels. 


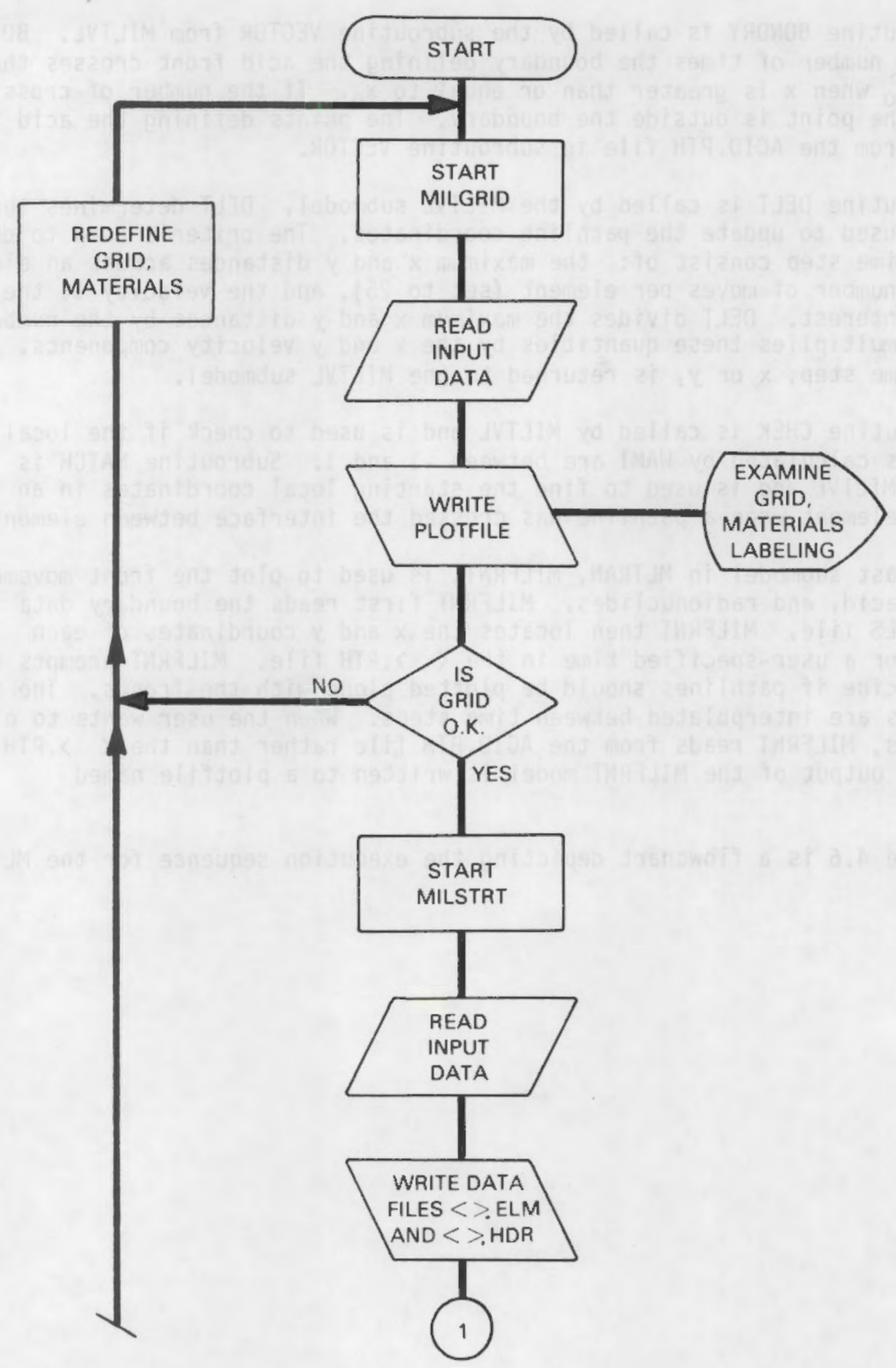

FIGURE 4.6. MLTRAN Flowchart 


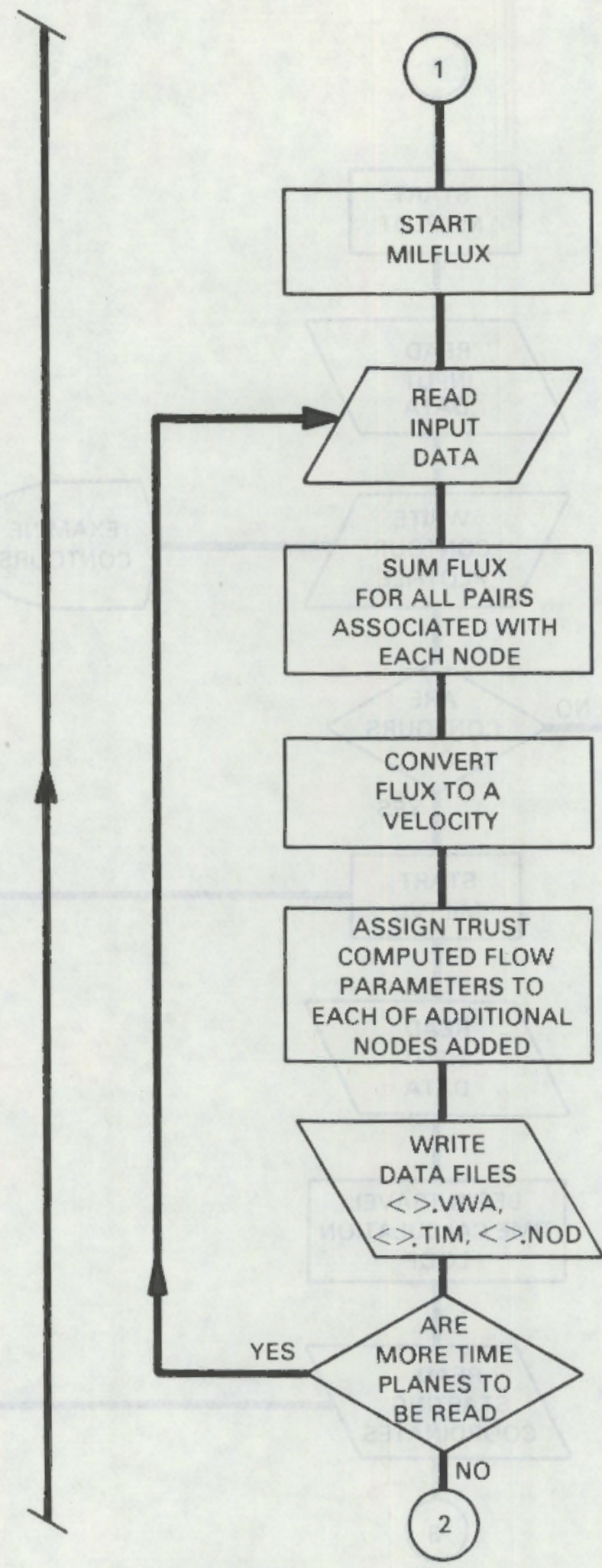

FIGURE 4.6. (contd) 


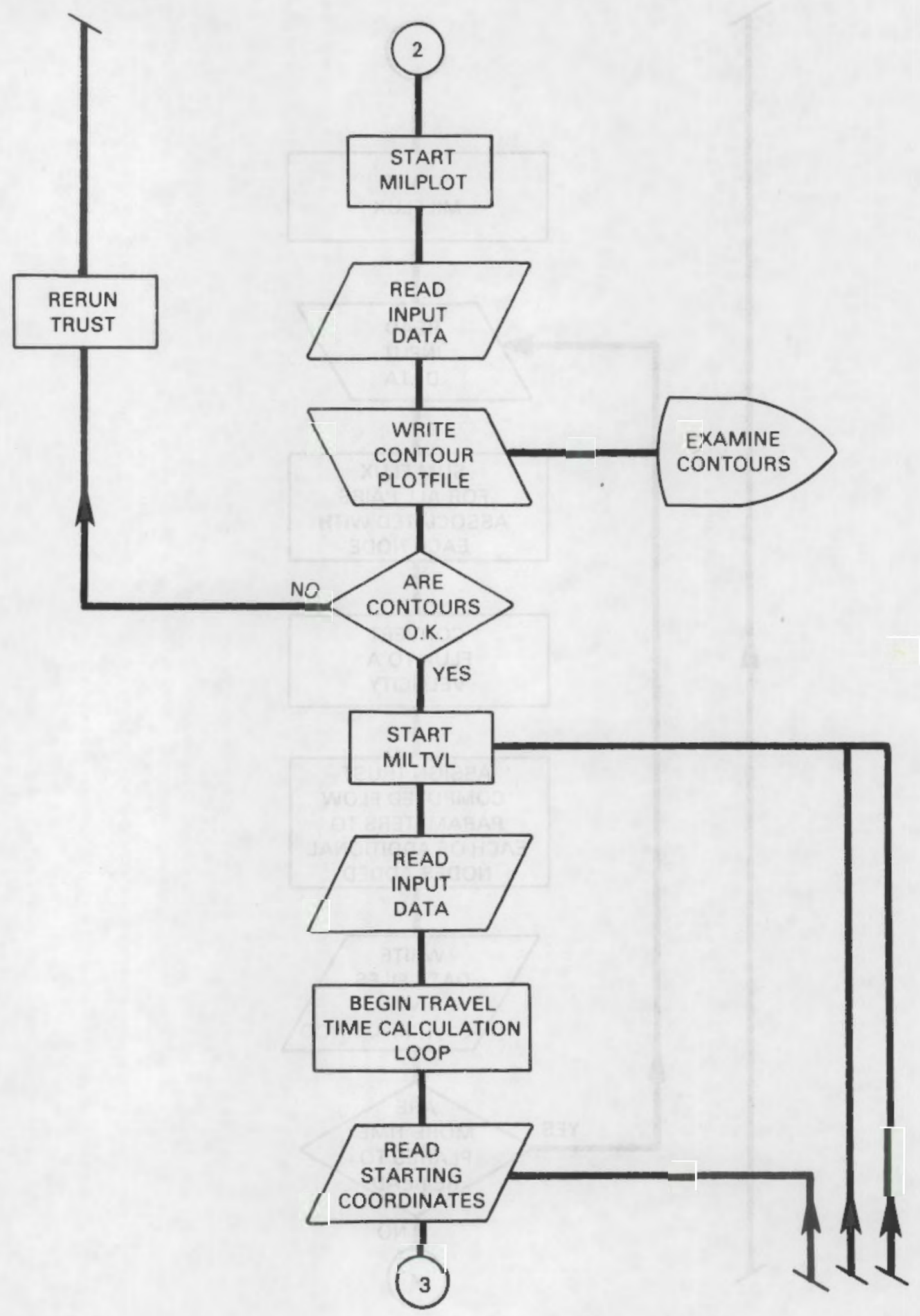

FIGURE 4.6. (contd) 


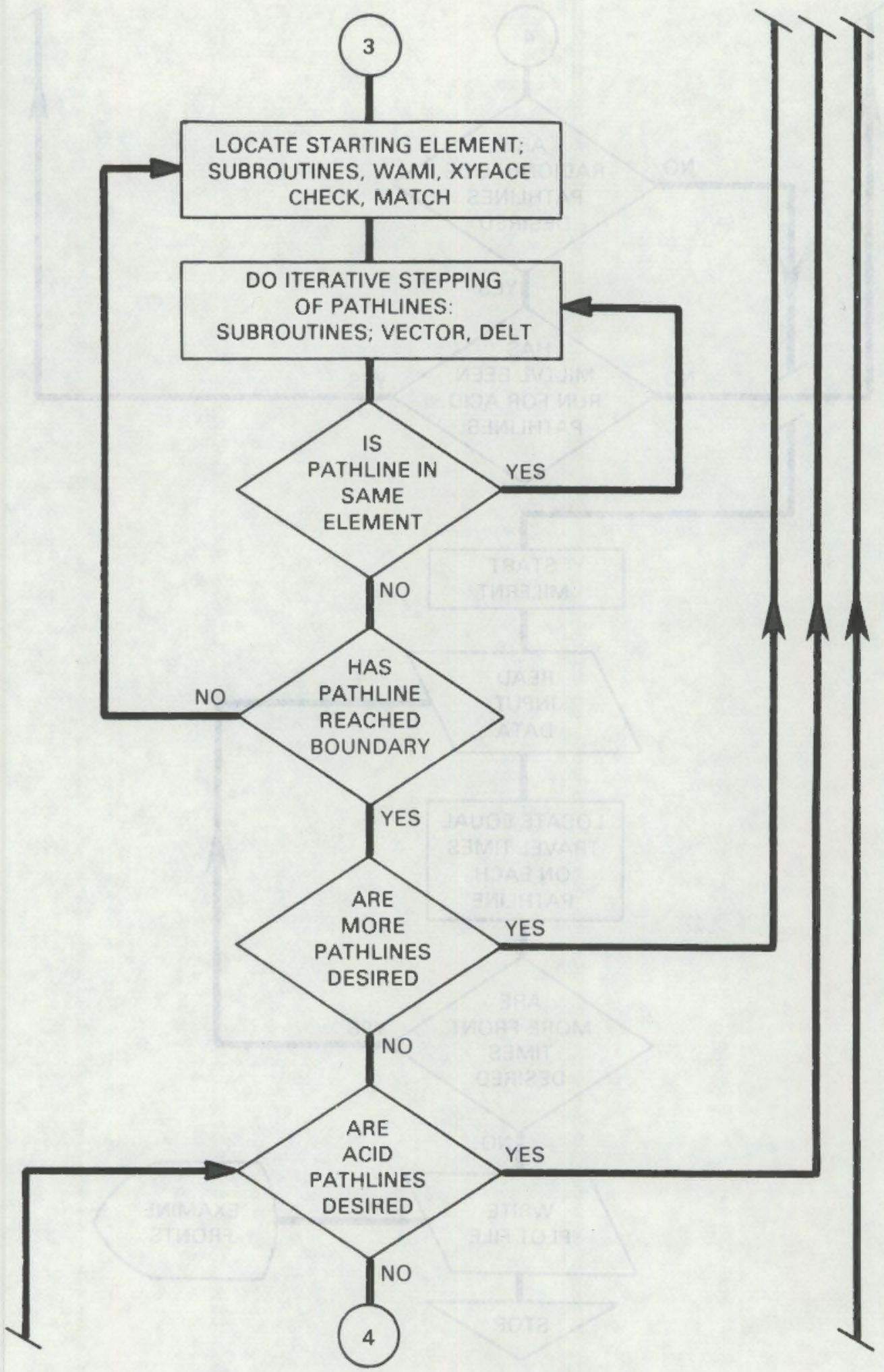

FIGURE 4.6. (contd) 


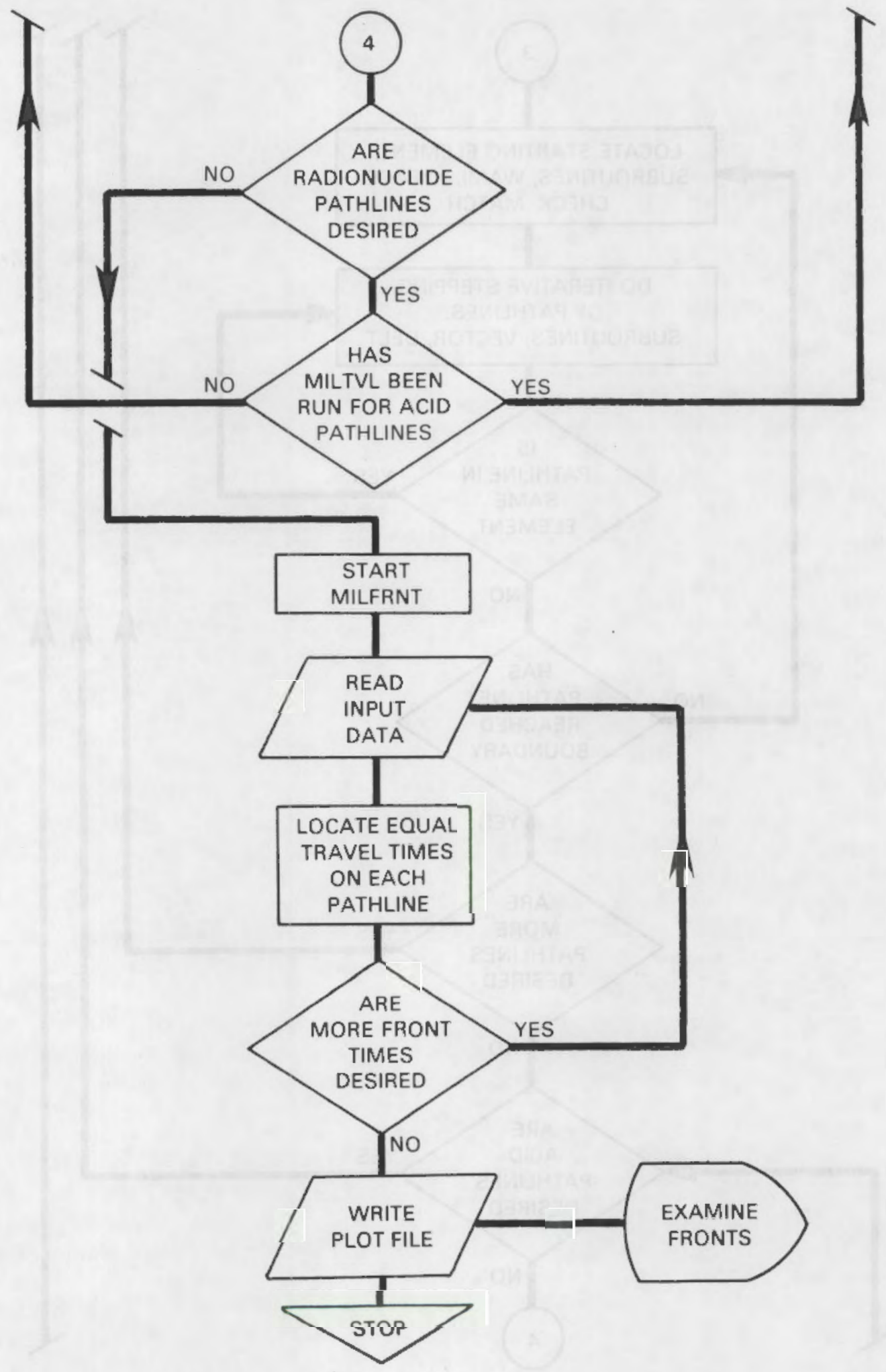

FIGURE 4.6. (contd) 


\subsection{MLTRAN TEST CASE NO. 1}

This first test case examines pathlines from a storage reservoir to a river in a flow system that is saturated, steady-state, homogeneous, and isotropic. In this test case the MLTRAN model is first tested using an analytical velocity field from the equations of Nelson and Schur (1980). In the second portion of this test case the TRUST-II model is used to generate the steady-state velocity field. The results from the MLTRAN model, pathlines, travel times, and discharge locations, are compared with the analytical results of Nelson and Schur (1980). Appendix A includes a brief derivation of this two-dimensional solution to the flow equation.

Figure 4.7 depicts the flow field, only half of which is simulated. First, we use the analytical solution to generate a velocity field for an irregular rectangular grid. This analytical velocity field is written to the $<>$.VWA file. We then use MLTRAN to approximate travel paths, corresponding discharge locations and travel times for various pathlines. In this first comparison, we do not use the TRUST-II model and the MILFLUX submodel. Part of the finite-element grid that is used to simulate the flow system is shown in Figure 4.8. The part of the grid that is not shown in Figure 4.8 is extended to 731.5 meters in the $y$ coordinate direction using large elements so that the flux across the boundary may be assumed to have a zero flux in the y direction. Table 4.2 lists boundary conditions, hydraulic properties, and other parameters used in the model.

The pathlines generated using the analytical solution are shown by the solid lines in Figure 4.9. Table 4.3 lists the corresponding discharge location and travel time for each pathline. The pathlines simulated by the MLTRAN model with the analytical velocity field are shown by the dashed lines in Figure 4.9; Table 4.4 shows the simulated discharge locations and travel times. Seven pathlines are examined in each case.

We then run the TRUST-II model, using the parameters listed in Table 4.2. The same finite-element grid shown in Figure 4.8 is used to transform TRUST-II's integrated finite-difference grid to a finite-element grid compatible with the MLTRAN model. The pathlines simulated using the TRUST-II results are the dashed lines shown in Figure 4.10 ; solid lines are the analytical pathlines. Table 4.5 shows the discharge locations and travel times.

By examining Figures 4.9 and 4.10 , we see that the approximate pathlines generated by MLTRAN follow the general shape of the analytical pathlines. The accuracy of the simulated patnlines depends on the grid size relative to changes in the local gradient. Table 4.6 lists a root mean square (RMS) measure of the errors in discharge locations and arrival times for Test Case No. 1.

Patnline analysis can be used to determine contaminant arrival distributions at outflow locations. The arrival time versus arrival location curve provides a valuable criterion for evaluating the effect of errors caused by the 


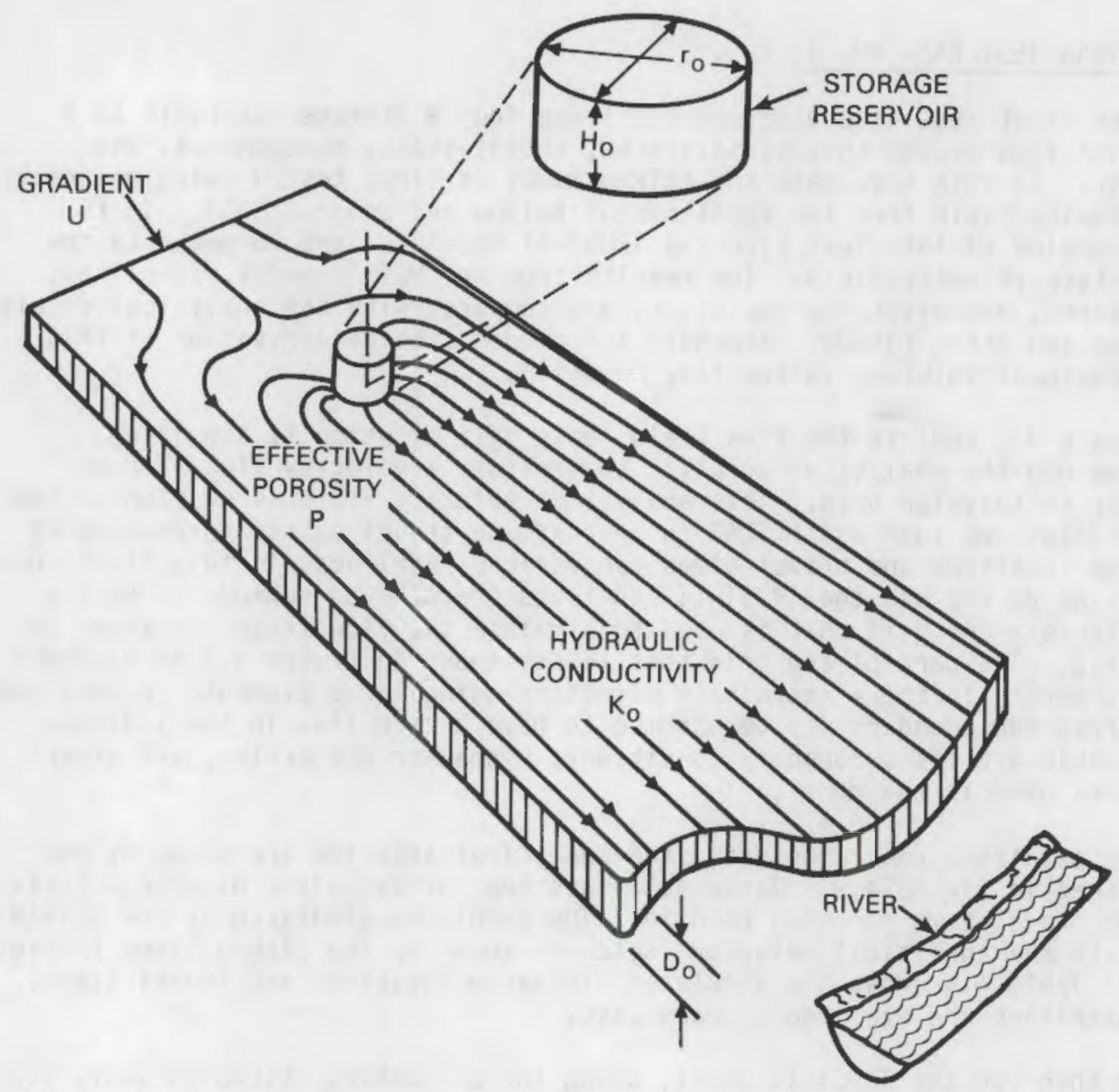

FIGURE 4.7. Steady-State Flow Field for Test Case No. 1

approximation over discrete intervals of a continous function. Because the MLTRAN model is an approximation, individual simulated pathlines may deviate significantly from the individual analytical or quasi-analytical pathlines. The overall effect of a series or set of pathlines may be a better measure of the applicability of the MLTRAN model because that is the primary intended use of the model. The arrival time versus arrival location curves allow the user to evaluate the effect of errors inherent in the discrete approximation used by the MLTRAN model.

Figure 4.11 shows the arrival time versus arrival location curves for the simulated and analytical results of Test Case No. 1. The simulated data points compare quite well with the curve of analytic data points. 


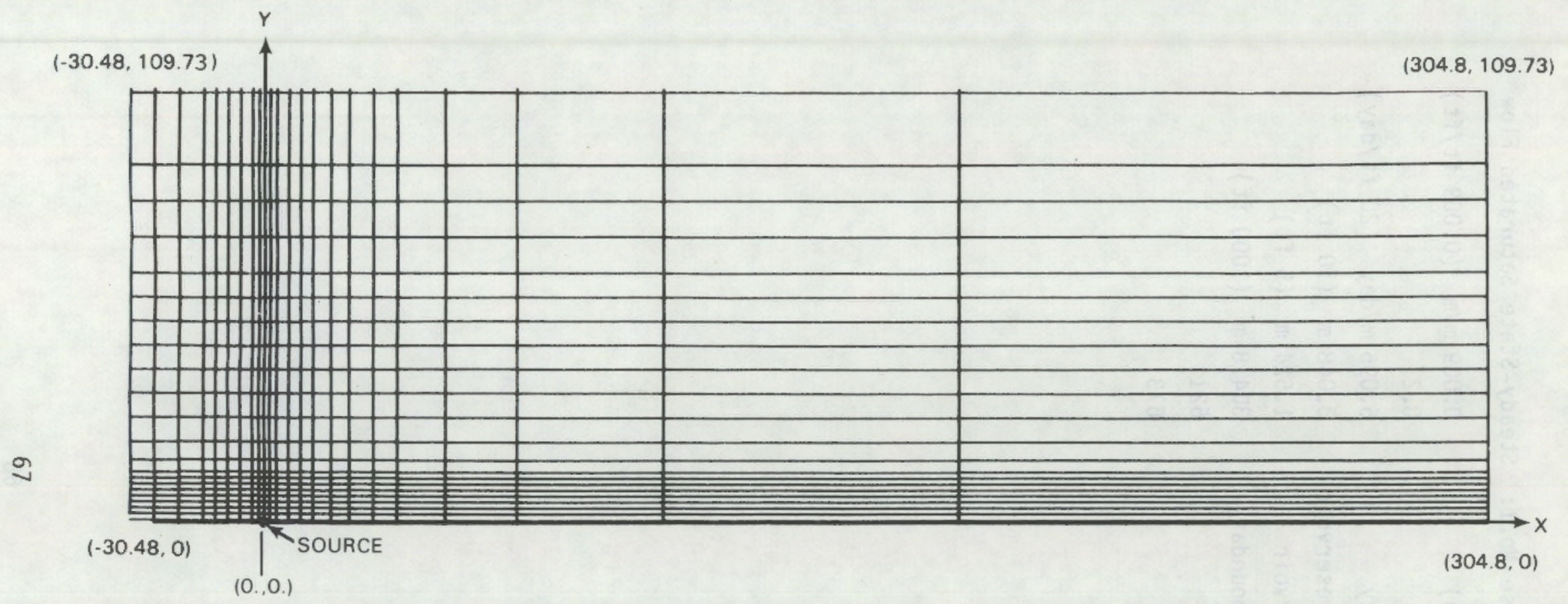

FIGURE 4.8. Discretized Flow Domain for Test Case No. 1 
TABLE 4.2. Test Case No.1: Steady-State Saturated Flow

Gradient (x direction) $\quad 0.009 \mathrm{~m} / \mathrm{m} \quad(0.009 \mathrm{ft} / \mathrm{ft})$

Porosity

0.2

Hydraulic conductivity

$6.096 \mathrm{~m} /$ day $(20 \mathrm{ft} /$ day $)$

Diameter of storage reservoir

$3.048 \mathrm{~m} \quad(10 \mathrm{ft})$

Head in storage reservoir

$1.524 \mathrm{~m} \quad(5 \mathrm{ft})$

Distance to outflow boundary

$304.8 \mathrm{~m} \quad(1000 \mathrm{ft})$

Number of elements

621

Number of nodes

673 


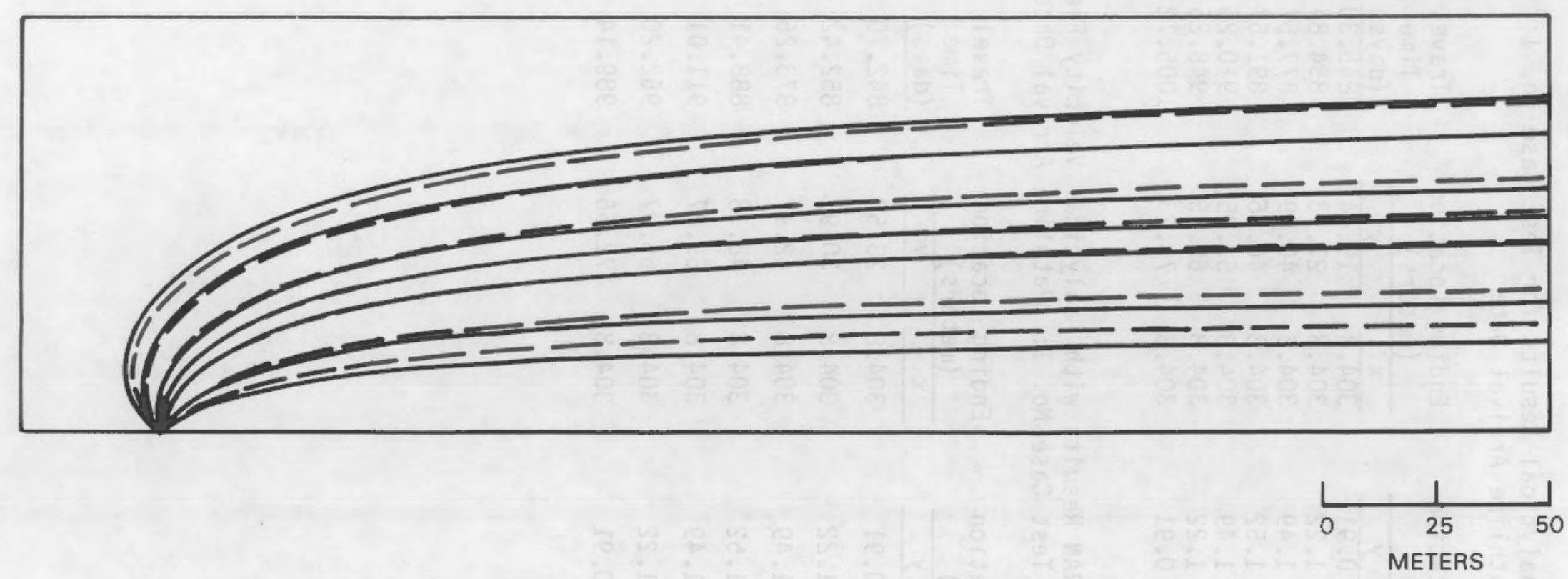

FIGURE 4.9. Test Case No. 1 -- Analytical Patnlines (solid lines) Compared with the MLTRAN Analytical Velocity Field Pathlines (dashed lines) 
TABLE 4.3. Analytical Results for Test Case No. 1: Pathline Arrival Data

\begin{tabular}{|c|c|c|c|c|}
\hline \multicolumn{2}{|c|}{$\begin{array}{l}\text { Starting Location } \\
\text { (meters) }\end{array}$} & \multicolumn{2}{|c|}{$\begin{array}{l}\text { Ending Location } \\
\text { (meters) }\end{array}$} & $\begin{array}{c}\text { Travel } \\
\text { Time }\end{array}$ \\
\hline$\frac{x}{1.22}$ & $\frac{y}{0.91}$ & $\frac{x}{304.8}$ & $\frac{y}{19.44}$ & $\frac{\text { (days) }}{845,30}$ \\
\hline 0.91 & 1.22 & 304.8 & 27.93 & 854.84 \\
\hline 0.30 & 1.49 & 304.8 & 40.99 & 877.57 \\
\hline 0.0 & 1.52 & 304.8 & 46.85 & 891.57 \\
\hline-0.33 & 1.49 & 304.8 & 53.25 & 910.2 \\
\hline-0.91 & 1.22 & 304.8 & 65.25 & \\
\hline-1.22 & 0.91 & 304.8 & 73.23 & 1005.72 \\
\hline
\end{tabular}

TABLE 4.4. MLTRAN Results with Analytical Velocity Field for Test Case No. 1: Pathline Arrival Data

\begin{tabular}{|c|c|c|c|c|}
\hline \multicolumn{2}{|c|}{$\begin{array}{c}\text { Starting Location } \\
\text { (meters) }\end{array}$} & \multicolumn{2}{|c|}{$\begin{array}{l}\text { Ending Location } \\
\text { (meters) }\end{array}$} & \multirow{2}{*}{$\begin{array}{c}\text { Travel } \\
\text { Time } \\
\text { (days) }\end{array}$} \\
\hline$x$ & $y$ & $x$ & $y$ & \\
\hline 1.22 & 0.91 & 304.8 & 23.53 & 842.70 \\
\hline 0.91 & 1.22 & 304.8 & 30.91 & 852.42 \\
\hline 0.30 & 1.49 & 304.8 & 42.17 & 873.26 \\
\hline 0.0 & 1.52 & 304.8 & 48.38 & 888.41 \\
\hline-0.33 & 1.49 & 304.8 & 55.87 & 911.01 \\
\hline-0.91 & 1.22 & 304.8 & 65.97 & 952.20 \\
\hline-1.22 & 0.91 & 304.8 & 72.56 & 989.14 \\
\hline
\end{tabular}




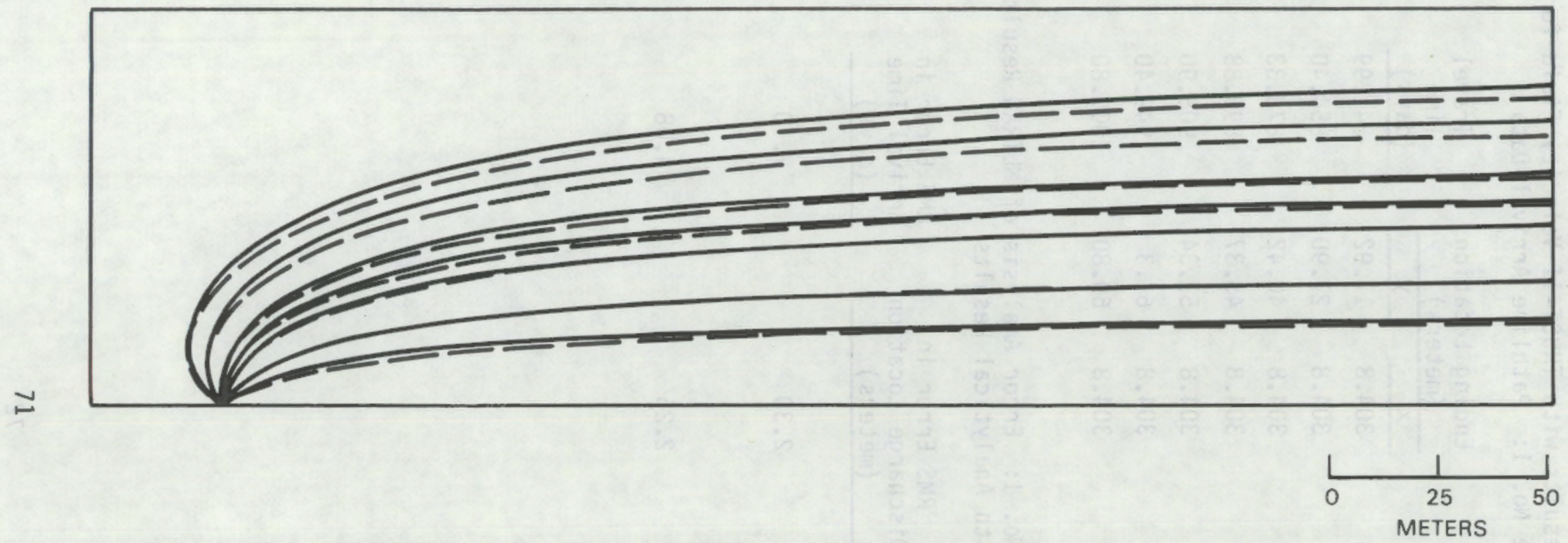

FIGURE 4.10. Test Case No. 1 -- Analytical Patnlines (solid lines) compared with TRUST-II MLTRAN Pathlines (dashed lines) 
TABLE 4.5. MLTRAN Results with TRUST-II Velocity Field for Test Case No. 1: Pathline Arrival Data

\begin{tabular}{|c|c|c|c|c|}
\hline \multicolumn{2}{|c|}{$\begin{array}{c}\text { Starting Location } \\
\text { (meters) }\end{array}$} & \multicolumn{2}{|c|}{$\begin{array}{l}\text { Ending Location } \\
\text { (meters) }\end{array}$} & \multirow{2}{*}{$\begin{array}{l}\text { Travel } \\
\text { Time } \\
\text { (days) } \\
\end{array}$} \\
\hline$x$ & $y$ & $x$ & $y$ & \\
\hline 1.22 & 0.91 & 304.8 & 17.92 & 841.99 \\
\hline 0.91 & 1.22 & 304.8 & 27.90 & 854.40 \\
\hline 0.30 & 1.49 & 304.8 & 40.42 & 878.33 \\
\hline 0.0 & 1.52 & 304.8 & 45.37 & 890.88 \\
\hline-0.33 & 1.49 & 304.8 & 51.34 & 908.90 \\
\hline-0.91 & 1.22 & 304.8 & 61.3 & 949.40 \\
\hline-1.22 & 0.91 & 304.8 & 69.80 & 1000.80 \\
\hline
\end{tabular}

TABLE 4.6. Test Case No. 1: Error Analysis of MLTRAN Results Compared with Analytical Results

RMS Error in Discharge Location

MLTRAN results with analytical velocity field

MLTRAN results with TRUST-II velocity field (meters)

2.25
7.10

RMS Error in Arrival Time (days)

4.08 


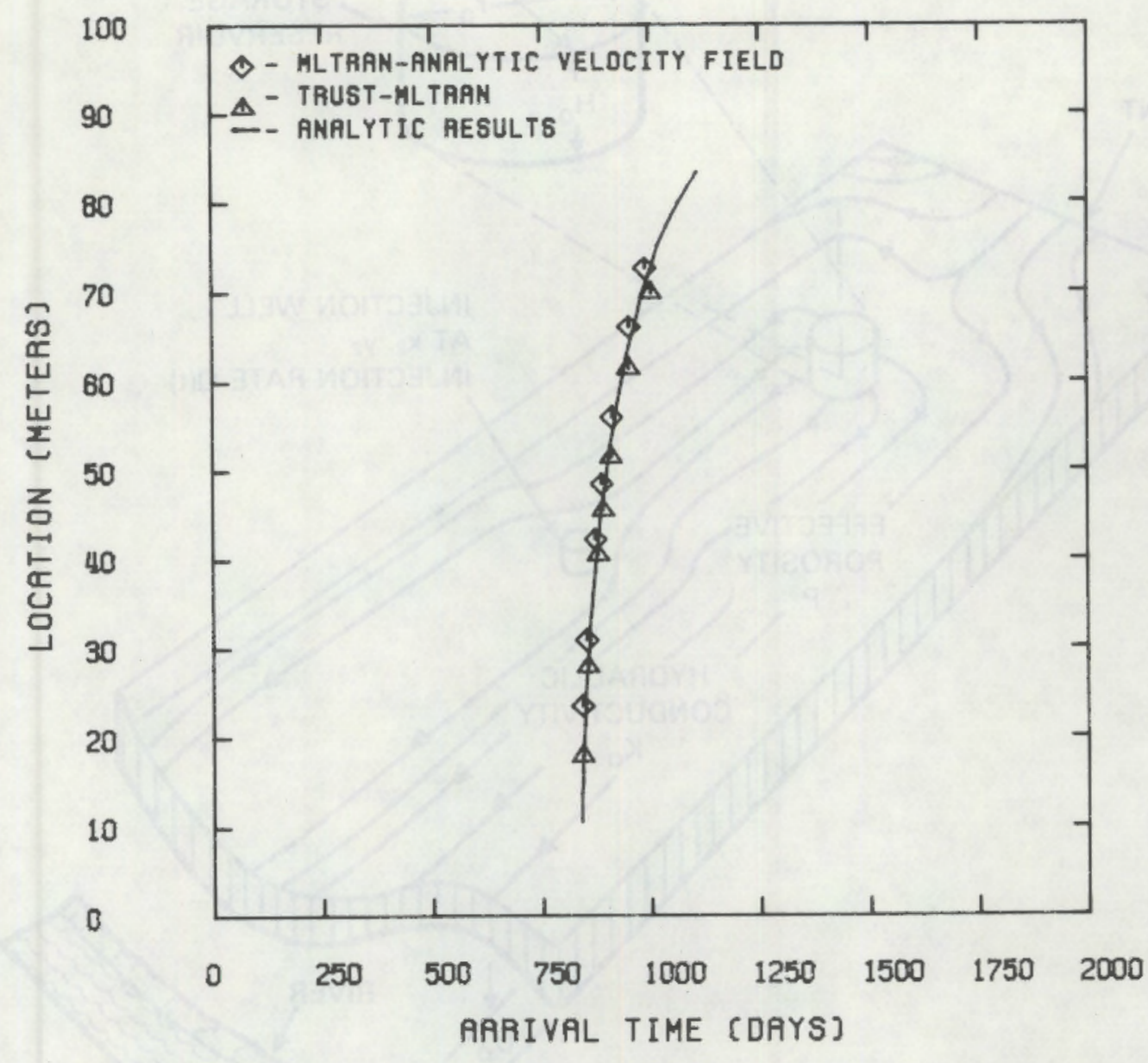

FIGURE 4.11. Arrival Time Versus Arrival Location on River

\subsection{MLTRAN TEST CASE N0. 2}

This second test case examines pathlines in a flow system that is saturated, transient, homogeneous, and isotropic. The flow system is depicted in Figure 4.12. Transient flow conditions are the result of an injection well located downgradient from the storage reservoir. The injection well is operated on a cyclic basis. The injection rate is described by:

$$
Q\left(t^{\prime}\right)=Q q_{j}+Q a_{j} \sin \left[2 \pi \frac{t^{\prime}-T_{0}}{T_{m j}-T_{0 j}}\right]
$$




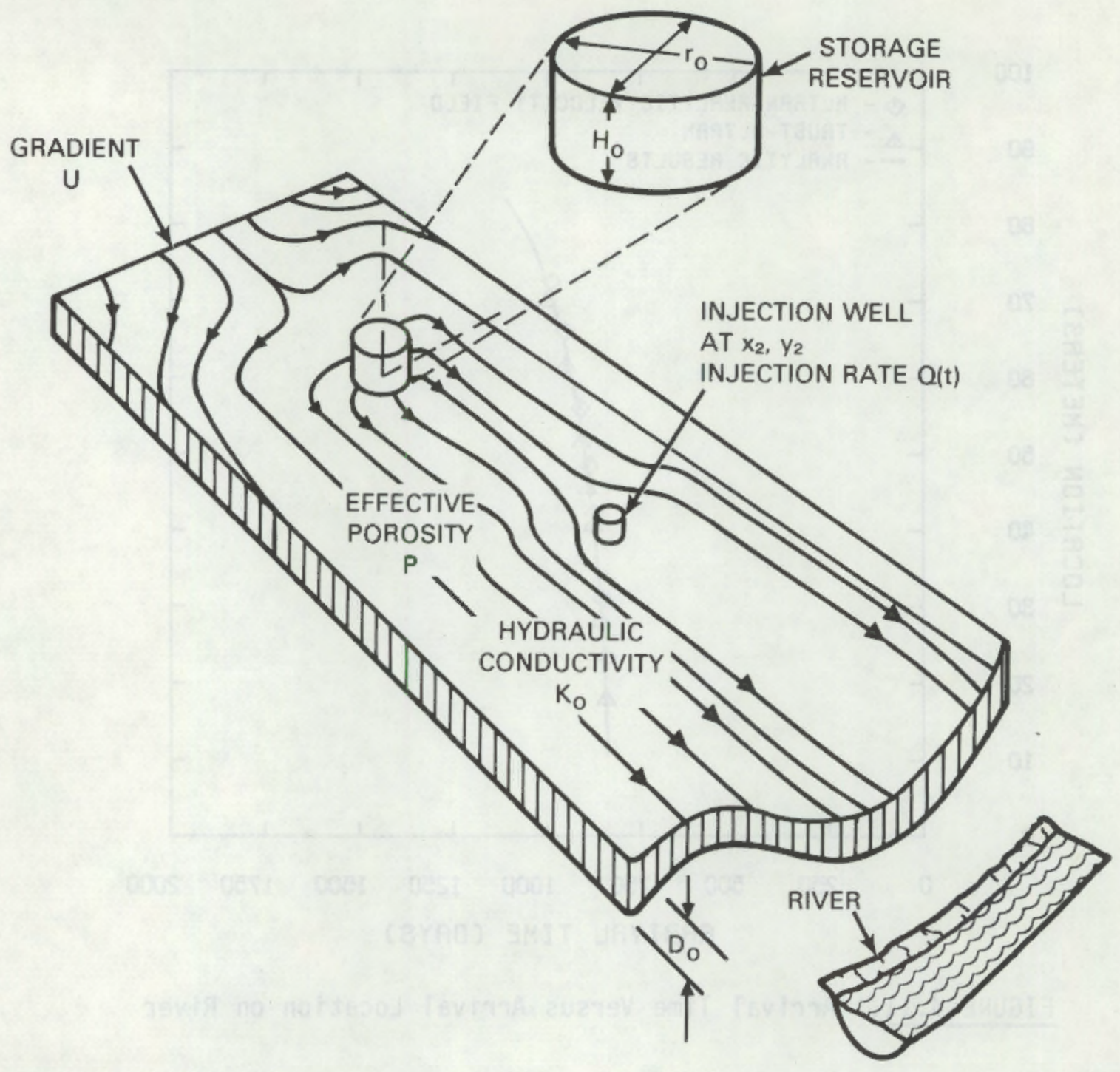

FIGURE 4.12. Test Case No. 2 Transient Flow System

where

$$
\begin{aligned}
& Q\left(t^{\prime}\right)=\text { the time-dependent injection rate } \\
& Q_{j}=\text { the mean injection rate } \\
& Q_{a_{j}}=\text { the maximum injection rate } \\
& t^{\prime}=\text { the current time } \\
& T_{0 j}=\text { the beginning time of the cyclic injection rate } \\
& T_{m j}=\text { the ending time of the cyclic injection rate. }
\end{aligned}
$$


To reduce computation time, we simulate only nalf of the flow system even though it is not symmetric about the $x$ axis. Because the TRUST-II model is not used in this test case we need not define boundary conditions along the $x$ axis. The analytical expressions for the $x$ and $y$ velocity components of Nelson and Schur (1980) are used to generate transient velocity fields, which are input into the <>.VWA file. Table 4.7 lists boundary conditions, hydraulic properties, and other parameters. Figure 4.13 shows the grid used to discretize the flow domain. Velocity data for 29 time planes, every 50 days, are generated and written to the $\langle>$. VWA file.

The MLTRAN pathlines using these analytical velocity fields are the dashed lines shown in Figures 4.14 and 4.15 , for departure times of 50 days and 500 days, respectively. Tables 4.8 and 4.9 list the corresponding travel time and discharge location for each pathline. The analytical potential contours for two time planes are shown in Figures 4.16, and 4.17.

The quasi-analytical model PATHS is used to verify the MLTRAN results. The PATHS model uses a fourth-order Runge-Kutta integration routine to solve the pair of characteristic differential equations for each pathline. The characteristic equations are the same as those used to generate the $x$ and $y$ velocity components for each time plane. The pathlines from the PATHS model are the solid lines shown in Figures 4.14 and 4.15 , for departure times of 50 and 500 days, respectively. Tables 4.10 and 4.11 list the travel times and discharge locations.

TABLE 4.7. Test Case No. 2: Transient Saturated Flow

\begin{tabular}{|c|c|c|}
\hline Porosity & 0.2 & \\
\hline Gradient ( $x$ direction) & $0.009(\mathrm{~m} / \mathrm{m})$ & $(0.009 \mathrm{ft} / \mathrm{ft})$ \\
\hline Hydraulic conductivity & $6.096 \mathrm{~m} /$ day & $(20 \mathrm{ft} /$ day $)$ \\
\hline Diameter of storage reservoir & $3.048 \mathrm{~m}$ & $(10 \mathrm{ft})$ \\
\hline Head in storage reservoir & $1.524 \mathrm{~m}$ & $(5 \mathrm{ft})$ \\
\hline Distance to outflow boundary & $304.8 \mathrm{~m}$ & $(1000 \mathrm{ft})$ \\
\hline Number of elements & 1736 & \\
\hline Number of nodes & 1827 & \\
\hline Number of time planes & 29 & \\
\hline Mean inflow rate of injection well & $35.4 \mathrm{~m}^{3} /$ day & $\left(1250 \mathrm{ft}^{3} /\right.$ day $)$ \\
\hline Maximum inflow rate of injection well & $70.8 \mathrm{~m}^{3} /$ day & $\left(2500 \mathrm{ft}^{3} /\right.$ day $)$ \\
\hline Beginning time of cyclic flow rate & 50 days & \\
\hline Ending time of cyclic flow rate & 500 days & \\
\hline tes of injection well $x, y$ & $152.4 m, 30.48 m$ & $(500 \mathrm{ft}, 100 \mathrm{ft})$ \\
\hline
\end{tabular}




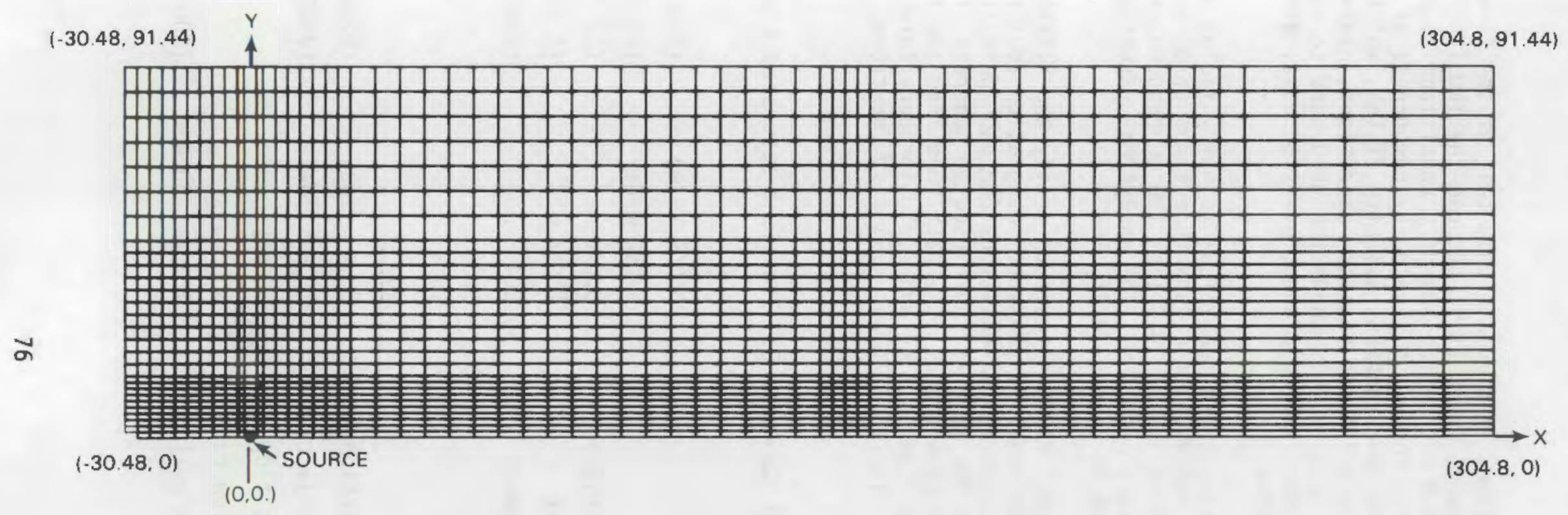

FIGURE 4.13. Discretized Flow Domain Test Case No. 2 


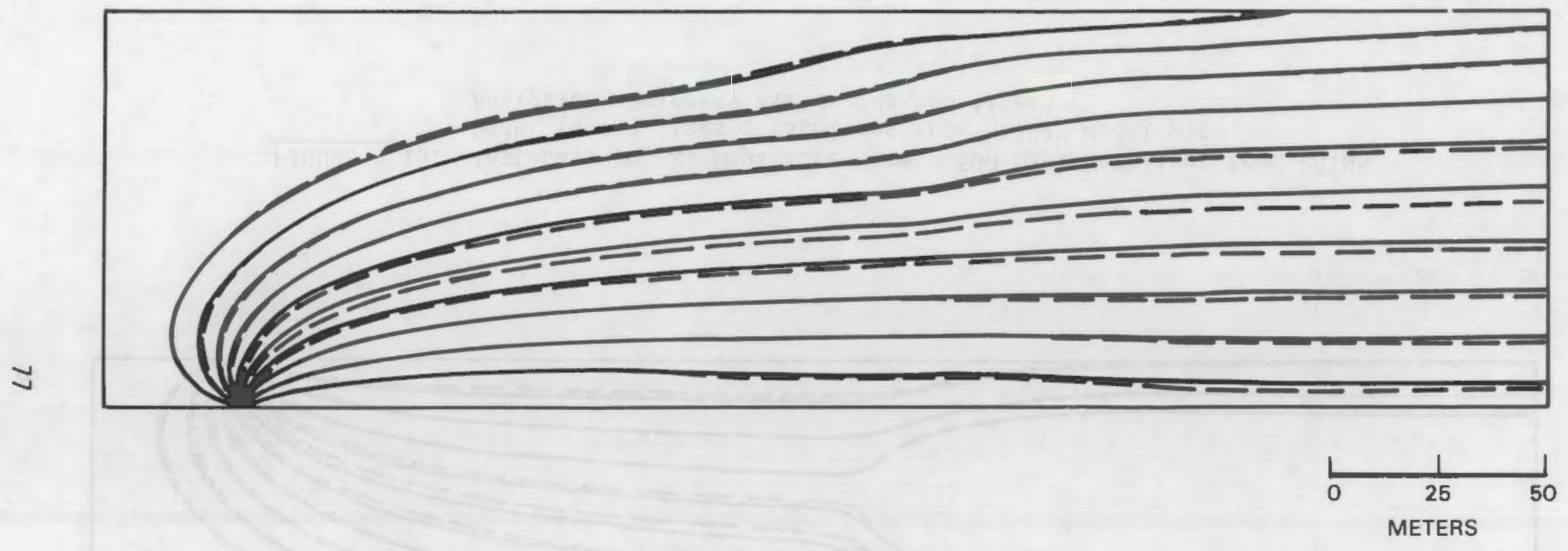

FIGURE 4.14. Test Case No. 2: Departure Time $=50$ Days; Patnlines from PATHS Model (solid lines); Pathlines from MLTRAN Model with Analytical Velocity Fields (dashed lines) 


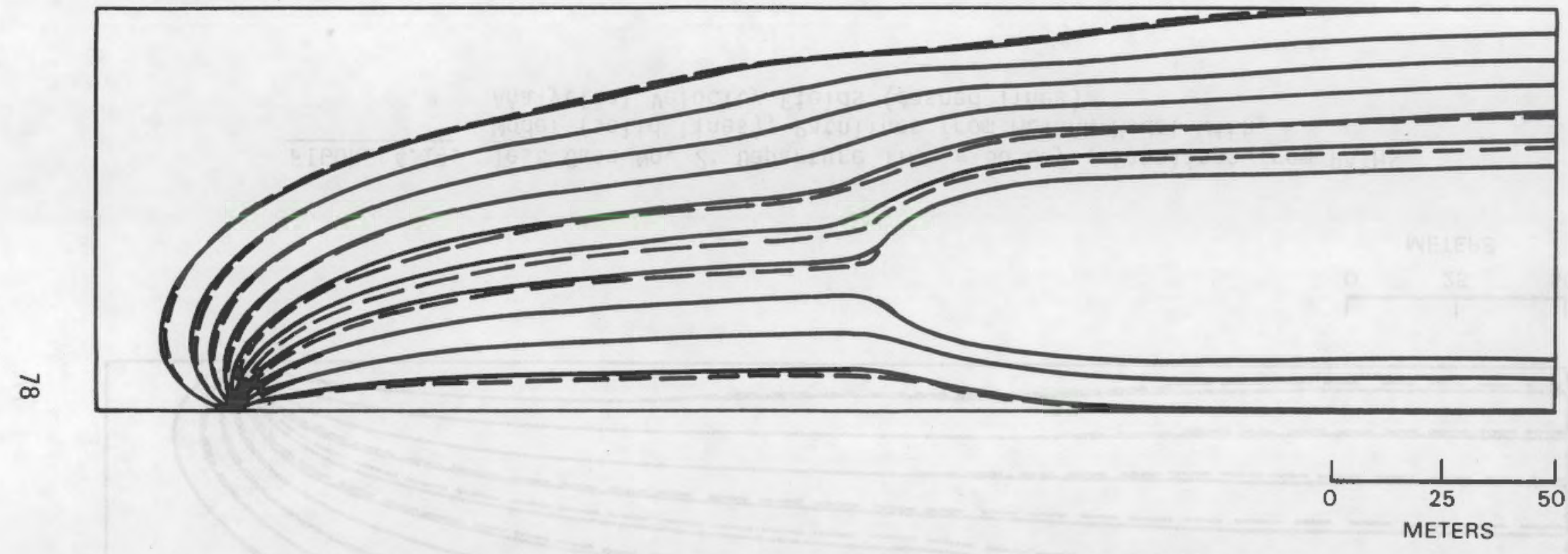

FIGURE 4.15. Test Case No. 2: Departure Time $=500$ Days Pathlines from PATHS Model (solid lines); Pathlines from MLTRAN Model with Analytical Velocity Fields (dashed lines) 
TABLE 4.8. MLTRAN Results with Analytical Velocity Field Test Case No. 2: Transient Saturated Flow, Departure Time $=50$ Days

\begin{tabular}{|c|c|c|c|c|c|c|}
\hline \multirow{2}{*}{$\begin{array}{c}\text { Departure } \\
\text { Time } \\
\text { (days) }\end{array}$} & \multicolumn{2}{|c|}{$\begin{array}{l}\text { Starting Location } \\
\text { (meters) }\end{array}$} & \multicolumn{2}{|c|}{$\begin{array}{l}\text { Ending Location } \\
\text { (meters) }\end{array}$} & \multirow{2}{*}{$\begin{array}{c}\text { Arrival } \\
\text { Time } \\
\text { (days) } \\
\end{array}$} & \multirow{2}{*}{$\begin{array}{c}\text { Path } \\
\text { Length } \\
\text { (meters) }\end{array}$} \\
\hline & $x$ & $y$ & $\mathrm{x}$ & $y$ & & \\
\hline 50 & 1.43 & 0.52 & 304.8 & 3.86 & 884.31 & 304.02 \\
\hline 50 & 1.24 & 0.89 & 304.8 & 14.93 & 887.84 & 305.68 \\
\hline 50 & 0.96 & 1.19 & 304.8 & 25.74 & 892.97 & 308.21 \\
\hline 50 & 0.60 & 1.39 & 304.8 & 36.61 & 900.86 & 311.44 \\
\hline 50 & 0.21 & 1.51 & 304.8 & 47.26 & 914.87 & 315.62 \\
\hline 50 & -0.21 & 1.51 & 304.8 & 59.73 & 941.97 & 322.60 \\
\hline 50 & -0.60 & 1.39 & 304.8 & 70.91 & 977.68 & 330.58 \\
\hline 50 & -0.96 & 1.19 & 304.8 & 79.42 & 1017.8 & 339.42 \\
\hline 50 & -1.24 & 0.89 & 304.8 & 86.85 & 1071.4 & 350.15 \\
\hline${ }_{50}(\mathrm{a})$ & -1.43 & 0.52 & 247.9 & 91.44 & 975.07 & 308.79 \\
\hline
\end{tabular}

(a) The last pathline exits the defined flow domain at $y=91.44$ meters before reaching the river. This pathline is not included in the error analysis in Table 4.12.

The pathlines generated using the MLTRAN model follow the quasi-analytical patnlines fairly closely, considerably better than in Test Case No. 1. This is because of the finer grid resolution used in Test Case No. 2. Table 4.12 lists the RMS measure of the errors in discharge locations and arrival times for Test Case No. 2.

Figure 4.18 shows the arrival time versus arrival location curves for both departure times. The MLTRAN data points, with additional points listed in Table 4.13, agree quite well with the curve of data points resulting from the quasi-analytical PATHS model. The sharp variation or bump in the arrival time versus arrival location curve for a departure time of 500 days is caused by the pathlines that travel around the recharge mound caused by the injection well downgradient from the storage reservoir. The longer travel paths require longer travel times. The recharge mound has a less-pronounced effect on the patnlines that start at a departure time of 50 days; nowever, variations in the travel patns can be seen in Figure 4.14. 
TABLE 4.9. MLTRAN Results with Analytical Velocity Field Test Case No. 2: Transient Saturated Flow, Departure Time $=500$ Days

\begin{tabular}{|c|c|c|c|c|c|c|}
\hline \multirow{2}{*}{$\begin{array}{c}\text { Departure } \\
\text { Time } \\
\text { (days) }\end{array}$} & \multicolumn{2}{|c|}{$\begin{array}{l}\text { Starting Location } \\
\text { (meters) }\end{array}$} & \multicolumn{2}{|c|}{$\begin{array}{l}\text { Ending Location } \\
\text { (meters) }\end{array}$} & \multirow{2}{*}{$\begin{array}{c}\text { Arrival } \\
\text { Time } \\
\text { (days) }\end{array}$} & \multirow{2}{*}{$\begin{array}{c}\text { Path } \\
\text { Length } \\
\text { (meters) }\end{array}$} \\
\hline & $x$ & $y$ & $x$ & $y$ & & \\
\hline $500(a)$ & 1.43 & 0.52 & 260.26 & 0.0 & $\overline{1184.8}$ & 259.97 \\
\hline 500 & 1.24 & 0.89 & 304.8 & 7.41 & 1327.3 & 306.63 \\
\hline 500 & 0.96 & 1.19 & 304.8 & 11.78 & 1343.6 & 311.02 \\
\hline 500 & 0.60 & 1.39 & 304.8 & 55.62 & 1382.9 & 317.57 \\
\hline 500 & 0.21 & 1.51 & 304.8 & 59.82 & 1383.1 & 318.85 \\
\hline 500 & -0.21 & 1.51 & 304.8 & 66.99 & 1410.5 & 324.37 \\
\hline 500 & -0.66 & 1.39 & 304.8 & 74.20 & 1446.8 & 331.99 \\
\hline 500 & -0.96 & 1.19 & 304.8 & 80.04 & 1485.6 & 340.46 \\
\hline 500 & -1.24 & 0.89 & 304.8 & 85.78 & 1535.6 & 351.13 \\
\hline $500^{(a)}$ & -1.43 & 0.52 & 277.2 & 91.44 & 1528.8 & 339.27 \\
\hline
\end{tabular}

(a) The first and last pathlines exit the defined flow domain at $y=0.0$ and $y=91.44$ meters, respectively, before reaching the river. These two pathlines are not included in the error analysis in Table 4.12. 


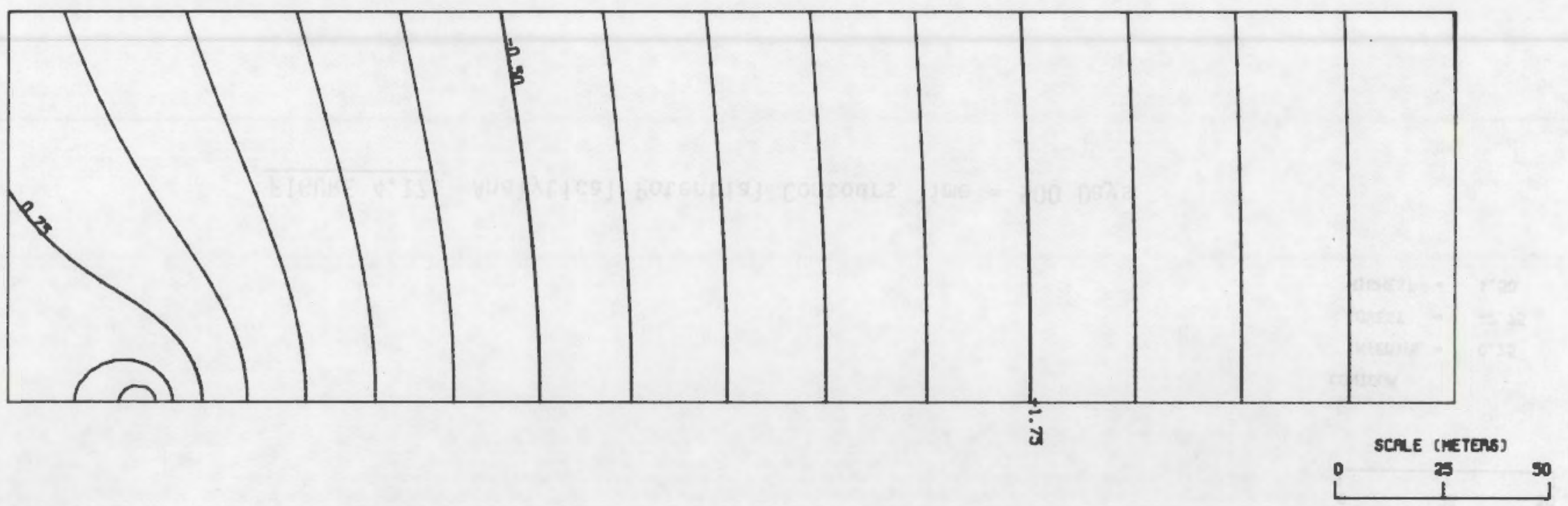

cowroun

INTERVRL - 0.25

LUVEST - -2.75

HICEST $=1.50$

FIGURE 4.16. Analytical Potential Contours Time $=50$ Days 


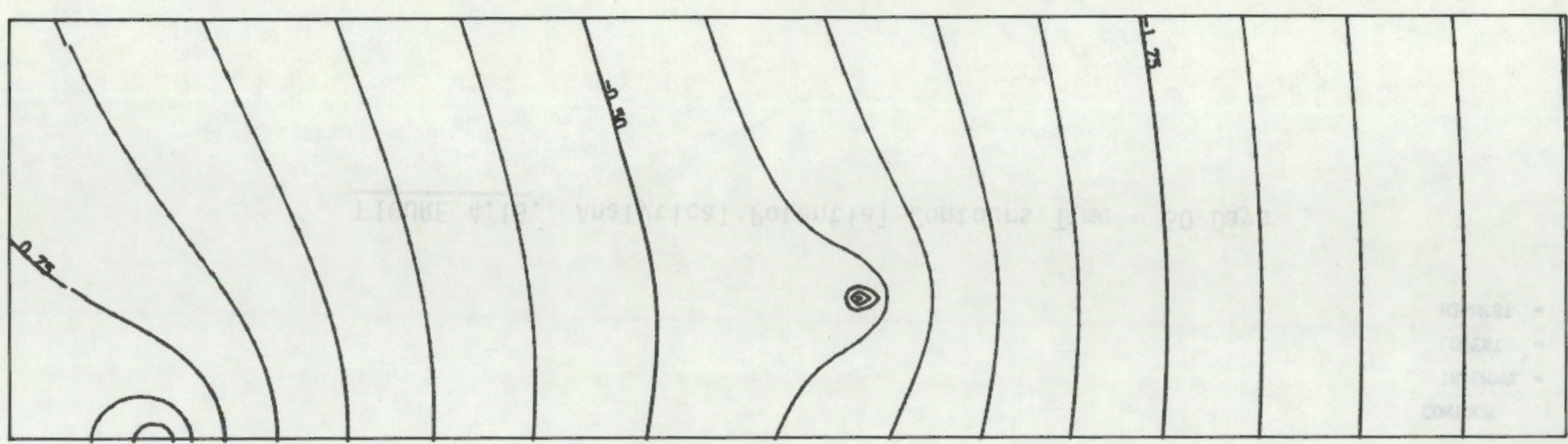

FIGURE 4.17. Analytical Potential Contours Time $=500$ Days 
TABLE 4.10. Quasi-Analytical Results from PATHS Model Test Case No. 2: Transient Saturated Flow, Departure Time $=50$ Days (Pathline Arrival Data)

\begin{tabular}{|c|c|c|c|c|c|c|}
\hline \multirow{2}{*}{$\begin{array}{c}\text { Departure } \\
\text { Time } \\
\text { (days) } \\
\end{array}$} & \multicolumn{2}{|c|}{$\begin{array}{l}\text { Starting Location } \\
\text { (meters) }\end{array}$} & \multicolumn{2}{|c|}{$\begin{array}{l}\text { Ending Location } \\
\text { (meters) } \\
\end{array}$} & \multirow{2}{*}{$\begin{array}{l}\text { Arrival } \\
\text { Time } \\
\text { (days) } \\
\end{array}$} & \multirow{2}{*}{$\begin{array}{c}\text { Path } \\
\text { Length } \\
\text { (meters) }\end{array}$} \\
\hline & $x$ & $y$ & $x$ & $y$ & & \\
\hline 50 & 1.43 & 0.52 & 304.8 & 5.01 & 885.47 & 304.34 \\
\hline 50 & 1.24 & 0.89 & 304.8 & 15.37 & 888.99 & 305.99 \\
\hline 50 & 0.96 & 1.19 & 304.8 & 26.42 & 894.00 & 308.40 \\
\hline 50 & 0.60 & 1.39 & 304.8 & 38.33 & 904.00 & 312.24 \\
\hline 50 & 0.21 & 1.51 & 304.8 & 50.33 & 921.72 & 317.54 \\
\hline 50 & -0.21 & 1.51 & 304.8 & 61.12 & 945.68 & 323.30 \\
\hline 50 & -0.60 & 1.39 & 304.8 & 70.74 & 977.72 & 330.86 \\
\hline 50 & -0.96 & 1.19 & 304.8 & 79.33 & 1018.01 & 339.64 \\
\hline 50 & -1.24 & 0.89 & 304.8 & 86.82 & 1072.01 & 350.28 \\
\hline 50 & -1.43 & 0.52 & 304.8 & 93.08 & 1153.51 & 364.60 \\
\hline
\end{tabular}

TABLE 4.11. Quasi-Analytical Results from PATHS Model Test Case No. 2: Transient Saturated Flow, Departure Time $=500$ Days (Pathline Arrival Data)

\begin{tabular}{|c|c|c|c|c|c|c|}
\hline \multirow{2}{*}{$\begin{array}{c}\text { Departure } \\
\text { Time } \\
\text { (days) } \\
\end{array}$} & \multicolumn{2}{|c|}{$\begin{array}{l}\text { Starting Location } \\
\text { (meters) }\end{array}$} & \multicolumn{2}{|c|}{$\begin{array}{l}\text { Ending Location } \\
\text { (meters) }\end{array}$} & \multirow{2}{*}{$\begin{array}{c}\text { Arrival } \\
\text { Time } \\
\text { (days) } \\
\end{array}$} & \multirow{2}{*}{$\begin{array}{c}\text { Path } \\
\text { Length } \\
\text { (meters) } \\
\end{array}$} \\
\hline & $x$ & $y$ & $x$ & $y$ & & \\
\hline 500 & 1.43 & 0.52 & 304.8 & 0.28 & 1324.0 & 304.7 \\
\hline 500 & 1.24 & 0.89 & 304.8 & 7.48 & 1327.6 & 306.95 \\
\hline 500 & 0.96 & 1.19 & 304.8 & 8.65 & 1345.0 & 311.33 \\
\hline 500 & 0.60 & 1.39 & 304.8 & 56.41 & 1367.0 & 317.15 \\
\hline 500 & 0.21 & 1.51 & 304.8 & 62.02 & 1388.0 & 320.26 \\
\hline 500 & -0.21 & 1.51 & 304.8 & 68.34 & 1413.9 & 325.51 \\
\hline 500 & -0.60 & 1.39 & 304.8 & 74.49 & 1445.6 & 332.19 \\
\hline 500 & -0.96 & 1.19 & 304.8 & 80.40 & 1485.0 & 340.79 \\
\hline 500 & -1.24 & 0.89 & 304.8 & 86.20 & 1535.0 & 351.38 \\
\hline 500 & -1.43 & 0.52 & 304.8 & 92.55 & 1609.4 & 365.81 \\
\hline
\end{tabular}


TABLE 4.12. Test Case No. 2: Transient Saturated Flow, Error Analysis of MLTRAN Results Compared with PATHS Results

\begin{tabular}{|c|c|c|}
\hline Departure Time & $\begin{array}{c}\text { RMS Error in } \\
\text { Discharge Location } \\
\text { (meters) }\end{array}$ & $\begin{array}{l}\text { RMS Error in } \\
\text { Arrival Time } \\
\text { (days) }\end{array}$ \\
\hline 50 days & 1.35 & 2.88 \\
\hline 500 days & 0.98 & 3.3 \\
\hline
\end{tabular}

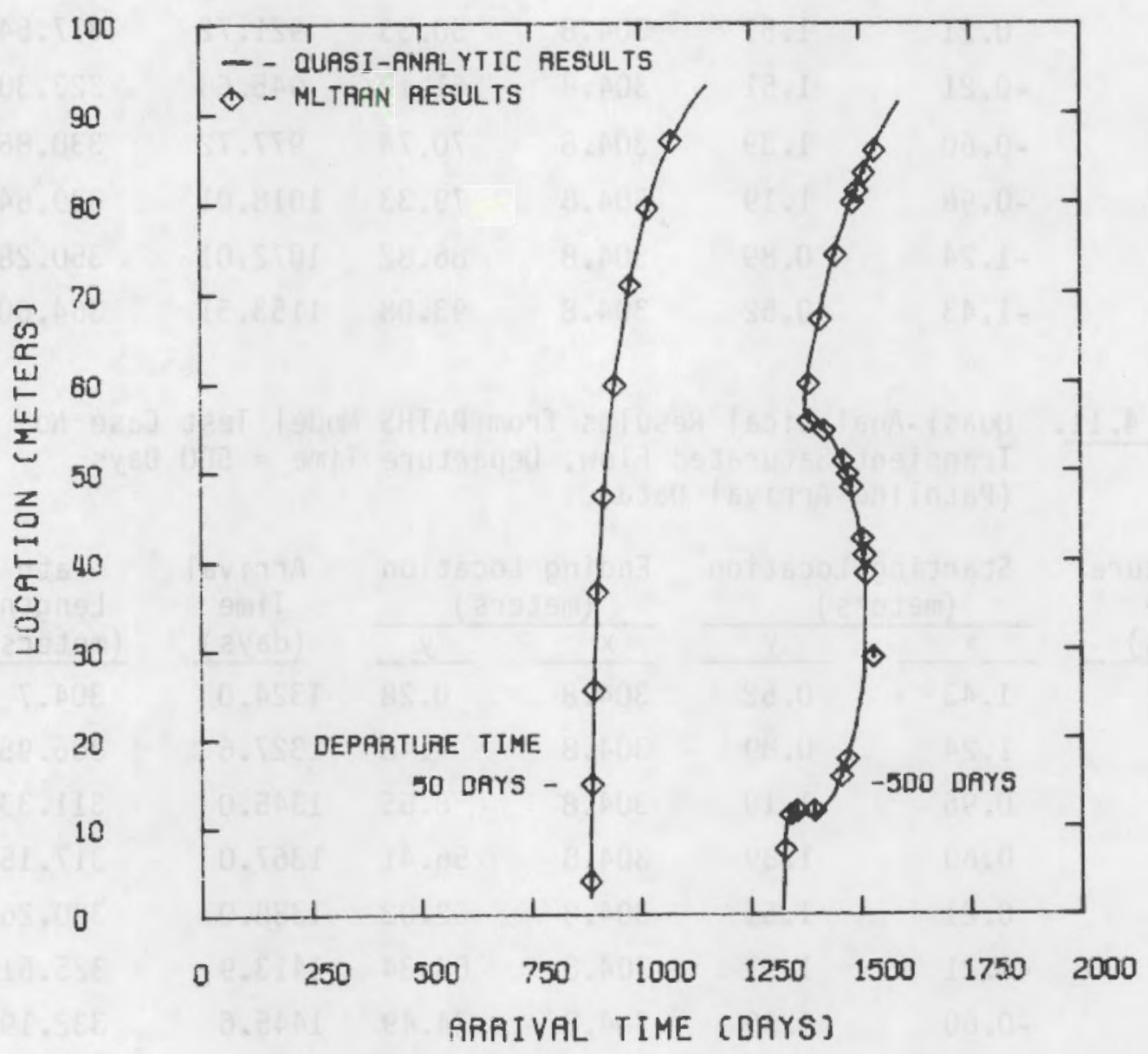

FIGURE 4.18. Test Case No. 2: Arrival Time Versus Arrival Location Curve 
TABLE 4.13. Test Case No. 2: MLTRAN Results from Transient Saturated Flow (Pathline Arrival Data)

\begin{tabular}{|c|c|c|c|c|c|c|}
\hline \multirow{2}{*}{$\begin{array}{c}\text { Departure } \\
\text { Time } \\
\text { (days) } \\
\end{array}$} & \multicolumn{2}{|c|}{$\begin{array}{l}\text { Starting Location } \\
\text { (meters) }\end{array}$} & \multicolumn{2}{|c|}{$\begin{array}{l}\text { Ending Location } \\
\text { (meters) }\end{array}$} & \multirow{2}{*}{$\begin{array}{c}\text { Arrival } \\
\text { Time } \\
\text { (days) }\end{array}$} & \multirow{2}{*}{$\begin{array}{c}\text { Path } \\
\text { Length } \\
\text { (meters) }\end{array}$} \\
\hline & $x$ & $y$ & $x$ & $y$ & & \\
\hline 500 & 1.15 & 0.99 & 304.8 & 9.34 & 1330.4 & 307.66 \\
\hline 500 & 1.02 & 1.13 & 304.8 & 11.35 & 1337.8 & 309.68 \\
\hline 500 & 0.96 & 1.18 & 304.8 & 11.78 & 1343.6 & 311.02 \\
\hline 500 & 0.88 & 1.24 & 304.8 & 11.85 & 1354.1 & 312.75 \\
\hline 500 & 0.82 & 1.28 & 304.8 & 11.72 & 1368.0 & 314.88 \\
\hline 500 & 0.78 & 1.31 & 304.8 & 11.79 & 1386.6 & 316.56 \\
\hline 500 & 0.77 & 1.31 & 304.8 & 11.81 & 1390.3 & 316.77 \\
\hline 500 & 0.74 & 1.33 & 304.8 & 15.70 & 1455.5 & 318.51 \\
\hline 500 & 0.73 & 1.33 & 304.8 & 29.23 & 1529.1 & 314.55 \\
\hline 500 & 0.73 & 1.33 & 304.8 & 38.47 & 1512.5 & 315.16 \\
\hline 500 & 0.73 & 1.33 & 304.8 & 42.42 & 1505.2 & 317.08 \\
\hline 500 & 0.73 & 1.34 & 304.8 & 48.15 & 1480.2 & 318.79 \\
\hline 500 & 0.72 & 1.34 & 304.8 & 52.13 & 1453.2 & 320.1 \\
\hline 500 & 0.72 & 1.34 & 304.8 & 53.89 & 1432.6 & 319.73 \\
\hline 500 & 0.71 & 1.35 & 304.8 & 54.55 & 1418.9 & 319.4 \\
\hline 500 & 0.69 & 1.35 & 304.8 & 54.87 & 1408.3 & 318.94 \\
\hline 500 & 0.67 & 1.37 & 304.8 & 55.15 & 1395.9 & 318.39 \\
\hline 500 & 0.65 & 1.37 & 304.8 & 55.24 & 1391.1 & 318.15 \\
\hline 500 & 0.64 & 1.38 & 304.8 & 55.33 & 1387.7 & 317.93 \\
\hline 500 & 0.60 & 1.40 & 304.8 & 55.62 & 1382.9 & 317.57 \\
\hline 500 & 0.47 & 1.45 & 304.8 & 56.80 & 1377.5 & 317.35 \\
\hline 500 & -0.96 & 1.18 & 304.8 & 86.04 & 1485.6 & 340.46 \\
\hline 500 & -1.02 & 1.13 & 304.8 & 81.25 & 1494.7 & 342.47 \\
\hline 500 & -1.12 & 1.02 & 304.8 & 83.29 & 1511.8 & 346.13 \\
\hline
\end{tabular}

\subsection{MLTRAN EXAMPLE PROBLEM}

Tnis example illustrates the application of TRUST-II and MLTRAN to partially saturated flow problems. A single point source on the soil surface is simulated. The initial moisture content of the soil is very low: relative saturation is $1 \cdot 10^{-4}$. We chose this geometry and these initial conditions so that the results from the TRUST-II model could be compared with analytical results.

The analytical solution to a form of Richard's equation requires two basic assumptions to linearize the problem. The first assumption is that the unsaturated nydraulic conductivity, $k$, is exponentially related to pressure, $n$, as follows: 


$$
K=k_{0} \exp (\alpha n)
$$

where $\alpha$ and $K_{0}$ are empirical constants. The second assumption is that the derivative of the unsaturated nydraulic conductivity with respect to tne water content is a constant:

$$
\frac{\partial K}{\partial \theta}=K
$$

where $k$ is a constant. This second assumption is the more restrictive of the two. Although this linearization may not truly represent field soils, it does provide for a sound analytical treatment of the problem of infiltration into a dry soil.

Using a Kirchnoff integral transformation a "matric flux potential", \$, is defined after Gardner (1958) by:

$$
s=L_{\infty}^{n} K(n) d n
$$

The gradient of this matric flux potential gives the components of the Darcian velocity. For a conductivity described by Equation (4.44), the differential equation may be written as:

$$
\frac{d \theta}{d t}=\nabla^{2} \theta-\alpha \frac{d \phi}{d z}
$$

The second assumption implies that the derivative of the water content with respect to the matric flux potential, is also a constant:

$$
\frac{d A}{d s}=a / K
$$


Substituting Equation (4.48) into Equation (4.47) yields:

$$
\frac{d \Phi}{d t}=\frac{k}{\alpha} \nabla^{2} \Phi-k \frac{d \Phi}{d z}
$$

The derivation of an analytical solution to this linearized form of Richard's equation is presented by Lomen and Warrick (1974) and Batu (1982). The computer code used to evaluate the analytical solution was developed by Warrick, Lomen and Tonellato (1981). We made slight modifications to the input and output files.

Figures 4.19 and 4.20 snow tne soil characteristic curves that result from the linearizing assumptions. Figure 4.21 shows the grid used to discretize the flow domain. Only nalf of the flow system was simulated because of symmetry about the $Z$ axis. The very fine grid resolution was required to accurately track the wetting front as it moved into the desiccated soil. We simulated a source strength of $500 \mathrm{~cm} /$ day $\left(1000 \mathrm{~cm}^{3} /\right.$ day for the whole flow system). The analytical solution is for line sources; however, in the TRUST-II simulation the source node has a finite volume of $4.9 \times 10^{-2} \mathrm{~cm}^{3}$. The initial conditions for the analytical solution are dry soil. For the TRUST-II simulation tne initial moisture content of the soil was at a relative saturation of $1 \times 10^{-4}$.

Parameters used in this example are listed in Table 4.14. The boundary conditions along all three boundaries of the flow domain shown in Figure 4.21, are prescribed to be no-flow conditions. Because the flow system was only simulated over a short time period, the wetting front never reached the boundary between points $B$ to $C$ of Figure 4.21 ; thus we felt that a no-flow boundary condition was a reasonable assumption for the short time periods.

The type of soil we used for this example is Pima clay loam. The empirical constants $\alpha, K_{0}$, and $k$ used to describe the soil moisture characteristics are: $\alpha=0.0141 / \mathrm{cm}, K_{0}=9.9 \mathrm{~cm} /$ day, and $k=77.0 \mathrm{~cm} /$ day (Warrick 1975). Although this problem has been linearized in terms of the matric flux potential, it is still a nonlinear problem in terms of pressure potential for the TRUST-II simulation.

Potential contours for times of 0.5 and 1.0 days are shown in Figures 4.22 and 4.23 , respectively. The analytical contours and those generated with the TRUST-II model match very well. Figure 4.24 snows the patnlines generated with MLTRAN and Table 4.15 shows the travel times and final coordinates of the pathlines. Figure 4.25 snows the fronts generated by MILFRNT for times of 0.75 and 1.25 days. 
PRESSURE HEAD VS CONOUCTIVITY

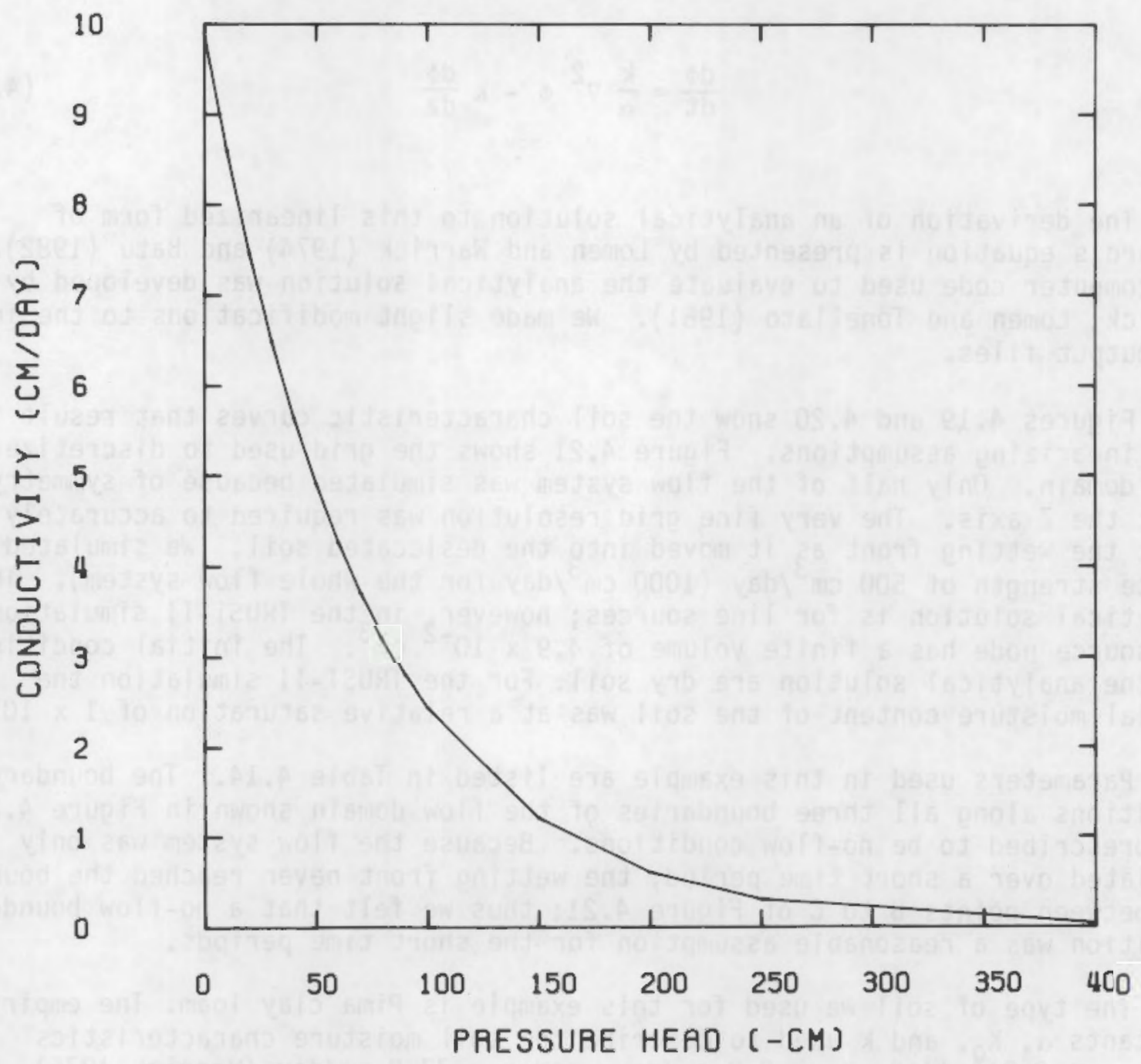

FIGURE 4.19. Partially Saturated Hydraulic Conductivity 
PRESSURE HEAD VS SATURATION

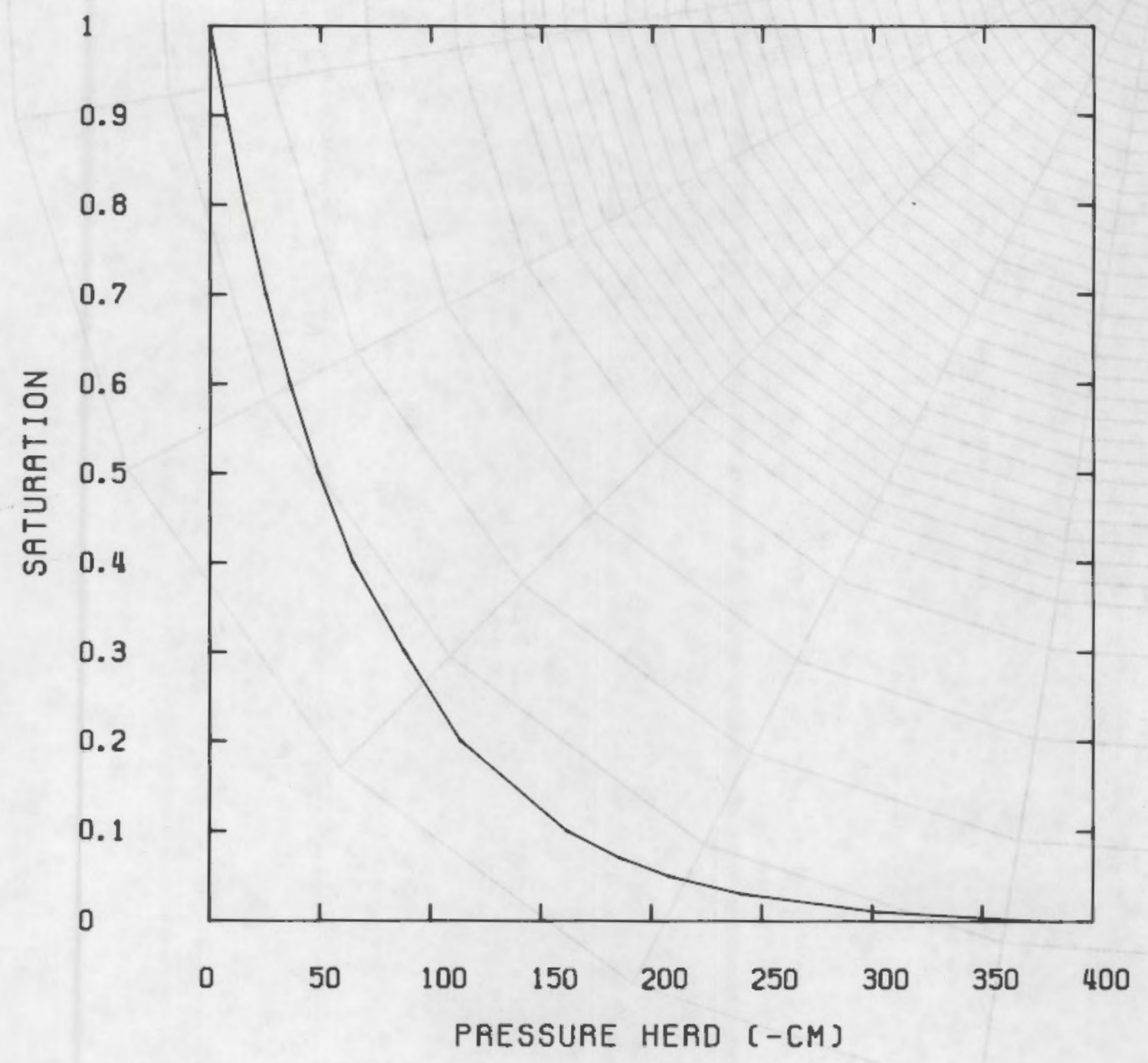

FIGURE 4.20. Soil Characteristic Curve for Example Problem 


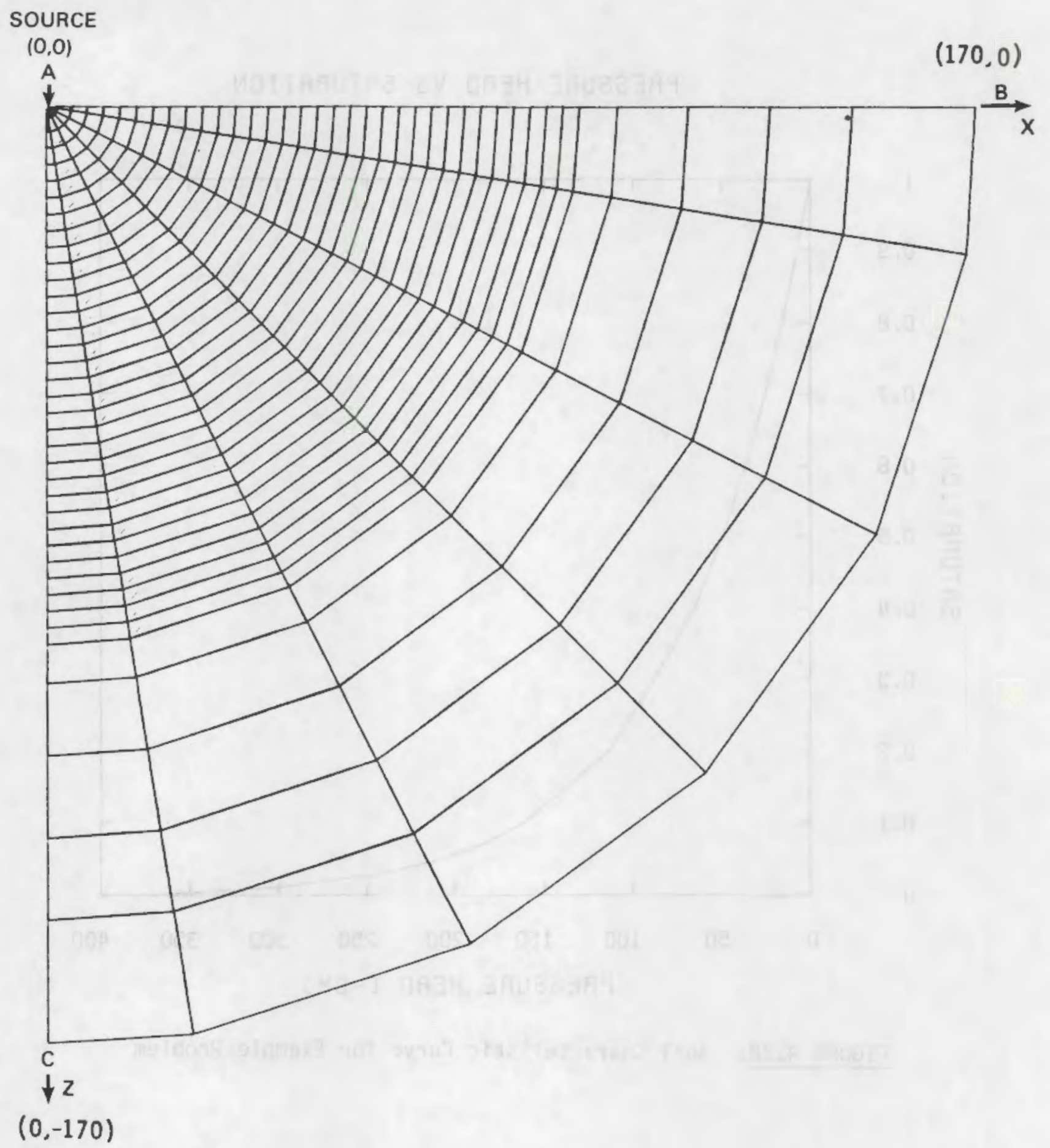

FIGURE 4.21. Discretized Flow Domain for Example Problem 
TABLE 4.14. Example Problem, Partially Saturated Point Source

Boundary conditions

Initial conditions

Source strength
All boundaries in Figure 4.21 are no flow conditions

Relative saturation of $1 \cdot 10^{-4}$

500 cubiç centimeters per day (1000 $\mathrm{cm}^{3} /$ day for the entire flow system which is symmetric about the $z$ axis)

Soil moisture characteristics shown in Figure 4.20

Partially saturated hydraulic conductivity shown in Figure 4.19

Empirical constants used to generate soil moisture characteristic curve and hydraulic conductivity curve

$\begin{array}{ll}\alpha & 0.014 \mathrm{~cm}^{-1} \\ \mathrm{~K}_{0} & 9.9 \mathrm{~cm}^{-1} \text { day } \\ \mathrm{k} & 77.0 \mathrm{~cm} / \text { day }\end{array}$

Number of element

228

Number of nodes

273 


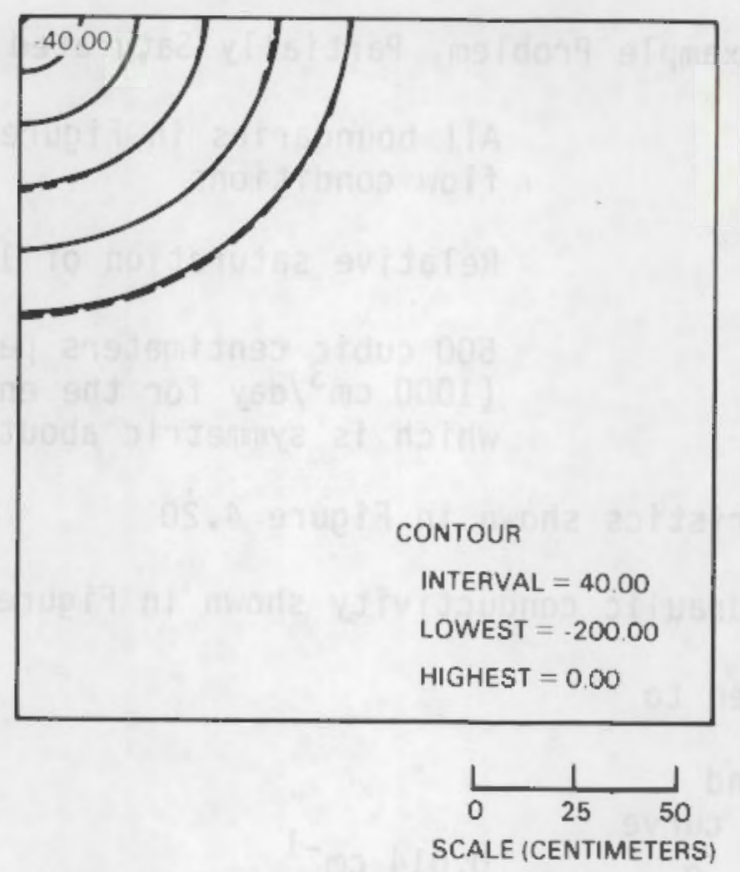

FIGURE 4.22. Pressure Head Contours, for Example Problem Time $=0.5$ Days; Analytical = Solid Lines; TRUST-II = Dashed Lines

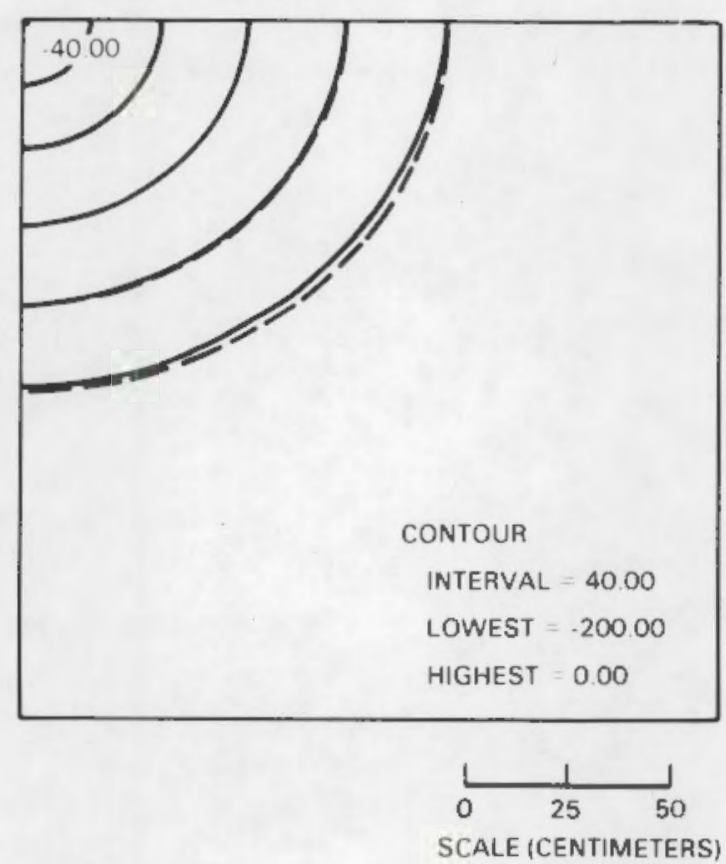

FIGURE 4.23. Pressure Head Contours for Example Problem, Time $=1.0$ Days; Analytical = Solid Lines

TRUST-II = Dashed Lines 


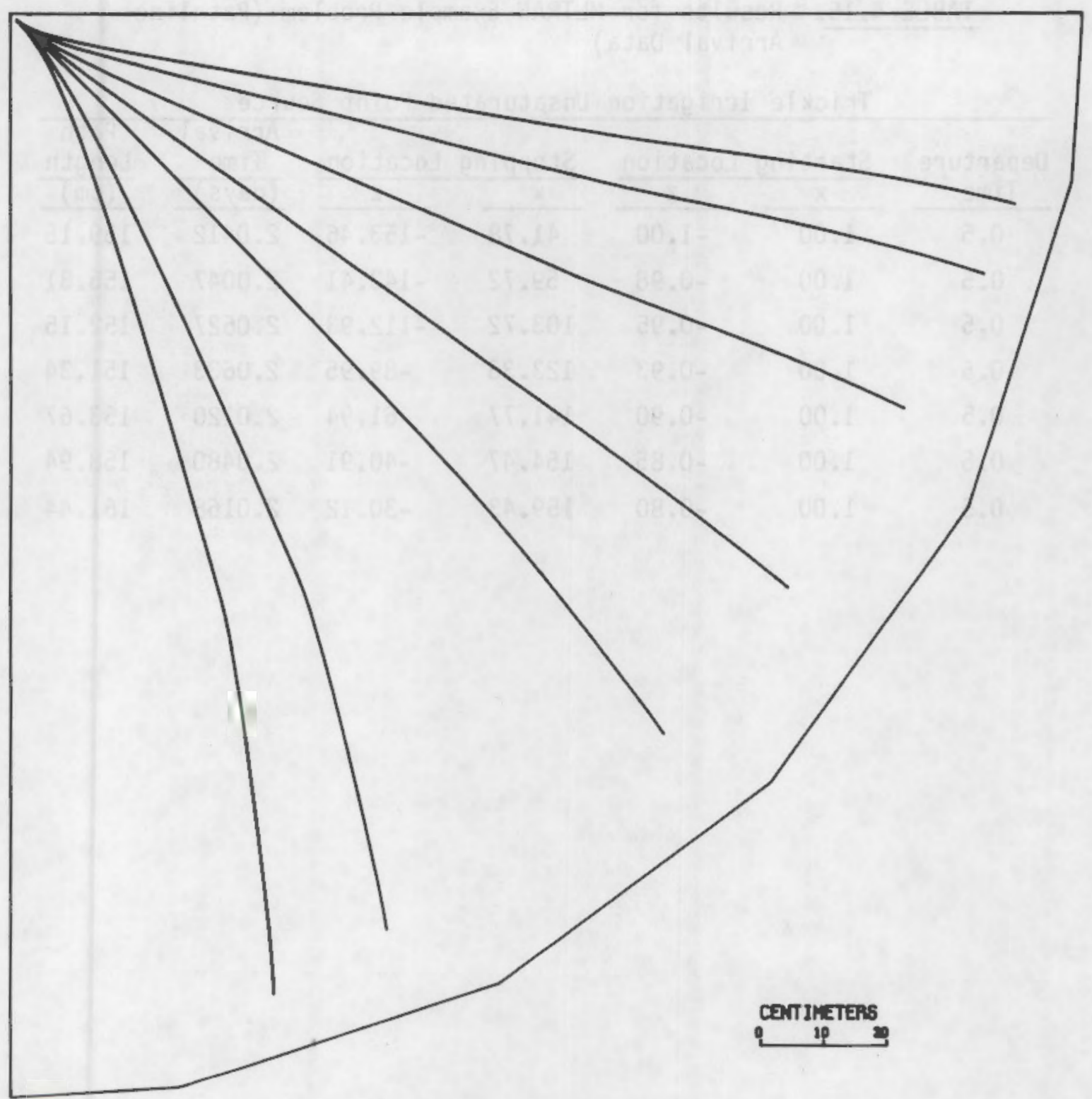

FIGURE 4.24. MLTRAN Pathlines for Example Problem 
TABLE 4.15. Results for MLTRAN Example Problem (Pathline Arrival Data)

Trickle Irrigation Unsaturated Point Source

\begin{tabular}{|c|c|c|c|c|c|c|}
\hline $\begin{array}{c}\text { Departure } \\
\text { Time } \\
\end{array}$ & $\frac{\text { Starting }}{x}$ & $\frac{\text { Location }}{2}$ & $\frac{\text { Stopping }}{\mathrm{x}}$ & $\frac{\text { Location }}{z}$ & $\begin{array}{l}\text { Arrival } \\
\text { Time } \\
\text { (days) } \\
\end{array}$ & $\begin{array}{l}\text { Path } \\
\text { Length } \\
(\mathrm{cm})\end{array}$ \\
\hline 0.5 & 1.00 & -1.00 & 41.78 & -153.46 & 2.0412 & 159.15 \\
\hline 0.5 & 1.00 & -0.98 & 59.72 & -143.41 & 2.0047 & 155.31 \\
\hline 0.5 & 1.00 & -0.95 & 103.72 & -112.93 & 2.0627 & 152.15 \\
\hline 0.5 & 1.00 & -0.93 & 123.33 & -89.95 & 2.0633 & 151.34 \\
\hline 0.5 & 1.00 & -0.90 & 141.77 & -61.94 & 2.0120 & 153.67 \\
\hline 0.5 & 1.00 & -0.85 & 154.47 & -40.91 & 2.0480 & 158.94 \\
\hline 0.5 & 1.00 & -0.80 & 159.43 & -30.12 & 2.0168 & 161.44 \\
\hline
\end{tabular}




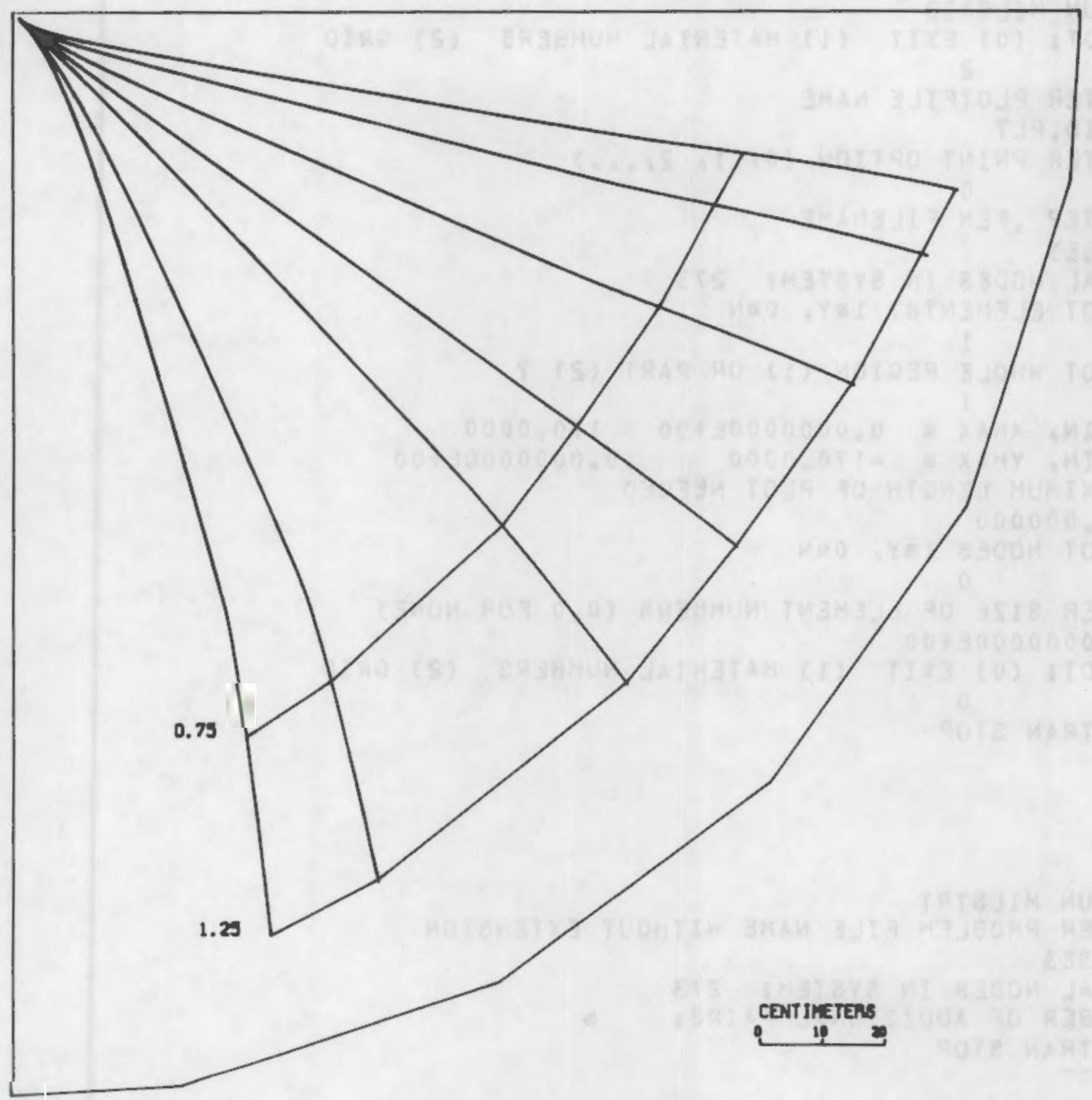

FIGURE 4.25. MLTRAN Water Fronts for Example Problem

The following is a listing of typical control streams for the MLTRAN submodels. The listings are the control parameters used for this example. The problem name used to describe the data files is CASE3. We ran the programs in batch mode, and the stream of program prompts and commands used to run the submodels interactively are identical to these batch run streams. 


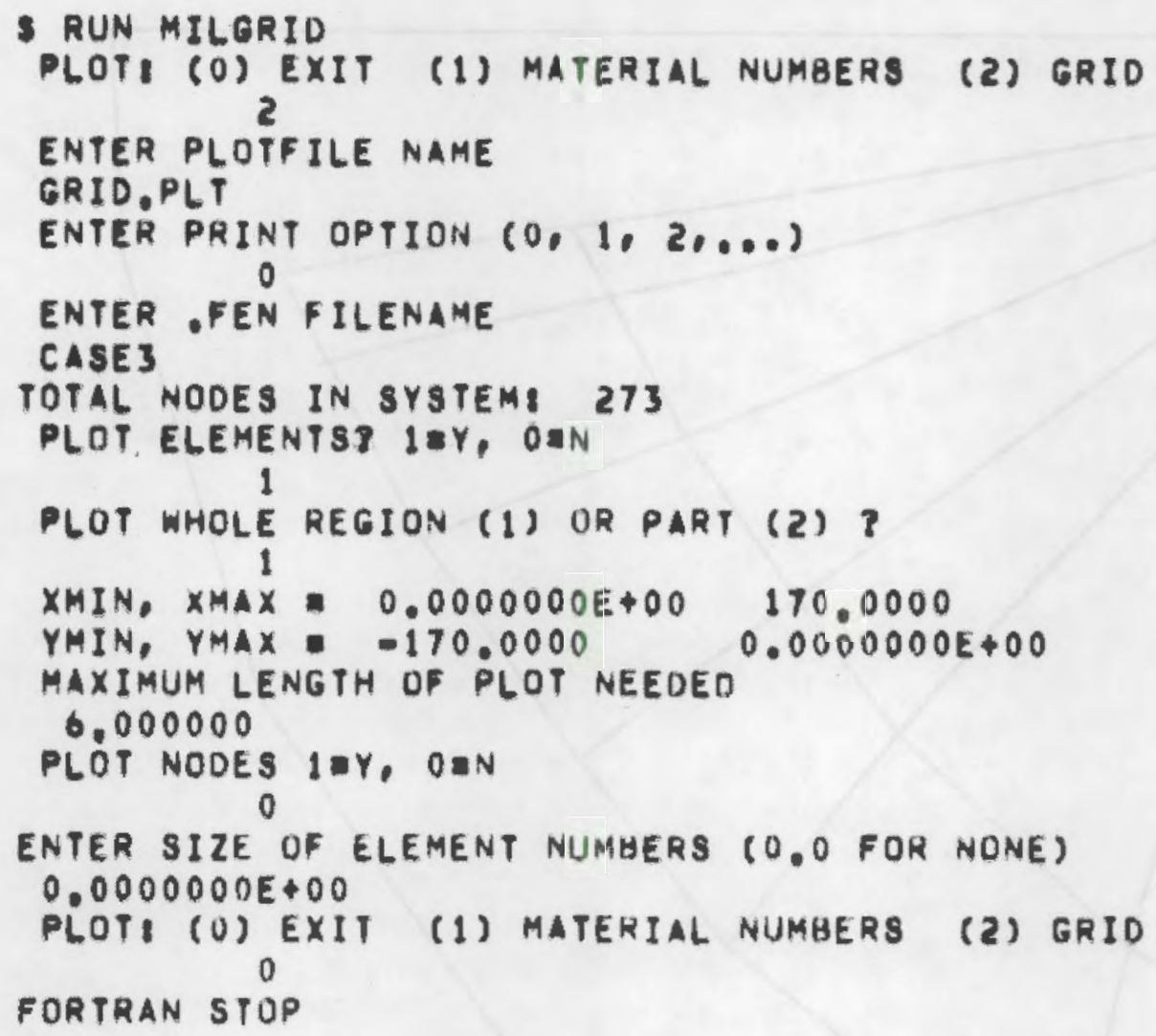




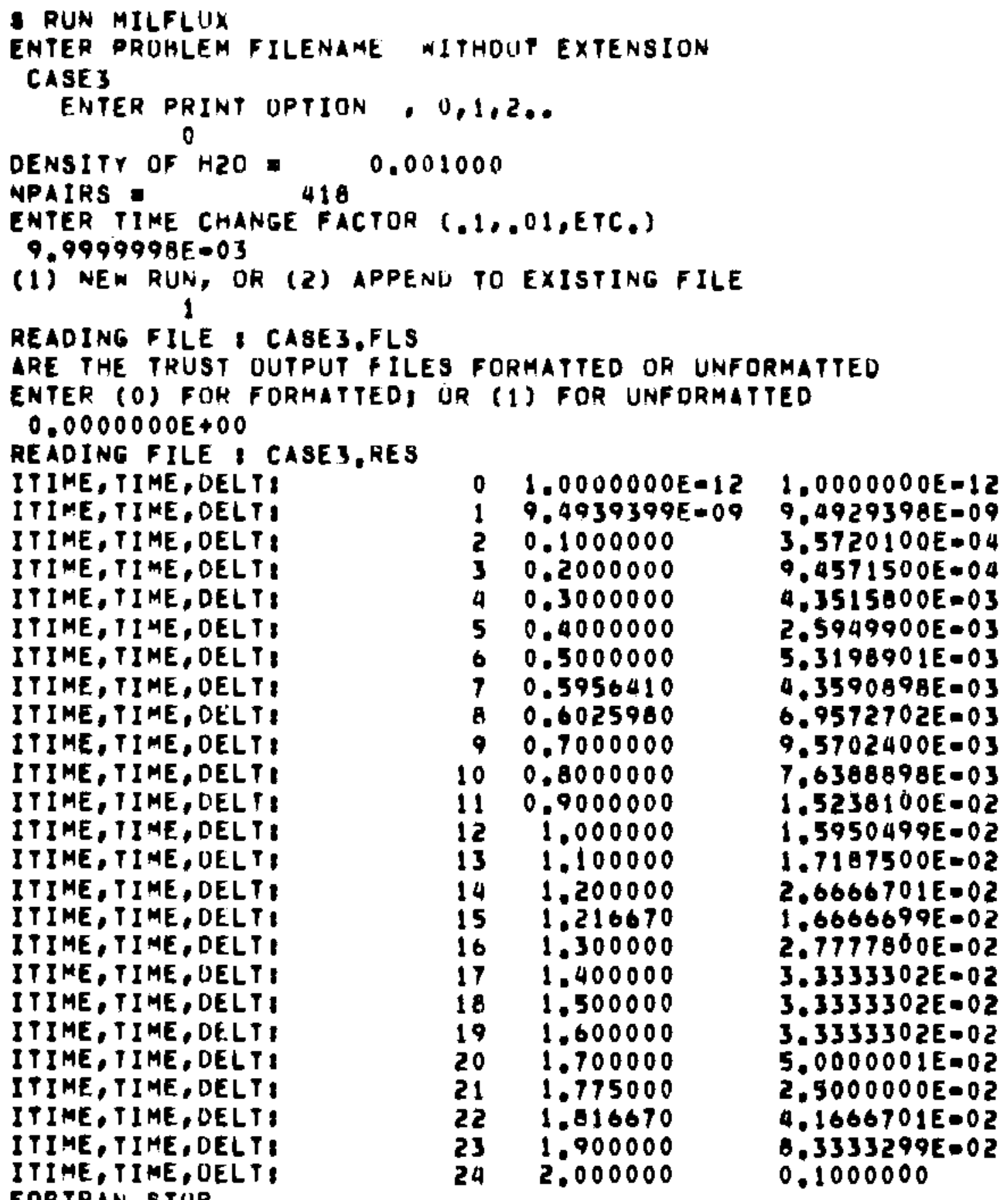




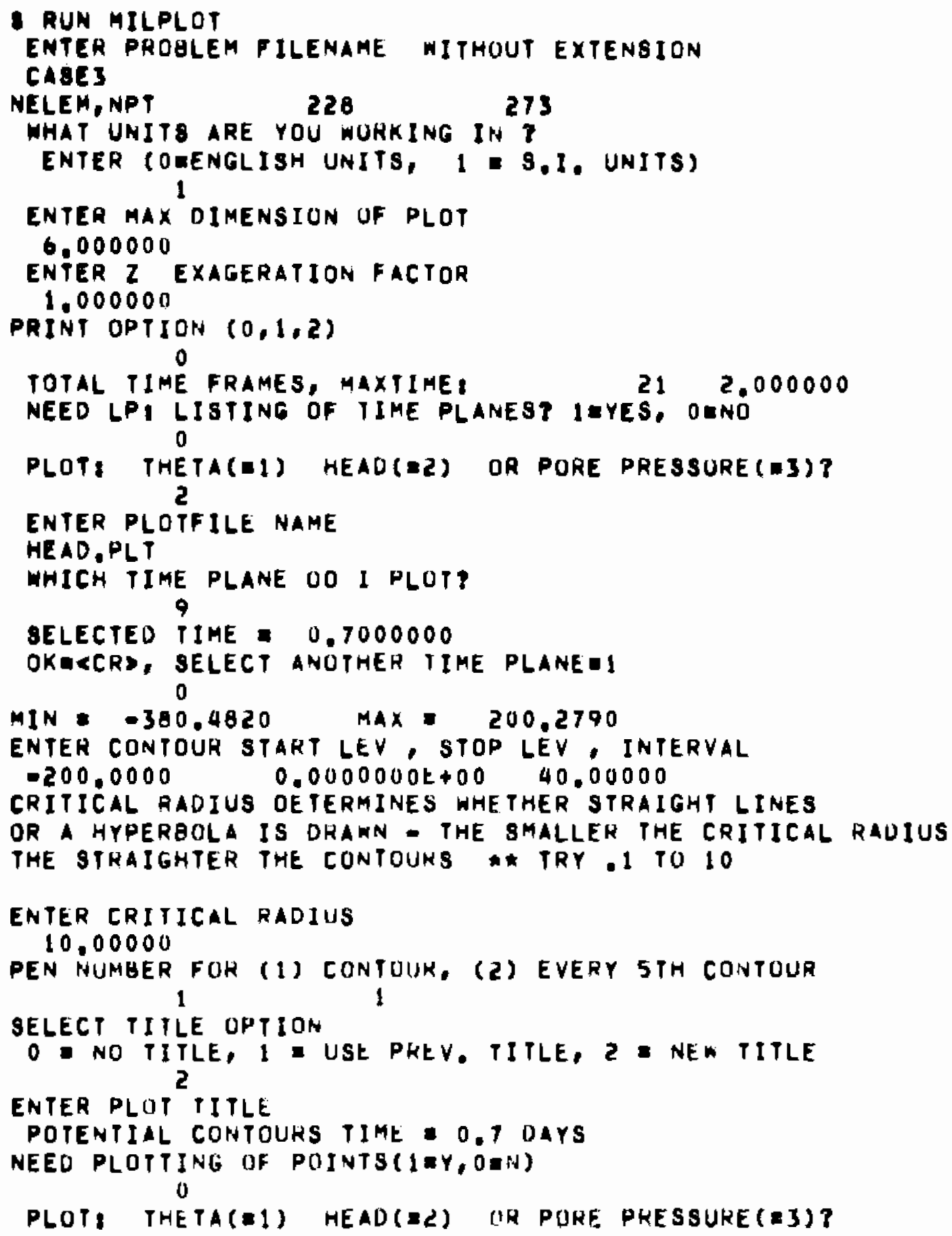


BRUN MILITRYL

ENTER MPHINT $(0,1,2,1)$

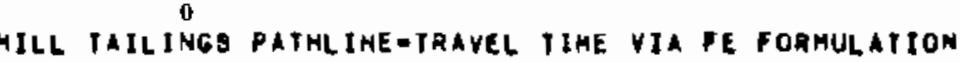

ENTER PaOHLEM FILE DEBIGNATION (MITHOUT EXIENGION)

CABE 3

SIMULATEO GESULTS SPECIFIED FOR,

MAXIMIJH SIHULATED TIME: 2.0000

21 TIHE PLANES

CONTHOL FILE (WI) OR TERHIHAL INPUT (DO) ?

ENTEN COHTROL-FILE MAHE

CASES.CTL

ENTER PLOTF

CABES.PLT

WMERE DO YOU WANT TO PUT FHE SCALE IT

UPPER LEF 1 - 1, UPPER RIGHT - 2

LOWER LEFT : 3, LOMER RIGHT: 4

WHAT UNITS T,ENTER O FOR ENGLISH IOR I FOR S.I. UNITS

WHAT ARE THE UHITS ?

( INCHES, FEET, CENIIHETERB, MEIEAB)

CENTIHETENS

ENIER KDS

ONT UNHETARDEO

1 Single rethrohtion factor used

2 - THU RETARUATION FACTOKS FOR OJFFERENT FLUTD MEOIA

- IN WAMII YLPI I IAHTING IN ELETENT HUMAER

PATHLINE-THAVEL TIME RESUL IS FRUH TRUST VIA MLIAAN

TRICKLE IRRIGAIIDN UNGATUNATED POIAT SOURCE

CONTHOL INFIRHAIIUN $259.9999999 E-09$

$-9.9999998 E-03$
FLUX DATH INPUT

IIHE PLANERT TIARTING TIHE 0.5000000

STARTING OATAL ELEHENIA 262

X9, YS $1.000000 \quad-1.000000$

STEP - ELEHENT

$x$ GLOHAL.

Y GLOHAL

TIME (OAYB)

25

TOTAL
DISTANCE COD
COSHE VALLEY ELEMENT ELEMENT STEP 
MILTRYL,LOG\$1

$4-M A Y-190312156$

ATHLIHE TEHMINATED FOH MAXIMUH IIHE

ELEH XSTAAT YSTART

$41.711^{X E N O}$

STARIING IN ELEHENT NUMEER
PATHLINE-TRAVEL TIME RESULTS FROM TRUST VIA MLTRAN

TRICKLE IARIGATIIJN UNGATURATEO POINT SOURCE

COHTROL INFURHATIOH $259.9999999 \mathrm{E}=09$

$-9.999999 B E-03$

PLUX DATA INPUT TIME PLANE STARTING TIME 0.5000000

STARTING OATAL ELEMENTA

ST,YS $1.000000 \quad 0.9000000262$

STEP ELEMENT X GLOHAL

ATHLINE TERHIHATEO FOH HAXIMUH TIHE

$\begin{array}{lll}\text { ELEM } & \times 9 T A R T & \text { YSTART } \\ 257 & 1.0000 & 0.40000\end{array}$

Y GLOBAL

UHAEH

$59.487^{\text {XEND }}$

OTARTING IN ELEHENT NUHHEH
PATHLINE-IRAVEL TIHE RESUL TS FRUN TRUST VIA MLTRAN

TRICKLE IARIGATJUN UNBATUAATED POINT BOURCE

CONIROL INFORMATION $259.99999995-09$

$-9.9999998 E-03$

PLUX DATA INPUT

TIME PLANE-

7 SILRTING TIME 0.5000000

XS,YS $1.000000 \quad 0.9500000$

STEP N ELEMENT

ATHLTNE TERMINATED O OLOQAL

ATHLINE TERHINATED FOR HAXIMUH TIME

$\begin{array}{lll}\text { ELEA } & \text { XSTART } \\ 256 & 1.0000 & -0.95000\end{array}$

Y GLOBAL

STAHTING IH ELEMENT NUMBER
PATHLINE-TRAVEL TIME RESULTS FAOM THUBT VIA HLTRAM

TAICELE IRRIGATION UNSATURATEO POINT SOURCE

CONTRDL INFOHHATION

$259.9999999 E=09$

FiUX DATA INPUT

TIHE PLAHE D STARTING TIME 0.5000000

GTATIMU OATA

BTARTIMG OATAL ELEMENI

0.9300000

262

BTEP ELEHENT W TLOHAL
ATHLINE TERHINATEO FOH MAXIMUH TIME

ELEK XSTART YSTART

255

1,0000

$-0.43000$

$\checkmark$ GLOBAL

$121.96^{\text {XENO }}$

- IN HAMli YLDI, -1.00

GTARTING IN ELEMENT NUHBER

PATHLINE-IRAVEL IIHE HESHLTS

IRICKLE IRHILATION UNSATUKATED POINT SOURCE

CONTRUL INFORMATIUN $259.9999999 E-09$

$-9.999999,1 E=0 \mathrm{~B}$
Poge 2

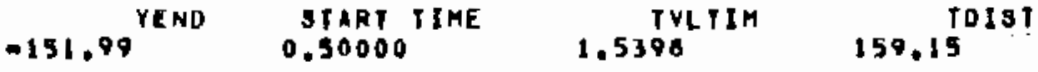


MILTAVL,LOGTI

$4=\operatorname{MAr}-1983 \quad 12156$

FtUX DATA INPUT

IIHE PLANEE T STARIING TIHE 0.5000000

gTARTIMG Datar

$x \rightarrow$ Y Y 1.000

262

$=0,9000000$

BTEP" ELEHENT $X$ GLOAAL.

ATHLINE TERMINATED FOH MAXIMUM TIME

ELEM

1.0000

$-0,90000$

Y OLDBAL

$140.30^{X E N D}$
ITHE (DATS)

$-61,228^{\text {YENO }}$
Pooe 3

TOTAL BEU ULO NEM DISTANCE COSINE VALLEY ELEHENT ELENEAT STEP TTRT TIME TVLTIM

VLTIS $153.67^{\text {TOISI }}$

0.50000

1.5090

* IN WAHII yLDI, 1 - 1,00

BTARTING IN ELEHENT NUHAER 262

PATHL INE OTRAVEL TIME RESOLTS FROM TRUST YIA MLTAAN

TAICKLE IRRIGATION UNBATUHATEO POINT SOURCE

CONTAOL INFORMATION $259.9999 .999 E-09$

$-9.999999 A E=03$
CONTAOL INFORAMTI

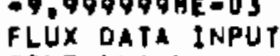

TIHE PLANE: T SIAATING TIME 0.5000000

STAATING DATAL ELEMENTE 262

Xs,vg $1.000000 \quad-0.0500000$

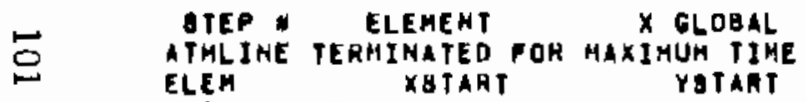

asa $1.0000 \quad 0.85000$

Y GLOBAL

IRAVEL

TIHE (DAYS)

153.16 XEND

$-40.471^{\text {YENO }}$ DOTAL CBAD

ULV NEW

DTART TIHE

TVLTIH

159.10101

IN WAMII YLP!.

STARTING IN ELEHEN 7 NUMBER

262

PATHLINE-TRAYEL TIME RESUL TS FROM TRUST YIA HLTRAN

TRICKLE IRRIGATION UNBATUMATED POINT SOURCE

CONTRUL INFIIRHATION
$-9.999999 \mathrm{AE}=03$

$09,999999 A E=03$

TIME PLANE INPUT

7 STAHTING TIME 0,5000000

$\times 3, Y 9 \$, 0000000,8000000$

QTEP ELEMENT
ATHLIHE TERHINATEO FOH MAXIMUM TIHE

ATHLINE TERHINATEO FOH MAXIMUM TIHE
ELEM

$\begin{array}{lll}\text { ELEH } & \text { XSTAFT } & \text { YSTAR } \\ 254 & 1.0000 & -0.80000\end{array}$

Y GLOBAL

TRAVEL

TIHE (DAYS) TOTAL
DIOTANCE COSINE

$157.96^{x \in N D}$

$-29.797^{\text {YEND }}$

DTAHT TIHE

valier glemento

BLD MEN

0.50000

IVLIIH

1.5186

161.45 


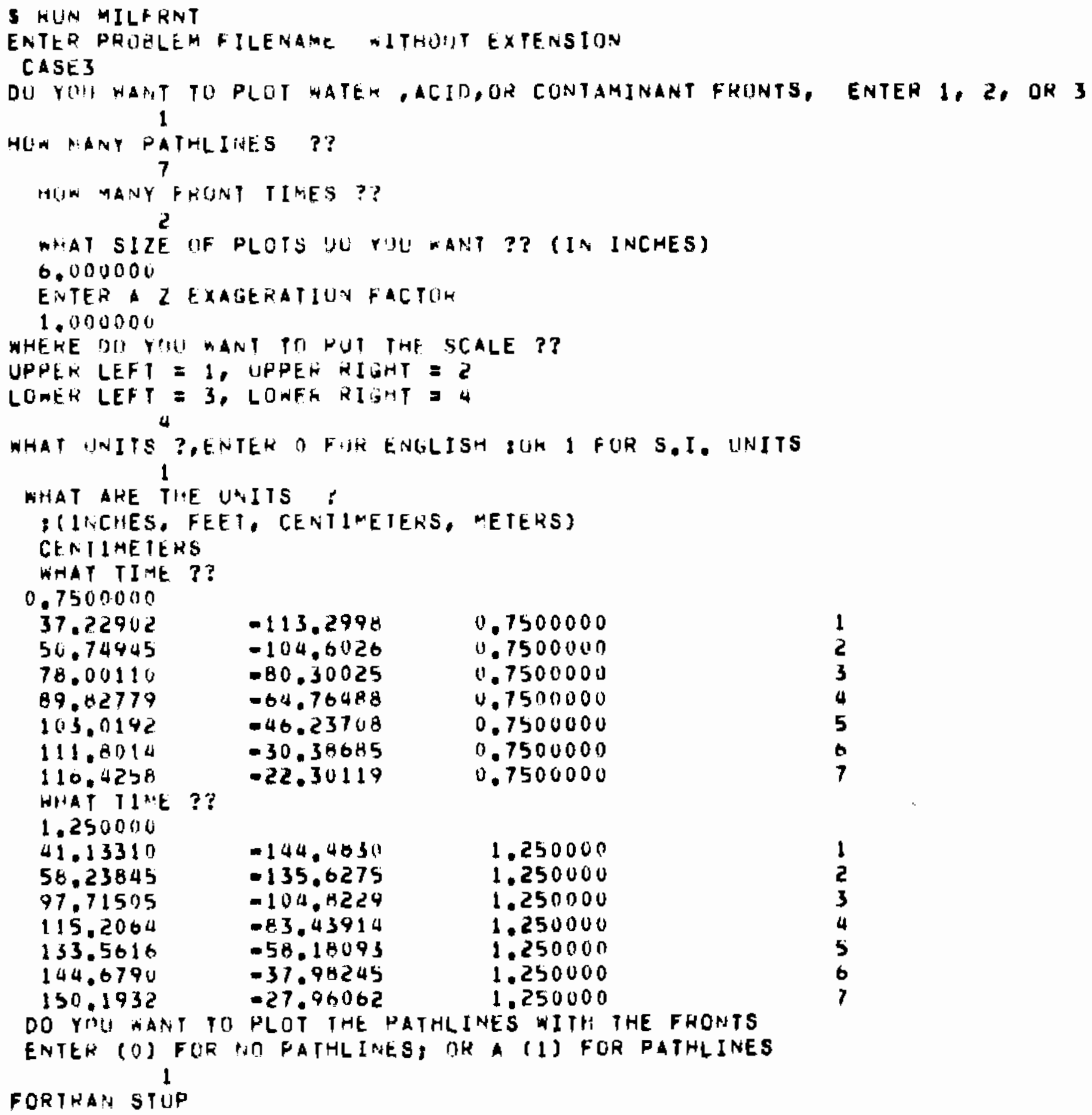


TABLE 4.16. Data Files Used by MLTRAN. This file description uses

a problem name description indicated by $\langle>$ followed

by a three-character extension: < >.TRS

\section{Filename}

\begin{tabular}{|c|}
\hline 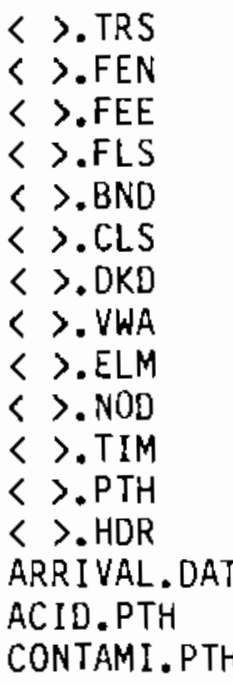 \\
\hline
\end{tabular}

TRUST-II output

file (named in

$\langle>$.FLS)

User-named

plotfiles

User-named control file (optional)
Data Description

TRUST-II input deck

Node locations and additional nodes

Quadrilateral finite-element description

Filenames of timeplane data

Overlay notice

Boundary coordinates

Soil properties

Potential, water content, velocity data

Element, node data

Material zone, elevation data

Listing of time planes

Pathline data

General node, element data

Arrival data

Acid pathline data

Contaminant pathline data

Potential, water content, porosity and the flux data

Plot data

Control parameters
File Type

Formatted

Formatted

Formatted

Formatted

Formatted

Formatted

Formatted

Direct access unformatted

Direct access unformatted

Direct access unformatted

Formatted

Formatted

Formatted

Formatted

Formatted

Formatted

Formatted or Unformatted (user option)

Unformatted

Formatted
Output

File Use

Input file

Input file

Input file

Input file

Input file

Input file

Input file

Internal

Internal

Internal

internal

Internal

Internal

Output file

internal

Internal

Input file

Input file 


\subsection{MLTRAN INPUT MANUAL}

The < >.FEN file (See Table 4.16) contains the element nodes and their Cartesian coordinates plus any additional nodes not defined in the TRUST-II grid that are used to create the quadrilateral elements.

- CARD 1

Col. $1-8$

Format $(18,2 \mathrm{~F} 15.0)$

Col. $9-23$

NODE

Node number

Col . 24-38

$$
x(i)
$$

$x$-coordinate

$y$-coordinate

CARD 1 is entered for each integrated finite-difference node defined in the TRUST-II input deck and each additional node added to create quadrilateral elements for MLTRAN. Some of the MLTRAN submodels use the variables NDE( $i$ ) and $K$ for the node number and $X X$, YY for the Cartesian coordinates.

- CARD 2

- CARD 3

Col . $1-10$

Co1. $11-20$
Blank (A blank card is used to terminate the list of nodes.)

Format (2 I 10)

NPR1(i) Contains new node added for MLTRAN

NPR2(i) Contains node number from TRUST-II

- CARD 4

Blank

The < >.FEE file contains the quadrilateral finite-element description. The nodes defining elements must be listed in a counter-clockwise rotation. Only one card type is used. This element description includes any additional nodes added.

- CARD 1

Col. $1-10 \mathrm{~K}$

Col. 11-20 NN

Col. $21-30 \mathrm{NOD}(1)$

Col. 31-40 NOD(2)

Col. 41-50 NOD( 3 )

Col. 51-60 NOD (4)
Format (10I10)

Element number

Number of corners (always 4)

lst corner - node number from < >.FEN list

2nd corner - node number from < >.FEN list

3 rd corner - node number from $<>$.FEN list

4th corner - node number from < >.FEN list

The < >BND is a file used for plotting an overlay boundary around the pathline plots. The MILTVL submodel draws straight lines between the points listed in the < >.BND file.
ค CARD 1
Col. 1- 5 ND
Format (I5, 2F10.0)
Col. 6-16 XBP
Number
$x$ coordinate
Col. 17-27 YBP
$y$ coordinate

Card 1 is repeated for all $x, y$ turning points on the overlay. If the number in Columns 1 through 5 is 0 the pen is moved to the new coordinates without drawing a line. 
The < >. DKD file contains the bulk density of each soil as well as the distribution coefficients of each soil.

- CARD 1

Record 1 NUB

Free field format

Number of soils

n CARD 2

Record 1 DENS(i)

Free field format

Record 2 RKO(i)

Bulk density of soil number $i\left[M / L^{3}\right]$

Acid distribution coefficient $\left(K_{d}\right)$ for soil

number $i\left[L^{3} / M\right]$

Record 3 AKD(i) Contaminant distribution coefficient ( $\left.k_{d}\right)$ for soi] number $i$ under acid conditions $\left[\mathrm{L}^{3} / \mathrm{M}\right]$.

Record 4 CAKD(i) Contaminant distribution coefficient $\left(K_{d}\right)$ for soil number $i$ under basic conditions $\left[\mathrm{L}^{3} / \mathrm{M}\right]$.

n CARD 2 is repeated for each type of soil.

The < >.TRS file is a copy of the TRUST-It input file (Reisenauer et al. 1982). Data are read from Blocks 3, 4, and 5 of the TRUST-II input file.

The 〈user named control> file is optional and may be used for control of the MILTVL subprogram, which begins by asking if the user wants to use control file or terminal input. Both options require identical input; the control file is more convenient if several runs are to be made or if a large number of pathlines are to be generated.

ง CARD 1

Record 1 XDIM

- CARU 2

Record 1 ZEX

- CARD 3

Record 1-80 TITLEl

ค CARD 4

Record 1 IBNDRY

- card 5

- CARD 6
Format (F20.0)

Length of output plot [L]

Format (F20.0)

The $Z$ exaggeration factor for plotting ( 1 for no exaggeration)

Format (80A1)

Title for output files

Free field format

Control flag to plot boundary (l=yes, $0=$ no)

Blank line

Free field format 


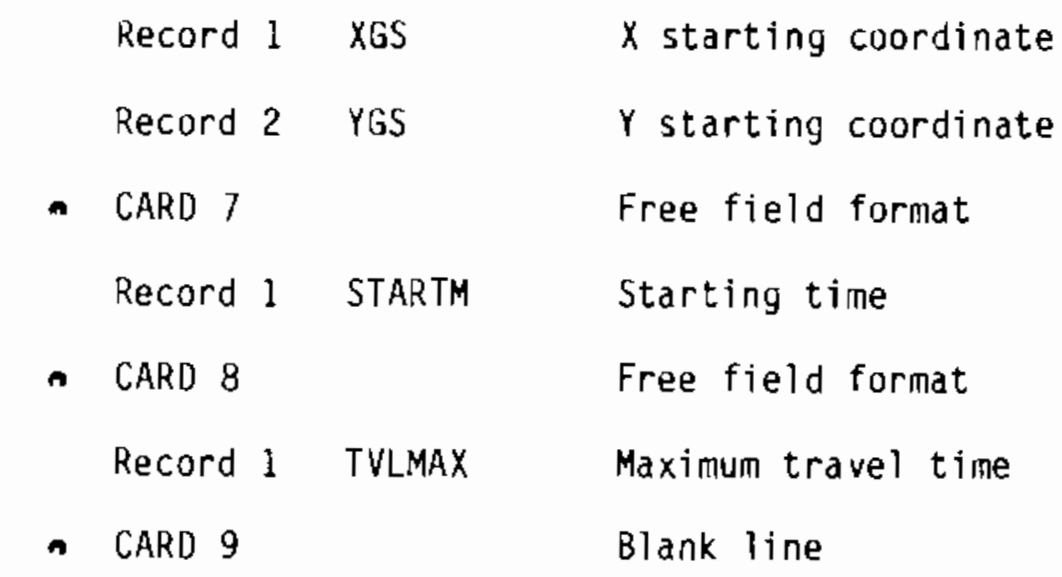

CARDS $6,7,8,9$ are repeated for each pathline starting point.

The < >.CLS file contains the coordinates of nodes defining the boundary of the flow system.

- CARD 1

Record 1 NPSBND

- CARD 2

Record $1 \quad X F B$

Record 2 YFB
Free field format

Number of points to be read in

Free field format

$x$ coordinate

y coordinate domain.

Card 2 is repeated for all points defining the boundary of the flow

The $<>$.FLS file contains the names of the files that contain the sequential time plane data from the TRUST-II model.

ค CARD 1

Format (7A4)

Co1. 1-28 FILE1

Contains file name plus three-character extension: i.e., CASE3.DAT

Card 1 is repeated for as many files as is necessary.

Five data files are created internally by the various MLTRAN submodels to be used by the other submodels. The five data files are: <>.WWA, <>.HDR, $<>$.ELM, < >.NOD, and < >.PTH. The < >.WWA file is an unformatted direct access file created by the MILFLUX submodel. The < >.VWA file is used in the MILTVL and MILPLOT submodels. The data stored in this file include the water content, the potential, the $x$-velocity component, and the y-velocity component for each node at every time plane. The $\langle>$. WWA file is read from the subroutine VECTOR within the MILTVL submodel. 
The < >.HDR file is a formatted file created by the MILSTRT submodel. The $\langle>$.HOR file is used by all of the other submodels except MILGRID. The data contained in this file includes: the number of nodes, number of elements, number of additional node pairs, the minimum and maximum $x, y$ coordinates for the flow system, and the node numbers constituting the additional node pairs.

The < >.ELM file is an unformatted direct access file created by the MILSTRT submodel. The data stored in the <>.ELM file includes: the number of nodes forming an element (must be 4 ), the four element numbers each sharing one face with the given element, the minimum $x$-coordinate of the element, the maximum $x$-coordinate of the element, the difference between the minimum and maximum $x$-coordinates of the element, the minimum $y$-coordinate of the element, the maximum $y$-coordinate of the element, the difference between the minimum and maximum $y$-coordinates of the element, the four $x$-coordinates of the nodes defining the element, the four $y$-coordinates of the nodes defining the element, the numbers of the two nodes defining each of the four faces of the element, and finally, the element numbers sharing each of the four nodes of the element. All of the above data are stored on one record and a record is written for each element. The < >.ELM file is read from subroutine WAMI in the MILTVL. submodel.

The $<>$ NOD is an unformatted direct access file created by the MILFLUX submodel. The data contained in the $\langle>$. NOD file include: the node numbers, material zone numbers, $x$ and $y$ coordinates, and elevation for each node. The $\langle>$.NOD file is read in the MILTVL submodel.

The < >.PTH file is a formatted file written by the MILTVL submodel. The data contained in the <>.PTH file are: the $x, y$ coordinates and the time for eacn step of each patnline. The <>.PTH file is read in the MILFRNT submode1. The <>.PTH file is terminated with a zero in Columns 1 through 5 of the last line. MILTVL also generates an ACID.PTH and a CONTAMI.PTH file, depending on the various options used ( $K_{d}$ for acid or $K_{d}$ for contaminant). The ACID.PTH and the CONTAMI.PTH files have the same data format as the $<>$.PTH file. 
REFERENCES

Batu, V. 1982. "Time-Dependant, Linearized Two-Dimensional Infiltration and Evaporation from Nonuniform and Nonperiodic Strip Sources." Water Resources Research 18(6): 1725-1733.

Bear, J., and M. Jacobs. 1965. "On the Movement of Water Bodies Injected into Aquifers." Journal of Hydrology 3:37-57.

Beyer, T. 1975. FLECS User's Manual. Department of Computer Science, University of Dregon, Eugene, Oregon.

Burdine, N. T. 1953. "Relative Permeability Calculation from Size Distributions Data. Trans. AIME 198:71-78.

Childs, E. C., and N. Collis-George. 1960. "The Permeability of Porous Materials." Proc. Roy. Soc., Ser. A 201:392-405.

Foote, H. P., W. A. Rice and C. T. Kincaid. 1982. DIGRID: An Interactive Grid Generating Program. PNL-4345 (NUREG/CR-2845), PaCific Northwest Laboratory, Richland, Washington.

Gardner, W. R. 1958. "Some Steady State Solutions of the Unsaturated Moisture Flow Equation with Application to Evaporation from a Water Table." Soil Science $85: 228-232$.

Haverkamp, R., M. Vauclin, J. Touma, P. J. Wierenga, and G. Vachaud. 1977. "A Comparison of Numerical Simulation Models for One-Dimensional Infiltration." Soil Sci. Soc. of America 41:285-294.

IMSL Library Reference Manual. 1980. International Mathematics and Statistical Libraries, Inc., Houston, Texas.

Kozeny, J. 1927. 'Uber Kapillare Leitung das Wassers im Boden, Sitzungsber. Akad. Wiss, Wien 136:271-306.

Lomen, D. 0., and A. W. Warrick. 1974. "Time-Dependant Linearized Infiltration. II. Line sources." Soil Science Soc. Am. Proc. 38:568-572.

Millington, R. J., and J. P. Quirk. 1961. "Permeability of Porous Solids." Proc. Faraday Society 57:1200-1206.

Mualem, Y. 1976. "A New Model for Predicting the Hydraulic Conductivity of Unsaturated Porous Media." Water Resources Res. 12(3):513-522.

Narasimhan, T. N., and P. A. Witherspoon. 1976. "An Integrated Finite Difference Method for Analyzing Fluid Flow in Porous Media." Water Resources Research 12(1):57-64. 
Nelson, R. W., and J. A. Schur. 1980. PATHS Groundwater Hydrologic Model. PNL-3162, Pacific Northwest Laboratory, Richland, Washington.

Reisenauer, A. E., K. T. Key, T. N. Narasimhan, and R. W. Nelson. 1982. TRUST: A Computer Program for Variably Saturated Flow in Multidimensional, Deformable Media. PNL-3975, (NUREG/CR-2360) Pacific Northwest Laboratory, Richtand, Washington.

Sherry, G. P. 1982. Constitutive Relationships for Unsaturated Uranium Mill Tailings. Master's Thesis, Colorado State University, Ft. Collins, CoTorado.

Su, C., and R. H. Brooks. 1976. Hydraulic Functions of Soils From Physical Experiments and Their Applications. WRRI-41, Water Resources Research Institute, Oregon State University, Corvalvis, Oregon.

Van Genuchten, R. 1978. Calculating the Unsaturated Hydraulic Conductivity with a New Closed-Form Analytical Model. 78-WR-05, Department of Civi Engineering, Princeton, New Jersey.

Warrick, A. W. 1975. "Analytic Solutions to the One-Dimensional Linearized Moisture Flow Equation for Arbitrary Input." Soil Science 120:79-84.

Warrick, A. W., D. 0. Lomen and P. J. Tonellato. 1981. Soil Moisture Flow for Point and Line Sources - Computer Programs for Linearized Solutions.

University of Arizona, Tucson, Arizona. 

APPENDIX A

DERIVATION DF TWO-DIMENSIONAL

STEADY-STATE PATHLINES 


\section{APPENDIX A}

\section{DERIVATION OF TWO-DIMENSIONAL STEADY-STATE PATHLINES}

The solution derived in this appendix is a reduced form of Equation (1) in Nelson and Schur (1980)--Equation A.1 below. This reduced form (Equation A.1) only applies to steady-state flow systems, as depicted in Figure 4.7 . Equation (1) of Nelson and Schur is more general in that it applies to transient, multiple-well flow systems, as depicted in Figure 4.12.

In this solution the doublet term from Equation (1) in Nelson and Schur (1980) is omitted. This means that the original circulate source (storage reservoir) is not an equipotential. The shape of the boundary equipotential is allowed to deviate a small amount from a cylindrical shape. The twodimensional ground-water potential, $h$, is expressed as:

$$
d^{\prime}=H_{0}-U_{0} x^{\prime}-\frac{H_{0}}{\ln \frac{R}{\left.r_{0}^{\prime}\right)}} \ln \left[\sqrt{\left(x^{\prime}\right)^{2}+\left(y^{\prime}\right)^{2}} \frac{r_{0}^{\prime}}{r^{\prime}}\right]
$$

where

$\phi=\phi^{\prime}\left(x^{\prime}, y^{\prime}\right)$ is the potential energy head function that satisfies the Laplace Equation

$U_{0}=$ the uniform and constant lateral flow gradient in the positive $x^{\prime}$ coordinate direction

$H_{0}=$ the head in the source of approximate radius $r_{0}^{\prime}$ with center at the origin

$\mathrm{R}=$ the distance (radial) to the ground-water outflow or remote boundary

$r_{0}^{\prime}=$ the dimensional approximate radius of the source located at the origin

$x^{\prime}$ and $y^{\prime}=$ the dimensional Cartesian coordinates with the origin at the center of the source

A convenient set of dimensionless variables is:

$$
x=\frac{x^{\prime}}{R}
$$




$$
\begin{gathered}
y=\frac{y^{\prime}}{R} \\
r_{0}=\frac{r_{0}^{\prime}}{R} \\
t=\frac{k_{0} H_{0}}{R^{2}} t^{\prime}
\end{gathered}
$$

where

$t^{\prime}=$ the dimensional time

$t=$ the dimensionless or scaled time

$K_{0}=$ the constant hydraulic conductivity of the confined porous stratum

and the other variables are as previously defined. Use of the expressions from Equation (A.2) in (A.1) gives the dimensionless potential, $\phi$, as:

$$
\phi=1-\frac{U_{0} R}{H_{0}} x-\frac{1}{\ln \left(\frac{1}{r_{0}}\right)} \ln \left[\frac{\sqrt{x^{2}+y^{2}}}{r_{0}}\right] \text {. }
$$

1

The dimensionless pore velocity is given by:

$$
\underline{V}=-\frac{1}{P} \nabla \phi
$$

where $\underline{v}=\frac{R}{K_{0} H_{0}} \stackrel{v^{\prime}}{ }$ and $\underline{v}^{\prime}=$ the dimensional pore velocity.

Differentiating Equation (A.3) yields the pathline characteristic equations. 


$$
\begin{gathered}
\frac{d x}{d t}=\frac{U_{0} R}{P H_{0}}+\frac{1}{P \ln \left(\frac{I}{r_{0}}\right)} \frac{x}{x^{2}+y^{2}} \\
\frac{d y}{d t}=\frac{1}{P \ln \left(\frac{1}{r_{0}}\right)} \frac{y}{x^{2}+y^{2}}
\end{gathered}
$$

The upstream stagnation point can be located by setting Equations (A.5) and (A.6) both $=0$ and solving for $y_{S}=0$ and $x_{S}$ becomes:

$$
x_{S}=r=-\frac{H_{0}}{U_{0} R \ln \left(\frac{1}{r_{0}}\right)}
$$

This term $y$ is used in the following equations.

THE STREAM FUNCTION

The stream function for the flow-system being considered will enable integrating along the steady pathlines to obtain the travel time. Specifically, the stream function is available as the complex conjugate of the previously derived potential Equation (A.3). The stream function in dimensioniess terms is:

$$
\psi=-\frac{U_{0} R}{H_{0}} y-\frac{1}{\ln \left(\frac{1}{\Gamma_{0}}\right)} \arctan \left(\frac{y}{x}\right)
$$

The terms on the right-hand side of the equation are easily shown to be the imaginary parts of the complex potential $\delta=\phi+i \psi$, which satisfies the Laplace Equation and the Cauchy-Riemann Condition.

The stream function values may be conveniently expressed as the fraction of the total outflow from the source. This can be done using the location of the stagnation point defined by Equation (A.7) because half of the flow will leave the source around the arc between $x=r_{0}, y=0$, and the stagnation point at $x_{s}, y_{5}$. That is, setting $\psi=\psi_{5} / 2$ in Equation (A.9), and substituting Equation (A.S) for $x$ and $y$ gives: 


$$
\frac{\psi_{s}}{2}=-\frac{\pi}{\ln \left(\frac{r_{0}}{r_{0}}\right)}
$$

Dividing Equation (A.8) by (A.9) gives (after rearranging):

$$
\frac{\psi}{\psi_{5}}=\frac{U_{0} R \ln \left(\frac{1}{r_{0}}\right)}{2 \pi H_{0}} y+\frac{1}{2 \pi} \arctan \left(\frac{y}{x}\right)
$$

Or, expressing in terms of $\gamma$ from Equation (A.7) and the ratio of total source outflow flux $\psi=\psi / \psi_{\text {s }}$ gives:

$$
\psi=\frac{y}{2 \pi \gamma}+\frac{1}{2 \pi} \arctan \left(\frac{y}{x}\right)
$$

The outflow flux, $w$, is really the ratio of outflow rates:

$$
\psi=\frac{Q_{0}}{Q_{0}}
$$

where

$$
Q_{0}=\frac{2 \pi D_{0} K_{0} H_{0}}{\ln \left(\frac{1}{r_{0}}\right)}=\frac{2 \pi D_{0} K_{0} H_{0}}{\ln \left(\frac{R}{r_{0}}\right)}
$$

A revised form of Equation (A.11) is very useful, i.e., solving for $x$ gives:

$$
\begin{gathered}
x=y \cot \left(2 \pi \psi-\frac{y}{\gamma}\right) \\
y \neq 0
\end{gathered}
$$


The constraint on $y=0$ is required for the cotangent to be well defined; accordingly, the implied correspondence in Equation (A.14) does not hold when $y=0$.

If we designate a particular $i^{\text {th }}$ streamline by the value, ${ }_{i}$, in Equation A.14 the equation for the $i^{\text {th }}$ steady streamline is:

$$
x=y \cot \left[2 \pi \psi_{i}-\frac{y}{y}\right\rceil, \text { for } y \neq 0
$$

\section{INTEGRATION TO OBTAIN TRAVEL-TIME EQUATION}

The elapsed time for a fluid particle to move along a steady pathline can be obtained for the flow system considered here through appropriate integration. The more involved case (when $y \neq 0$ ) is considered first. Later the simpler special case.

Both sides of Equation (A.16) are squared and the resulting expression for $x^{2}$ is substituted into the expression (A.6) for the $y$ component of velocity; that is:

$$
\frac{d y}{d t}=\frac{1}{p \ln \left(\frac{1}{r_{0}}\right)}\left[\frac{y}{y^{2}\left[1+\cot ^{2}\left(2 \pi w_{i}-\frac{y}{\gamma}\right)\right.}\right] \text {, }
$$

Upon rearranging:

$$
\frac{1}{\rho \ln \left(\frac{1}{r_{0}}\right)} \int_{0}^{T_{j}} d t=-\int_{y_{0 i}}^{y} y \gamma \csc ^{2}\left\{2 \pi^{\psi} i-\frac{y}{\gamma}\right\rceil \frac{-d y}{\gamma}
$$

Integrating by parts gives:

$$
\frac{1}{p \ln \frac{1}{r_{0}}} T_{i}=y \cot \left[2 \pi \psi_{i}-\left.\frac{y}{\gamma}\right|_{y_{0 i}} ^{y}\right.
$$




$$
+\gamma \int_{y_{0 i}}^{y} \cot \left[2 \pi \psi_{i}-\frac{y}{\gamma}\right\rceil\left(-\frac{1}{\gamma}\right) d y
$$

or

$$
\begin{gathered}
\frac{U_{0} R}{\mathrm{PH}_{0}} T_{i}=y \cot \left(2 \pi \psi_{i}-\frac{y}{\gamma}\right)-y_{0 i} \cot \left(2 \pi \psi_{i}-\frac{y_{0 i}}{\gamma}\right) \\
+\gamma \ln \frac{\mid \sin \left(2 \pi \psi_{i}-\frac{y}{\gamma} \mid\right.}{\left|\sin \left(2 \pi \psi_{i}-\frac{y_{0 i}}{\gamma}\right)\right|},
\end{gathered}
$$

which is the expression for calculating the time for a fluid particle to transverse the pathline denoted by the constant value $\Psi_{i}$. Equation (A.20) cannot be used when $y=0$ for the shortest pathline along the $x$ axis as a result of the restriction on Equation (A.20).

To use Equation (A.20) the value of $y$ where the streamline reaches the outflow boundary (i.e., at $x=1$ or $x^{\prime}=R$ ) is needed. If $x=1$ and $y=y_{\text {p }}$ are substituted into Equation (A.11) then an expression for the outflow or maximum $y$ value is obtained, i.e.:

$$
w_{i}=\frac{y}{2 \pi r}+\frac{1}{2 \pi} \arctan \left(y_{m}\right)
$$

and by rewriting:

$$
y_{\pi}+\gamma \arctan \left(y_{\pi}\right)-2 \pi \gamma \psi_{i}=0
$$

for which equation one needs roots for $y_{m}$. The roots for $y_{m}$ can be obtained using the method of false position.

The expression for travel time along the direct straight flow path along the $x$ axis is needed when $y=0$ because Equation (A.20) degenerates for $y=0$. Substituting $y=0$ into Equation (A.5) gives (after rearranging) and 
using Equation (A.7):

$$
\frac{d x}{d t}=\frac{U_{0} R}{P H_{0}}+\frac{1}{P \ln \left(\frac{1}{r_{0}}\right)}\left(\frac{1}{x}\right),
$$

then on rearranging and integrating,

$$
\frac{\mathrm{U}_{0} \mathrm{R}}{\mathrm{PH}_{0}} \int_{0}^{\mathrm{T}_{s}} \mathrm{dt}=\int_{r_{0}^{1}}^{1} \frac{x}{x+\gamma} d x
$$

or

$$
\frac{U_{0} R}{P H_{0}} T_{S}=1-r_{0}-\gamma \ln \left(\frac{1+\gamma}{r_{0}+\gamma}\right)
$$

Equation (A.25) can be written as:

$$
\frac{U_{0}{ }^{R}}{P H_{O}} T_{S}=1-\gamma \ln \left(\frac{1+\gamma}{\gamma}\right)-\varepsilon_{1}{ }^{0}
$$

where

$$
\varepsilon_{1}=r_{0}-\gamma \ln \left(1+\frac{r_{0}}{\gamma}\right)
$$

If $E$ is set equal to zero then the results of Bear and Jacobs (1965) are provided but we see that Equation (A.25) should be used in environmental assessment because it provides both the more accurate and so the worst-case arrival time. It is convenient to convert Equation (A.25) to dimensional form for every day use. Accordingly, using Equations (A.2): 


$$
T_{s}^{\prime}=\frac{P R}{U_{0} \bar{K}_{0}} 1-\frac{r_{0}^{\prime}}{\bar{R}}-\gamma \ln \frac{1+\gamma}{\frac{r_{0}^{\prime}}{R}+\gamma}
$$


- 
APPENDIX B

MICROF ICHE INDEX 
APPENDIX B

MICROFICHE INDEX

The following information is stored on the microfiche (attached to inside backcover) in the order indicated:

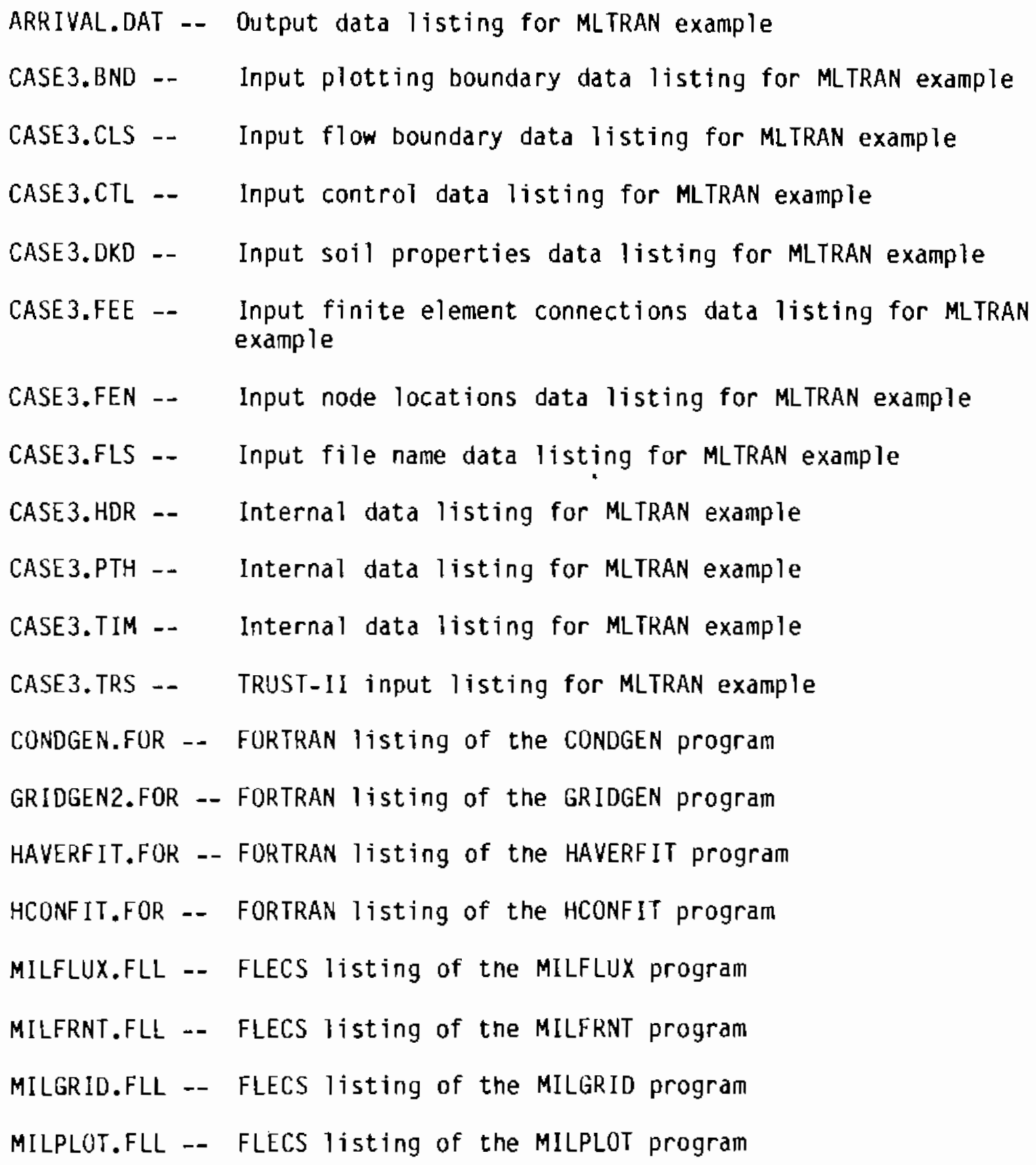




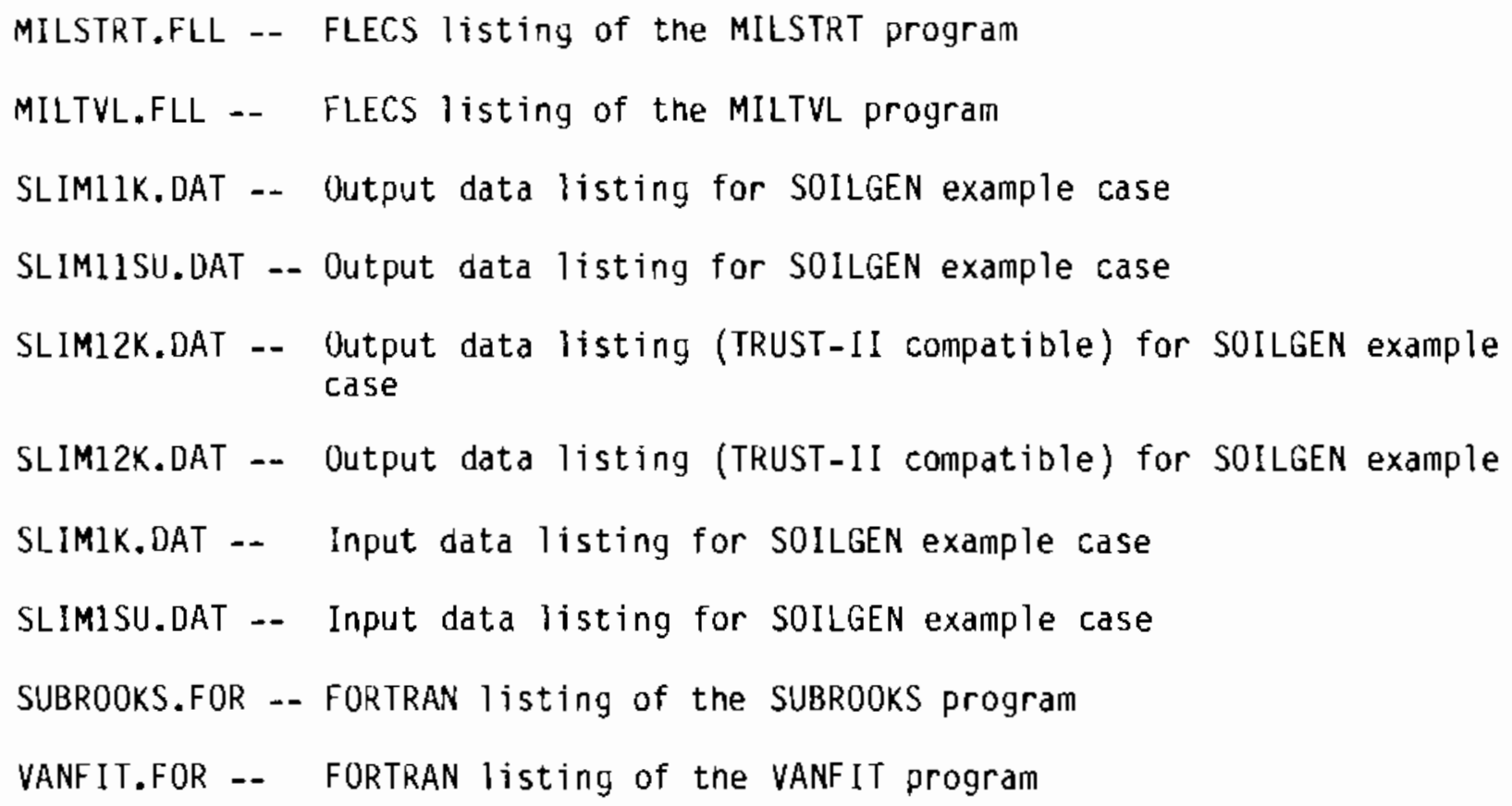



NUREG/CR-3443

PNL-4805

DISTRIBUTION

No. of

Copies

OFFSITE

U.S. Nuclear Regulatory Commission

Division of Technical Information and Document Control

7920 Norfolk Avenue

Bethesda, MD 20014

E. F. Cont $i$

NRC Office of Nuclear

Regulatory Research

Washington, DC 20555

Mark Matthews

UMTRAP

DOE Albuquerque Operations

Office

P.0. Box 5400

Albuquerque, NM 87115

Thomas Nicholson

NRC Office of Nuclear

Regulatory Research

Washington, DC 20555

C. N. Ostrowski

NRC Office of Nuclear

Regulatory Research

Washington, DC 20555

P. J. Garcia

NRC Office of Nuclear

Regulatory Research

Washington, DC 20555

D. R. Tweeton

Twin Cities Research Center

Bureau of Mines

5629 Minnehaha Avenue South

Minneapolis, MN 55417
No. of

Copies

\author{
L. L. Beratan \\ NRC Office of Nuclear \\ Regulatory Research \\ Washington, DC 20555 \\ Peter Ornstein \\ U.S. Nuclear Regulatory \\ Commission \\ Washington, OC 20555 \\ F. Swanberg \\ NRC Office of Nuclear \\ Regulatory Research \\ Washington, DC 20555 \\ John Starmer \\ U.S. Nuclear Regulatory \\ Commission \\ Washington, OC 20555 \\ G. N. Gnugnoli \\ NRC Office of Nuclear \\ Materials Safety and \\ Sa feguards \\ Washington, DC 20555 \\ Dr. Fred J. Molz, Director \\ School of Engineering and \\ Engineering Experiment \\ Station \\ Auburn University \\ Auburn, AL 36849 \\ Dr. T. N. Narasimhan \\ Lawrence Berkeley Labs \\ University of California \\ Berkeley, CA 94720 \\ Keros Cartwright \\ Illinois State Geological \\ Survey \\ 615 E. Peabody Drive \\ Champaign, IL 61820
}


No. of

Copies

Ron Lantz

Intera Environmental

Consultants, Inc.

11999 Katy Freeway

Suite 610

Houston, TX 77079

S. W. Childs

Department of Soil Science

Oregon State University

Corvallis, OR 97331

Dr. Genevieve Segol

Bechtel Civil and Minerals, Inc. P.0. Box 3965

San Francisco, WA 94119

Or. George T. Yeh

Room 203, Bldg. 1505

Oak Ridge National Laboratory

P.0. Box $X$

Oak Ridge, TN 37830

George Bloomsburg

University of Idaho

Moscow, ID 83843

Dr. Schlomo Neuman

Department of Hydrology and

Water Resources

University of Arizona

Tuscon, Arizona 85721

Dr. Daniel B. Stephens

Geosciences Department

New Mexico Institute of

Mining and Technology

Socorro, New Mexico 87801

Dr. Ralph Peters

Sandia National Laboratory

Albuquerque, New Mexico 87185

Joe Fernandez

Sandia National Laboratory

Albuquerque, New Mexico 87185
No. of

Copies

Lynn Tyler

Sandia National Laboratory

Albuquerque, New Mexico 87185

FORE IGN

Dr. Eshel Bresler

Soil Physicist

Agricultural Research

Organizational

The Volcanic Center

Institute of Soils and Water

P.0.B. 6

Bet Dagan, 50-250

ISRAEL

Dr. Robert W. Gillham

Department of Earth Sciences

University of Waterloo

Waterloo, Ontario

CANADA N2L361

Dr. G. de Marsily

Ecole Nationale

Superieure des Mines

Centre d'Informatique Geologigue

35, Rue Saint-Honore'

77305 Fontanebleau

FRANCE

ONSITE

50 Pacific Northwest Laboratory

F. H. Dove

M. D. Freshley

G. W. Gee

D. W. Mayer (5)

T. J. McKeon (13)

R. W. Nelson

C. A. Newbill

A. E. Reisenauer

S. C. Sneider

S. W. Tyler (13)

Publishing Coordination (2)

Technical Information (5)

Geosciences Research and

Engineering Department

Technical Library (5) 


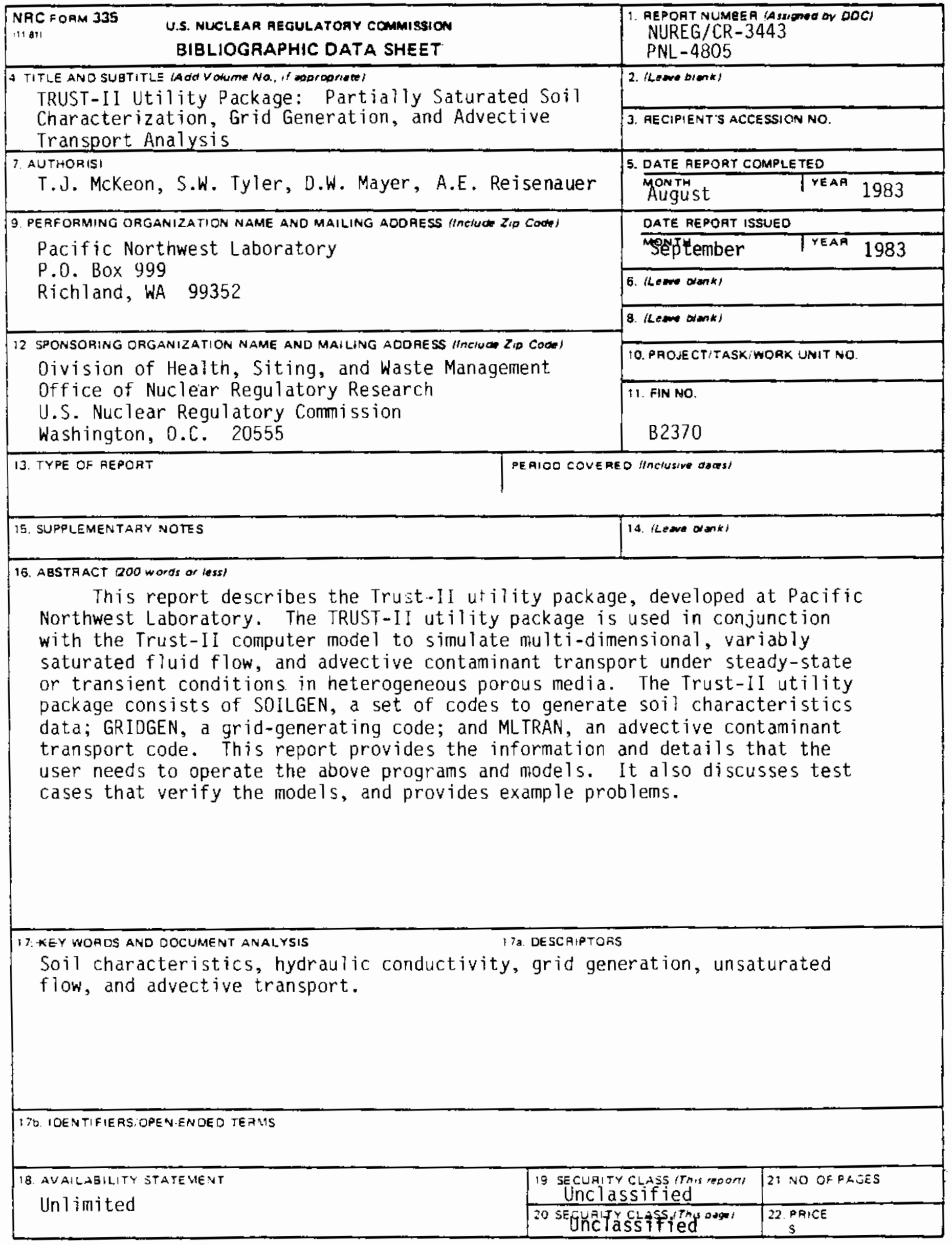


